\title{
An Adamantyl-Substituted Retinoid-Derived Molecule That Inhibits Cancer Cell Growth and Angiogenesis by Inducing Apoptosis and Binds to Small Heterodimer Partner Nuclear Receptor: Effects of Modifying Its Carboxylate Group on Apoptosis, Proliferation, and Protein-Tyrosine Phosphatase Activity
}

Marcia I. Dawson ${ }^{\star}$, , Zebin Xia ${ }^{\dagger}$, Gang Liu ${ }^{\dagger}$, Mao Ye $^{\dagger}$, Joseph A. Fontana ${ }^{\ddagger}$, Lulu Farhana ${ }^{\ddagger}$, Bhamik B. Patel $\ddagger$, Sankari Arumugarajah $\ddagger$, Mohammad Bhuiyan $\ddagger$, Xiao-Kun Zhang ${ }^{\dagger}$, YoungHoon Han ${ }^{\dagger}$, William B. Stallcup $§$, Jun-ichi Fukushi $§, \|$, Tomas Mustelin ${ }^{\perp}$, Lutz Tautz ${ }^{\perp}$, Ying Su ${ }^{\dagger}$, Danni L. Harris ${ }^{\#}$, Nahid Waleh $\nabla$, Peter D. Hobbs ${ }^{\nabla}$, Ling Jong $\nabla$, Wan-ru Chao $\nabla$, Leonard J. Schiff ${ }^{\star}$, and Brahma P. Sani ${ }^{\infty}$

$\uparrow$ Cancer Center, Burnham Institute for Medical Research, La Jolla, California 92037

$\$$ Wayne State University School of Medicine and Department of Veterans Affairs, Detroit, Michigan 48201

§Neuroscience and Aging Center, Burnham Institute for Medical Research.

$\perp$ Inflammatory and Infectious Disease Center, Burnham Institute for Medical Research. \#Molecular Research Institute, Mountain View, California 94043

VSRI International, Menlo Park, California 94025

IIT Research Institute (retired), Chicago, Illinois 60616

$\infty$ Southern Research Institute, Birmingham, Alabama 35025

\section{Abstract}

Apoptotic and antiproliferative activities of small heterodimer partner (SHP) nuclear receptor ligand (E)-4-[3'-(1-adamantyl)-4'-hydroxyphenyl]-3-chlorocinnamic acid (3-Cl-AHPC), which was derived from 6-[3'-(1-adamantyl)-4'-hydroxyphenyl]-2-naphthalenecarboxylic acid (AHPN), and several carboxyl isosteric or hydrogen bond-accepting analogues were examined. 3-Cl-AHPC continued to be the most effective apoptotic agent, whereas tetrazole, thiazolidine-2,4-dione, methyldinitrile, hydroxamic acid, boronic acid, 2-oxoaldehyde, and ethyl phosphonic acid hydrogen bond-acceptor analogues were inactive or less efficient inducers of KG-1 acute myeloid leukemia and MDA-MB-231 breast, H292 lung, and DU-145 prostate cancer cell apoptosis. Similarly, 3-ClAHPC was the most potent inhibitor of cell proliferation. 4-[3'-(1-Adamantyl)-4'-hydroxyphenyl]-3chlorophenyltetrazole, (2E)-5-\{2-[3'-(1-adamantyl)-2-chloro-4'-hydroxy-4-biphenyl]-ethenyl $\}-1 H$ -

\footnotetext{
*Address correspondence to Dr. Marcia I. Dawson, Burnham Institute for Medical Research, 10901 North Torrey Pines Rd., La Jolla, California 92037. Phone: 858-646-3165. Fax: 858-646-3197. E-mail: mdawson@ burnham.org.

"Present address: Kyushu University Hospital, Fukuoka City, Japan.

Supporting Information Available: Tables S1 and S2 showing data and calculations illustrated by graph in Figure 4, Table S3 listing HPLC analyses of target compounds using two different solvent systems, and Table S4 listing data on competitive inhibition of binding to SHP. This material is available free of charge via the Internet at http://pubs.acs.org.
} 
tetrazole, 5-\{4-[3'-(1-adamantyl)-4'-hydroxyphenyl]-3-chlorobenzylidene $\}$ thiazolidine-2,4-dione, and (3E)-4-[3'-(1-adamantyl)-2-chloro-4'-hydroxy-4-biphenyl]-2-oxobut-3-enal were very modest inhibitors of KG-1 proliferation. The other analogues were minimal inhibitors. Fragment-based QSAR analyses relating the polar termini with cancer cell growth inhibition revealed that length and van der Waals electrostatic surface potential were the most influential features on activity. 3-ClAHPC and the 3-chlorophenyltetrazole and 3-chlorobenzylidenethiazolidine-2,4-dione analogues were also able to inhibit SHP-2 protein-tyrosine phosphatase, which is elevated in some leukemias. 3-Cl-AHPC at $1.0 \mu \mathrm{M}$ induced human microvascular endothelial cell apoptosis but did not inhibit cell migration or tube formation.

\section{Introduction}

In investigating the effects of retinoids on cancer cell proliferation, we first noticed that the retinoid 6-[3'-(1-adamantyl)-4'-hydroxyphenyl]-2-naphthalenecarboxylic acid (AHPN ${ }^{\mathrm{a}}$ / CD437, 1 in Figure 1) ${ }^{1,2}$ displayed the atypical functions of inducing the cell-cycle arrest and initiating the apoptosis of MCF-7 breast cancer and other cancer cell lines. ${ }^{3,4}$ Further research led to our identification of (E)-4-[3'-(1-adamantyl)-4'-hydroxyphenyl]-3-chlorocinnamic acid (3-Cl-AHPC, 5 $)^{5}$ that retained these functions but not that exhibited by classical retinoids, namely the transcriptional activation of the retinoic acid nuclear receptor (RAR) subtypes to induce the transcription of genes regulated by trans-retinoic acid (trans-RA, 7) and its synthetic retinoid analogues. ${ }^{5-8}$ By inducing apoptosis of leukemia cells obtained from AML patients, 55 may have potential as a therapeutic agent for treating acute myeloid leukemia (AML). It also has the ability to induce apoptosis of cells from a variety of human cancer cell lines, including those derived from breast, lung, and prostate cancers. ${ }^{9}$ Moreover, apoptosis induced by $\mathbf{1}$ and $\mathbf{5}$ was found to be independent of the sensitivity of the cancer cell line to growth regulation by trans-RA or its $\mathrm{p} 53$ status, ${ }^{3,4}$ either of which is therapeutically advantageous because during cancer progression the ability of the trans-RA-RAR $\alpha$ complex to regulate proliferation or induce differentiation through induction of expression of the tumor suppressor gene RAR $\beta$ is lost 10,11 and the tumor suppressor gene $\mathrm{p} 53$ becomes dysfunctional or lost in about $50 \%$ of tumors. 12,13

Recently, we identified the first synthetic small-molecule ligands, 3-Cl-AHPC (5) and several analogues, for the nuclear receptor small heterodimer partner (SHP; NR0B2), ${ }^{14}$ which hitherto had only a putative ligand-binding domain and was classified as an orphan receptor. SHP is an atypical member of the steroid/thyroid hormone nuclear receptor family of transcription factors because it lacks the amino terminal sequence (AB), canonical DNA-binding domain (C), and hinge region (D) that are typical of other nuclear receptors and predominately functions as a transcriptional repressor through the binding of one of its three NR box motifs (LXXLL) to the activation function 2 (AF-2) site in the ligand-binding domain of its dimeric nuclear receptor partner. SHP has been found to bind such nuclear receptors as the androgen, aryl hydrocarbon receptor nuclear translocator, constitutive activated, estrogen, farnesoid, glucorticoid, liver X, pregnane X, peroxisome proliferator-activated, retinoic acid, retinoid X, thyroid hormone, TR3/nur77/NGFB-I, and vitamin D receptors. ${ }^{15-21}$ SHP modulates gene transactivation or suppression induced by its heterodimeric partner by recruiting histone deacetylases 1, 3, or 6, G9a histone 3 K9 methyltransferase, and other members of the Sin3aSwi/Snf repressor complex. 17

\footnotetext{
a Abbreviations: 3-Cl-AHPC, (E)-4-[3'-(1-adamantyl)-4'-hydroxyphenyl]-3-chlorocinnamic acid; AHPN, 6-[3'-(1-adamantyl)-4'hydroxyphenyl]-2-naphthalenecarboxylic acid; AML, acute myelocytic leukemia; DR5-tk-CAT, synthetic gene of retinoic acid response element of two direct repeats separated by five base pairs linked to the thymidine kinase promoter followed by the base sequence for chloramphenicol acetyl transferase gene; HMVE, human microvascular endothelial; RAR, retinoic acid receptor; RXR, retinoid X receptor; TTNC, $(E)-4-\left(5^{\prime}, 6^{\prime}, 7^{\prime}, 8^{\prime}\right.$-tetrahydro-5',5', $8^{\prime}, 8^{\prime}$-tetramethyl-2'-naphthalenyl)cinnamic acid; TTNN, 6-(5',6 $6^{\prime}, 7^{\prime}, 8^{\prime}$-tetrahydro-5',5', 8 ', $8^{\prime}$-tetramethyl-2'-naphthalenyl)-2-naphthalenecarboxylic acid.
} 
Tumor growth can be inhibited directly by inducing cancer cell death or indirectly by inhibiting tumor neovascularization (angiogenesis), a process that provides a conduit for delivery of nutrients to and removal of metabolic byproducts from the tumor. ${ }^{22}$ Tumor vasculature also provides a route for cancer cells to escape from the tumor and move to secondary metastatic sites. ${ }^{23}$ For these reasons, we explored the abilities of 3-Cl-AHPC (5) and its analogues to function as anticancer and antiangiogenic agents. We also undertook an analogue generation program to determine the pharmacophoric elements necessary to confer apoptotic activity to 5. Here, we report the effects of $\mathbf{5}$ and several analogues on the proliferation and functions of human microvascular endothelial (HMVE) cells and the impact that replacing the carboxylic acid group of $\mathbf{5}$ with other hydrogen-bond acceptors or isosteric-like groups has on cancer cell growth inhibition and induction of apoptosis.

\section{Results and Discussion}

\section{Chemistry}

Analogue Design-As a consequence of reports that therapeutic retinoids and RAR ligands such as trans-RA (7) and 9-cis-RA can cause adverse effects in cancer patients, ${ }^{24,25}$ a major facet of our design strategy has been introducing groups and scaffold modifications onto the AHPN scaffold that reduced interaction with the RAR subtypes. This strategy was first accomplished for the design of AHPC (4) by comparing the activities of members of our retinoid library in assays for retinoid activity with those of the retinoid TTNN $(8)^{26}$ from which AHPN (1) was originally derived. ${ }^{2}$ These assays, which historically have been widely used to assess retinoic acid-like activity, were (i) induction of keratin granule formation in vitamin-Adeficient hamster trachea in organ culture (TOC assay), which was developed by Sporn and co-workers; ${ }^{27}$ (ii) induction of differentiation in F9 embryonic teratocarcinoma cells (F9 assay), ${ }^{28}$ and (iii) inhibition of the induction of the proliferative enzyme ornithine decarboxylase in mouse epidermis by the tumor promoter 12- $O$-tetradecanoylphorbol-13acetate (TPA), which was developed by Verma and Boutwell (ODC assay). ${ }^{29}$ These assays have been reviewed by Sporn and Roberts. ${ }^{30}$ On the basis of its lower activities in the TOC and ODC assays, the cinnamic acid analogue (TTNC, 10 $)^{31}$ of TTNN $(\mathbf{8})$ was deemed to have less retinoid activity (Table 1). Similarly, the 3'-(1-adamantyl)-4'-hydroxyphenyl ring of 1 conferred lower retinoid activity than the 5,6,7,8-tetrahydro-5,5,8,8-tetramethyl-2naphthalenyl ring of $\mathbf{8}^{26}$ did in the ODC assay ${ }^{32}$ (Table 1), just as it was subsequently found by Shroot and co-workers to have lower activity in the RAR transcriptional activation assay. 1 Therefore, the two ring systems, 3-(1-adamantyl)-4-hydroxyphenyl and (E)-cinnamic acid, were joined at their 1-and 4-ring positions, respectively, to produce AHPC (4).

AHPC (4) effectively induced cancer cell apoptosis and exhibited lower activities in the TOC, F9, and ODC assays than AHPN; however, we observed that mice injected intravenously with AHPC displayed symptoms of retinoid-like toxicity. The structure of $\mathbf{4}$ was later reported as ST1926, which was found to have antileukemic activity. ${ }^{33}$ Recently, 4 was also found to transactivate the RARs $\alpha, \beta$, and $\gamma$ on a DR5-tk-CAT reporter construct in transfected COS-7 cells. ${ }^{34}$ Its half-maximal activation concentrations $\left(\mathrm{AC}_{50 \mathrm{~s}}\right)$ were 8-, 2.8-, and 4.7-fold higher, respectively, than those of trans-RA (7), thereby supporting our design strategy.

As Table 1 indicates, introduction of a substituent at the 5-position of the naphthalene ring in TTNN (8), which is ortho to the diaryl bond, reduced the retinoid activity of 5-Me-TTNN (9) in the TOC, F9, and ODC assays. By adapting this substitution strategy, namely introducing a chloro group adjacent to the diaryl bond of AHPN (1) and AHPC (4), we achieved a further reduction in RAR interaction by energetically hindering the diaryl rings of 5-Cl-AHPN (2) 35 and 3-Cl-AHPC (5) ${ }^{5}$ from assuming a small dihedral angle on binding to the RARs. ${ }^{6}$ According to molecular dynamics calculations on 2 , the increased dihedral angle for the 1',4diaryl bond caused the adamantyl group to interfere with the local dynamics of RAR $\gamma$ helix 
$\mathrm{H} 12$ to prevent the formation of the AF-2 site with helices $\mathrm{H} 3$ and $\mathrm{H} 4$ to which coactivator proteins bind to recruit the transcriptional complex necessary for retinoid-induced gene transcription.

We recently undertook quantitative structure-activity relationship (SAR) studies to identify the core recognition elements on 55 analogues of AHPN (1) and AHPC (4) that were necessary to induce the apoptosis of MDA-MB-231 breast cancer cells after treatment at $1.0 \mu \mathrm{M}$ for 96 h. The 'overlap rule' was used to align the training set in SYBYL QSAR, and the comparative molecular similarity index analysis (CoMSIA) electrostatic, hydrophobic, and steric fields were computed on a grid surrounding the overlapped ligands. The resulting CoMSIA analysis for apoptosis induction in MDA-MB-231 breast cancer cells [ $\ln (\%$ apoptosis)] resulted in a predictive $R^{2}$ of 0.78 and an un-cross-validated $R^{2}$ of 0.95 with a standard error of 0.45 . This seven-point descriptive model is illustrated in Figure 2A. Key polar points include two adjacent hydrogen-acceptor groups 1 and 2 and a hydrogen-donor/acceptor group 3 . The predictivity of this initial model was sufficient to score apoptosis induced by analogues similar in character to those in the training set. For example, if 3-Cl-AHPC (5) and (E)-3-\{5-[3'-(1-adamantyl)-4'hydroxyphenyl]-2-thienyl \}propenoic acid were left out of the training set and the CoMSIA model were used to predict their ability at $1.0 \mu \mathrm{M}$ to induce MDA-MB-231 apoptosis, the predicted versus experimental results were: $92 \%$ versus $43 \%$ for 5 and $0.8 \%$ versus $1 \%$ for the thienylpropenoic acid (Figure 2B). Thus, while not quantitative, even at this level the CoMSIA model was able to make order of magnitude predictions, underscoring the reasonableness of the model and the underlying pharmacophore. In the study reported here, we focus on identifying the character of the hydrogen-acceptor group(s) 1 and/or 2 required for induction of apoptosis.

Replacement of the carboxylic acid group of 3-Cl-AHPC (5) by isosteric and other groups having a similar pattern of polar atoms that function as hydrogen-bond acceptors was explored to determine whether pharmacologic properties could be improved with retention of apoptotic activity. Our earlier studies indicated that shifting the position of the carboxylate group relative to the phenolic hydroxyl was not successful. No apoptosis of trans-RA-resistant HL-60R leukemia cells ${ }^{36}$ was observed after 24-h treatment with $1.0 \mu \mathrm{M}$ 6-[3'-(1-adamantyl)-4'hydroxyphenyl]-3-naphthalenecarboxylic acid (11 in Table 2), compared to 98\% apoptosis with $1.0 \mu \mathrm{M}$ AHPN (1). The 96-h treatment of retinoid-resistant MDA-MB-231 breast cancer cells with $2.0 \mu \mathrm{M}$ 5-[3'-(1-adamantyl)-4'-hydroxyphenyl]-1-naphthalenecarboxylic acid produced only $4 \%$ apoptosis, compared to $46 \%$ apoptosis of MDA-MB-231 cells induced by $1.0 \mu \mathrm{M}$ 1. Replacement of the 2-carboxylate group with phenolic hydroxyl, carboxamide, and $N$-ethyl sulfonamide groups was similarly unsuccessful. Only $15 \%$ inhibition of primary human microvascular endothelial (HMVE) cell growth resulted on treatment with $1.0 \mu \mathrm{M} 6$ [3'-(1-adamantyl)-4'-hydroxyphenyl]-2-naphthol (12). The carboxamide derivative of 5-MeAHPN (3) at $1.0 \mu \mathrm{M}$ or $5.0 \mu \mathrm{M}$ was essentially inactive at inducing retinoid-resistant KG-1

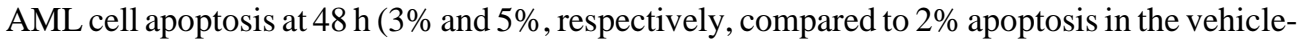
treated control) although 3 at $1.0 \mu \mathrm{M}$ and $5.0 \mu \mathrm{M}$ induced $51 \%$ and $73 \%$ apoptosis, respectively. After 48 h, KG-1 AML cell growth inhibition by the carboxamide derivative of 3 at $5.0 \mu \mathrm{M}$ was $3 \%$ compared to $2 \%$ in the control and $96 \%$ in $5.0 \mu \mathrm{M} 3$-treated cells. Similar results were obtained after $72 \mathrm{~h}$ of treatment. Evidently, KG-1 cells were unable to cleave a primary amide to the active carboxylate. Apoptosis induced in MDA-MB-231 cells after a 96-h treatment with the 2-(N-ethyl sulfonamide) analogue of $\mathbf{1}$ at $2.0 \mu \mathrm{M}$ was only $2 \%$, although growth inhibition was $30 \%$.

Because shifting the 2-carboxyl group of AHPN (1) to the 3-position and replacing the 2carboxyl group by a hydroxyl group (11 and $\mathbf{1 2}$ in Table 2) were unpromising, other modifications were investigated using 3-Cl-AHPC (5) as the scaffold. The tetrazole and thiazolidinedione termini were investigated using analogues $24,31,39$, and 43 . These termini 
were reported to reduce retinoid activity by the Dawson ${ }^{32}$ and Shudo 37,38 groups, respectively. The ability of nitriles ( $\mathrm{C}=\mathrm{O}$ bioisostere $)^{39}$ and hydroxamates to function as hydrogen-bond acceptors led to the design of $\mathbf{4 5}$ and $\mathbf{4 8}$, respectively. The boronic acid and phosphonic acid monoethyl ester analogues (57 and $\mathbf{6 3}$, respectively) were also investigated. In the latter case, the monoester rather than the free acid was prepared to improve membrane permeability.

On the basis of our finding that commonly used carboxylate replacements $\left(\mathrm{OH}\right.$ and $\left.\mathrm{CONH}_{2}\right)$ resulted in loss of apoptotic activity, we hypothesized that the carboxylate group of 3-Cl-AHPC (5) was crucial for bioactivity. Retinoid carboxylates are known to form strong salt bridges with the side-chain guanidinium groups of arginines in the ligand-binding pockets of RARs and RXRs. For example, the crystallographic structure of trans-RA (7) bound to the RAR $\gamma$ ligand-binding domain (PDB 2LBD) reveals a strong salt bridge between the carboxylate of 7 and the guanidinium group of Arg-278 located at the C-terminus of helix 5. ${ }^{40,41} \mathrm{We}$ further hypothesized that a putative arginine in the receptor protein for $5^{42}$ could interact with the carboxylate of $\mathbf{5}$. If this were correct, an analogue bearing a terminal 2-oxoaldehyde could undergo the Maillard reaction with the arginine guanadinium group or at least hydrogen-bond with this group. Methyl glyoxal and $\alpha$-diones undergo the Maillard reaction with the arginine guanidinium group to form pyrimidines. ${ }^{43-45}$ 2-Oxoaldehyde $\mathbf{6 0}$ was designed to test this hypothesis. The structures of these isosteric carboxylate analogues are shown in Table 3.

\section{Synthesis}

Routes to the 3-Cl-AHPC (5) analogues are shown in Scheme 1 and Scheme 2. Like 5, these analogues are characterized by a tetrasubstituted $1,1^{\prime}$-biphenyl core that was introduced by a Suzuki-Miyaura diaryl coupling reaction ${ }^{46}$ between the arylboronic acid $\mathbf{1 6}$ and a 4substituted 2-chlorophenyl triflate $(\mathbf{2 1}, \mathbf{2 8}, \mathbf{3 4}, \mathbf{4 0}$, or 50) using tetrakis(triphenylphosphine)palladium as the catalyst generally in the presence of $\mathrm{LiCl}$ and an aqueous base in refluxing dimethoxyethane (Scheme 1 and Scheme 2). Coupling yields ranged from $51 \%$ to $91 \%$. Intermediate $\mathbf{1 6}^{6}$ was prepared in three steps (74\% overall yield), namely (i) Friedel-Crafts monoalkylation of 4-bromophenol (15) with 1-adamantanol catalyzed by methanesulfonic acid or concd sulfuric acid, which gave comparable yields of 2-(1-adamantyl)-4-bromophenol and no detectable diadamantylation product; (ii) protection of the phenolic hydroxyl group of the adamantylation product as the benzyl ether; and (iii) low-temperature $\left(-78^{\circ} \mathrm{C}\right)$ lithiumhalogen exchange of resultant 3-(1-adamantyl)-4-benzyloxybromobenzene using $n$ butyllithium, conversion of the aryllithium to the arylboronate ester by treatment with tri(isopropyl) borate, and acid hydrolysis during workup.

4-Hydroxyl-3-chlorobenzaldehyde (17) was used to generate four of the triflate intermediates $(\mathbf{2 1}, \mathbf{2 8}, \mathbf{3 4}$, and 40) as shown in Scheme 1. In the case of the tetrazole-terminated targets 24 and $\mathbf{3 1}$ and the thiazolidendione-terminated target 39, the hydroxyl group of $\mathbf{1 7}$ was protected as the benzyl ether so that benzaldehyde $\mathbf{1 8}$ could be elongated to cinnamonitrile $\mathbf{1 9}$ and ethyl cinnamate $\mathbf{3 2}$ by olefination chemistry or be derivatized to the hydroxylimine $\mathbf{2 5}$ for dehydration to produce benzonitrile 26. The $E$ isomer predominated in the olefination products 19 and 32 according to their ${ }^{1} \mathrm{H}$ NMR spectra, which indicated about $5 \%$ of the $Z$ isomer at most. The unwanted isomer was readily removed by chromatography. Low-temperature $(-78$ ${ }^{\circ} \mathrm{C}$ ) cleavage of the benzyl ether protecting groups from 19, 26, and $\mathbf{3 2}$ using boron tribromide afforded phenols 20, 27, and 33. These phenols and $\mathbf{1 7}$ were converted to their respective triflates 21, 28, 34, and 40 using triflic anhydride and pyridine in dichloromethane. Diaryl coupling of the triflates with $\mathbf{1 6}$ introduced the substituted 1,1'-biphenyl scaffolds of intermediates $22,29,35$, and 41 , respectively.

After removal of the benzyl protecting groups from $\mathbf{2 2}$ and $\mathbf{2 9}$, the nitrile groups of their parent phenols $\mathbf{2 3}$ and $\mathbf{3 0}$ were allowed to undergo cycloaddition with trimethylsilyl azide in the 
presence of di(n-butyl)tin oxide ${ }^{47}$ to introduce the 5 -substituted tetrazole termini of targets $\mathbf{2 4}$ and 31, respectively. The ethyl cinnamate, intermediate $\mathbf{3 5}, 35$ was converted by hydride reduction followed by Swern oxidation 48 to $(E)$-cinnamaldehyde 37, which was subjected to condensation/elimination with 2,4-thiazolidinedione to afford the 5-cinnamylidene-2,4thiazolidinedinone 38. The substituted benzaldehyde, intermediate $\mathbf{4 1}$, was similarly transformed to the 5-benzylidene-2,4-thiazolidinedione $\mathbf{4 2}$. Thiazolidinedione formation produced both double-bond isomers. Their ${ }^{1} \mathrm{H}$ NMR spectra indicated that the $Z$-double bond isomers 38 and $\mathbf{4 2}$ predominated as demonstrated by the downfield positions $(0.4 \mathrm{ppm})$ of their vinylic protons trans to the sulfur atom $(\mathrm{H}-\mathrm{C}=\mathrm{C}-\mathrm{S})$ compared to those that were cis. Chromatographic purification and debenzylation of $\mathbf{3 8}$ and $\mathbf{4 2}$ afforded the 5-cinnamylideneand 5-benzylidene-2,4-thiazolidinedione targets 39 and 43, respectively. Knoevenagel condensation of benzaldehyde $\mathbf{4 1}$ with malononitrile 49 and debenzylation produced the 2benzylidenepropanedinitrile $\mathbf{4 5}$. However, if $\mathbf{1 7}$ were first converted to the 2-(3'-chloro-4'hydroxybenzylidene)propanedinitrile and then treated with triflic anhydride, the triflate ester was not obtained.

Syntheses of hydroxamic acid 48, boronic acid 57, 2-oxoaldehyde 60, and monoethyl phosphonate $\mathbf{6 3}$ are outlined in Scheme 2. Cinnamyl ester $\mathbf{3 5}$ from Scheme 1 was hydrolyzed to cinnamic acid $\mathbf{4 6}, 35$ which was converted to the activated ester by treatment with diisopropylcarbodiimide and 4-di-methylaminopyridine. Reaction of this ester with the tetrahydropyranyl ether of hydroxylamine $\mathrm{s}^{50}$ produced the protected hydroxamic acid $\mathbf{4 7}$. Concomitant low-temperature cleavage of the benzyl and tetrahydropyranyl protecting groups with boron tribromide afforded the hydroxamic acid target 48 . Reaction of the activated ester of 3-Cl-AHPC (5) with hydroxylamine failed to produce $\mathbf{4 8}$ in the presence of the unprotected phenolic group.

Construction of the 2-arylethenylboronic acid $\mathbf{5 7}$ was accomplished in eight steps from 2chloro-4-nitrophenol (49). Because aryl bromides and triflates typically undergo coupling with boronic acids with equal efficiency and the ortho chloro group in $\mathbf{4 9}$ was expected to hinder coupling by the aryl triflate, the bromo group was masked as a nitro group in triflate $\mathbf{5 0}$ to accomplish coupling with $\mathbf{1 6}$. The nitro group in the coupled product, 51, was then transformed to the bromo group by reduction to the amine and diazotization under hydrophobic conditions using tert-butyl nitrite in the presence of cupric bromide. ${ }^{51}$ Aryl bromide $\mathbf{5 3}$ underwent Sonagashira coupling with trimethylsilylacetylene ${ }^{52}$ to give the protected phenylacetylene 54. Desilylation of $\mathbf{5 4}$ with tetra( $n$-butyl)ammonium fluoride ${ }^{52}$ provided phenylacetylene 55. Benzodioxaborole $\mathbf{5 6}$ was prepared by the cis-hydroboration of $\mathbf{5 5}$ with catecholborane. 53 Treatment of 56 with boron tribromide $\left(-78{ }^{\circ} \mathrm{C}\right)$ cleaved both benzodioxa and benzyl protecting groups to produce the $(E)$-2-phenylethenyl boronic acid 57.

To prepare the 2-oxoketoaldehyde $\mathbf{6 0}$, we introduced the $(E)$-2-oxopropylidene group of $\mathbf{5 8}$ by olefination of benzaldehyde $\mathbf{4 1}^{6}$ with the ylid derived from (2-oxopropyl)

triphenylphosphonium bromide. ${ }^{54}$ The aldehyde group of $\mathbf{5 9}$ was obtained by selenous acid oxidation 55 of the methyl group of $\mathbf{5 8}$. Debenzylation of $\mathbf{5 9}$ afforded $\mathbf{6 0}$. Horner-EmmonsWadsworth olefination of $\mathbf{4 1}$ using the anion of tetraethyl methylenediphosphonate ${ }^{56}$ produced diethyl phosphonate $\mathbf{6 1}$, which on acid hydrolysis ${ }^{57}$ and debenzylation with boron tribromide produced the monoethyl phosphonate $\mathbf{6 3}$.

\section{Biological Activity}

Of the compounds shown in Table 3, only 3-Cl-AHPC (5) efficiently induced KG-1 cell apoptosis after a 48 -h treatment at $1.0 \mu \mathrm{M}(30 \%)$ or $5.0 \mu \mathrm{M}(55 \%)$. Its inhibition of cell growth was comparable (44\% and 67\%, respectively). After $96 \mathrm{~h}$ of treatment with $1.0 \mu \mathrm{M} \mathrm{5}$, apoptosis rose to $66 \%$ compared to $7 \%$ in the $\mathrm{Me}_{2} \mathrm{SO}$-alone control. Evidently, the region of the target protein with which the carboxylate group of $\mathbf{5}$ interacts to mediate its apoptotic effects is 
sufficiently constrained to prevent the other hydrogen-acceptor groups in the analogues shown in Table 3 from efficient interaction. However, similar constraints did not appear to impact inhibition of proliferation as potently. Thus, tetrazoles 24 and 31 and thiazolidinedione 43 were modest inhibitors of KG-1 cell proliferation as measured by cell counting but induced minimal apoptosis (2\%-10\% compared to $2 \%-3 \%$ in the control). On the basis of its efficient overlap with $\mathbf{5}$ and structural similarity, we had predicted that tetrazole $\mathbf{2 4}$ would have significant antiproliferative and apoptotic activities and that the longer thiazolidine 39 would lack such activities. However, both proved to be inactive in the apoptosis induction assays, and $\mathbf{3 9}$ lacked antiproliferative activity. 2-Oxoaldehyde $\mathbf{6 0}$ was also unable to induce apoptosis but did show weak growth inhibition $(38 \%$ at $5.0 \mu \mathrm{M})$. Recently, we demonstrated that 3-A-AHPC (6) antagonized 5-induced apoptosis but retained antiproliferative activity. ${ }^{6}$

3-Cl-AHPC (5) and its analogues were also assessed for their abilities to inhibit the proliferation of retinoid-resistant MDA-MB-231 breast, $\mathrm{H} 292$ lung, and DU-145 prostate cancer cells grown in the presence of $10 \%$ fetal bovine serum. Dose-response curves are shown in Figure 3. On the basis of their $\mathrm{IC}_{50}$ values (Table 3), H292 and DU-145 cells were generally more sensitive to inhibition under these growth conditions than MDA-MB-231 cells (Figure 3). The most potent inhibitor in the series was $\mathbf{5}$. Thiazolidinedione $\mathbf{4 3}$ displayed modest growth inhibitory activity against the lung and prostate cancer cell lines ( $\mathrm{IC}_{50}=3.6$ and $3.7 \mu \mathrm{M}$, respectively). Hydroxamic acid 48 displayed similar activity against prostate cancer cells $\left(\mathrm{IC}_{50}=3.5 \mu \mathrm{M}\right)$ and had an $\mathrm{IC}_{50}$ of about $6.3 \mu \mathrm{M}$ (extrapolated value) against breast cancer cells. The other analogues were less active.

Most of the AHPN analogues in the original training set for apoptosis induction had a carboxyl group at the 2-position of the naphthalene ring. Modifying this group had a deleterious impact on apoptosis induction but not on inhibition of proliferation (Table 3). We next addressed the impact on KG-1 cell growth of variations in the position and character of the polar hydrogenbond acceptor region (descriptive points 1 and 2 in Figure 2A) in an attempt to understand the biological data in terms of fundamental changes in the polar region. Thus, a fragment QSAR model was constructed using the isosteric polar/ hydrogen-bond acceptor replacements shown in Table 3 for the carboxyl group of 3-Cl-AHPC (5). While the number of analogues included in this portion of the SAR study was limited, a predictive fragment QSAR, $\ln \left(\mathrm{IC}_{50} \mathrm{KG}-1\right)=$ $-2.65+0.121$ POLAR_V $+0.062 \mathrm{p} K_{\mathrm{a}}$ (raw), having an $R^{2}$ of 0.76 and a standard error of 0.78 , using two independent variables could be developed and related to the $\ln \left(\mathrm{IC}_{50}\right)$ values. ${ }^{58}$ Polar volume (POLAR_V) and calculated (raw) $\mathrm{p} K_{\mathrm{a}}$ were the most important features influencing KG-1 growth inhibition. For the solid tumor cell lines, modestly predictive QSAR models $\left(R_{2}=0.5-0.8\right)$ were developed using the three properties of the longest length of the fragment $(L)$, minimum in computed electrostatic potential on the van der Waals surface of the fragments (MINIM_PS) and polar volume. In Figure 4 is illustrated the quality of the three-parameter QSAR model for MDA-MB-231 breast cancer cell growth inhibition $\mathrm{IC}_{50}$ values in terms of these properties. The resultant analysis had an $R^{2}$ of 0.75 and a standard error of 0.6. The QSAR equation $\ln \left(\mathrm{IC}_{50}\right.$ MBA-MB-231) $=4.14-0.30 L+14.9 \mathrm{MINIM} \_\mathrm{PS}+0.10 \mathrm{POLAR}$ V with the 'weights' of the elements revealing their 'relative contributions'. Analogously, analysis of the results on the other cell lines yielded similar equations: $\ln \left(\mathrm{IC}_{50} \mathrm{H} 292\right)=3.33+0.28 \mathrm{~L}+$ 11.78MINIM_PS + 0.090POLAR_V with an $R^{2}$ of 0.44 and a standard error of 1.1 and $\ln$ $\left(\mathrm{IC}_{50}\right.$ DU-145) $=3.87-0.073 \mathrm{~L}+19.3 \mathrm{MINIM} \_\mathrm{PS}+0.10 \mathrm{POLAR}$ V $\mathrm{V}$ with an $R^{2}$ of 0.54 and a standard error of 1.0. While the predictive $R^{2}$ values are only modest, the analyses do indicate that both the amount of polar atom (group) exposure and size are correlated with antiproliferative activity, whereas the other computed properties are not explanatory variables. Therefore, the analyses provide a preliminary indication of molecular design features coupled to growth inhibitory activity variations. 
The NR4A1 nuclear receptor protein was found to interact in the cytoplasm with the mitochondrial protein Bcl-2 to induce cancer cell apoptosis. ${ }^{59}$ The translocation of NR4A1 from nucleus to cytoplasm was observed to occur in several cancer cell lines after their transfer to media lacking serum and treatment with an analogue of AHPN (1). Once in the cytoplasm, NR4A1 was able to induce a proapoptotic conformational change in antiapoptotic Bcl-2 that led to mitochondrial cytochrome $\mathrm{c}$ release followed by apoptosis. Therefore, we attempted to correlate the sensitivity of MDA-MB-231 breast, H292 lung, and DU-145 prostate cancer cells to apoptosis induction by 3-Cl-AHPC (5) with their levels of NR4A1 (human TR3) protein expression. In lysates obtained from these cancer cell lines that had been both grown and treated with $1.0 \mu \mathrm{M} 5$ in media containing $10 \%$ fetal bovine serum we were not able to detect NR4A1 protein by Western blotting (data not shown). These results suggest that serum constituents could influence NR4A1 expression.

After Zhang et al. ${ }^{60}$ found evidence to suggest that AHPN (1) modulated enzyme activity on the basis of (i) its rapid induction of cell-cycle arrest and apoptosis; (ii) its lack of a requirement for gene transcription or protein synthesis as evidenced by resistance to actinomycin D or cycloheximide treatment, respectively, and (iii) its ability to inhibit the phosphohatidylinositol-3-kinase (PI3-K)/Akt pathway, we hypothesized that the effects of 1 as well as those of 5-Cl-AHPN (2) and 3-Cl-AHPC (5) could be due to inhibition of an enzyme. Pfahl and Piedrafita subsequently reported that the $\mathrm{IC}_{50}$ value obtained for $\mathbf{1}$ in inhibiting the dual-specificity mitogen-activated protein kinase phosphatase (MKP)-1 in vitro was in the 6$\mu \mathrm{M}$ range. ${ }^{61}$ Because of their report, we investigated the inhibitory activity of several analogues of $\mathbf{5}$ on the protein-tyrosine phosphatases (PTPs) SHP-2 and CD45, both of which are implicated in the development of some forms of leukemia. Somatic gain-of-function mutations were found to occur in the PTPN11 gene for the cytoplasmic Src-homology 2 domain-containing PTP (SHP-2) in juvenile myelomonocytic leukemia and lead to hyperactivation of oncogenic Ras. ${ }^{62,63}$ Phosphorylated (activated) SHP-2 was reported to be overexpressed in 23 of 25 peripheral blood or bone marrow samples from adult chronic myeloid myelocytic leukemia patients but was only poorly or not expressed in samples from normal adults. ${ }^{64}$ In addition, SHP-2 was observed to coimmunoprecipitate with phosphatidylinositol-3 kinase (PI3-K) in BCR-ABL tyrosine kinase-transformed cells. ${ }^{65}$ In earlier work, we had observed that $\mathbf{5}$ was able to inhibit the PI3-K/Akt pathway in cancer cells. 66 The KG-1 leukemia cell line is reported to express SHP-2. ${ }^{64}$ These observations suggested that inhibition of SHP-2 activity could affect KG-1 cell function and prompted us to investigate the effects of 5, 31, and $\mathbf{4 3}$ on KG-1 cells. Both $\mathbf{3 1}$ and $\mathbf{4 3}$ were found to inhibit SHP-2 PTP activity (Figure 5A) with $\mathrm{IC}_{50}$ values of $1.3 \mu \mathrm{M}$ and $2.2 \mu \mathrm{M}$, respectively, and, therefore, could serve as leads for the development of more potent and selective inhibitors of this enzyme. The $\mathrm{IC}_{50}$ value for 5 was found to be $2.1 \mu \mathrm{M}$. This small sample did not permit us to correlate KG-1 growth inhibition with inhibition of enzyme activity.

CD45 PTP is found on the surface of cells of lymphohematopoietic lineage, including leukemia cells, ${ }^{67}$ and the expression of its isoforms is altered in acute myeloid leukemia. ${ }^{67,68} \mathrm{We}$ observed that AHPC (4), 31, and $\mathbf{4 3}$ at $10 \mu \mathrm{M}$ inhibited CD45 activity by $84 \%, 46 \%$, and $53 \%$, respectively, when dimethylformamide was used as the vehicle. 3-Cl-AHPC (5) and $\mathbf{6 0}$ were not evaluated. However, because $\mathbf{4 5}, \mathbf{4 8}$, and $\mathbf{5 7}$ had similar CD45 inhibitory activities (68\%, $37 \%$, and $54 \%$, respectively) under these same conditions but at $5 \mu \mathrm{M}$ were not able to inhibit KG-1 cell proliferation, the probability that $\mathbf{4}, \mathbf{3 1}$, and $\mathbf{4 3}$ inhibit KG-1 proliferation by inhibiting CD45 activity appears to be very low. As shown in the dose-response curve of Figure $5 \mathrm{~B}, \mathrm{IC}_{50}$ values for $\mathrm{CD} 45 \mathrm{PTP}$ activity inhibition by $\mathbf{3 1}$ and $\mathbf{4 3}$ were $1.2 \mu \mathrm{M}$ and $2.3 \mu \mathrm{M}$, respectively, when dimethyl sulfoxide was used as the vehicle.

Cancer cells stimulate angiogenesis to promote tumor growth and metastasis. In the presence of growth factors released by tumors and their related stroma, human microvascular endothelial 
(HMVE) cells from the surrounding vasculature are induced to proliferate, migrate into the tumor, and assemble into microtubular vessels. Because cancer cells underwent both cell-cycle arrest and apoptosis in response to 3-Cl-AHPC (5) and 5-Cl-AHPN (2), we wondered whether proliferating primary HMVE cells would behave similarly in culture. As shown in Figure 6, 5 effectively reduced HMVE cell growth $\left(\mathrm{IC}_{50}=0.3 \mu \mathrm{M}\right)$. Thiazolidinedione 43 had low inhibitory activity $(30 \%$ inhibition at $1.0 \mu \mathrm{M})$, whereas $\mathbf{2 4 , 3 1}$, and $\mathbf{3 9}$ had no significant effect on HMVE cell growth compared to that of the vehicle-treated control.

We next examined whether 3-Cl-AHPC (5) would induce the apoptosis of proliferating HMVE cells in culture. Although no obvious cell detachment or rounding was observed after a 20-h incubation with $\mathbf{5}$, oligonucleosome levels were significantly enhanced after treatment with 0.25 or $0.50 \mu \mathrm{M} 5$ in a concentration-dependent manner, as shown in Figure 7 . These results demonstrate that $\mathbf{5}$ is able to induce HMVE cell apoptosis. Apoptosis induced by $0.5 \mu \mathrm{M} 5$ was $64 \%$ of that induced by $1.0 \mu \mathrm{M}$ adriamycin. These results suggest that 5 has potential in vivo antiangiogenic activity.

3-Cl-AHPC (5) was further examined for its effects on HMVE cell migration and tubule formation. As shown in Figure 8, $0.05 \mathrm{nM}$ to $0.50 \mu \mathrm{M} 5$ had no statistically significant effect on cell migration through Matrigel when cells were treated for 5-h compared to cells treated with only vehicle. Moreover, 18-h treatment with $0.25 \mu \mathrm{M}$ or $1.0 \mu \mathrm{M} 5$ had no statistically significant effects on either the level of tube formation or tube length in Matrigel by cells obtained from $80 \%$ confluent cultures (Figure 9). In contrast, trans-RA (7) and other classical retinoids are reported to inhibit angiogenesis in chick chorioallantoic membrane. ${ }^{69}$ To establish that these compounds were not exerting their effects through any retinoid-mediated pathway, the antiproliferative activity of AHPN (1) was compared to those of trans-RA (7), RAR $\gamma$-selective transcriptional agonist SR11254 (13), ${ }^{70,71}$ and RAR $\gamma$-selective antagonist SR11253 (14) 70,71 in HMVE cells. The results shown in Table 2 demonstrate that $\mathbf{1}$ was the most potent of the four compounds, although it was less efficient as a transactivator of the RARs than 7. ${ }^{1}$ 5-Cl-AHPN (2), AHPC (4), and 5 were also able to inhibit the proliferation of HMVE cells. In contrast, the 3-naphthalenecarboxylic acid and 2-naphthol analogues (11 and 12) of 1 were poor inhibitors of HMVE cell proliferation, just as they were of cancer cell growth.

Recently, we discovered that 3-Cl-AHPC (5) binds to the small heterodimer partner (SHP) nuclear orphan receptor. ${ }^{14}$ Interestingly, prior to its inducing the intrinsic apoptosis cascade in KG-1 AML and MDA-MB-231 breast cancer cells, 5 was found to interact with SHP in the nuclear Sin3A repressor complex. A recombinantly expressed glutathione $S$-transferase-SHP chimeric protein (GST-SHP) also bound $\mathbf{5}$, as evidenced by its ability to displace tritiated AHPN $^{42}$ from GST-SHP bound to glutathione-linked Sepharose beads, as did AHPN (1) and the 3-chlorophenyltetrazole and 3-chlorobenzylidenethiazolidinedione analogues (39 and 43, respectively). The relative competitive displacement efficiencies of the tritiated label were as follows: nonlabeled 1, 53\%; 5, 87\%; 3-A-AHPC (6), 72\%; tetrazole 39, 69\%; thiazolidinedione 43, 37\%; hydroxamic acid 48, 7\%; and boronic acid 57, $0 \%$ at $50 \mu \mathrm{M}$.

\section{Conclusion}

Thus, 3-Cl-AHPC (5) appears to negatively impact cancer cell growth through two signaling pathways, namely inhibiting cell proliferation and inducing apoptosis. Our results suggest that 5 also has antiangiogenic activity by modulating the same pathways in tumor microvasculature. The present fragment-based QSAR study on the hydrogen bond-accepting elements 1 and 2 of the pharmacophoric model shown in Figure 2A indicates that the dimensions of the elements and their minima in computed electrostatic potential on the van der Waals surface of the fragments have a major role in determining growth inhibitory activity. Defining the apoptotic 
activity properties of these elements was not possible because the present isosteric modifications of the carboxylate group abrogated apoptosis induction. These results suggest that if interaction with SHP regulates apoptotic activity, the region of SHP to which the carboxylate group binds is sterically constrained. Of the three hydrogen-acceptor analogues $(\mathbf{5}, \mathbf{3 1}$, and 43) evaluated as inhibitors of phosphatases, only $\mathbf{5}$ was a potent inhibitor of both apoptosis and cell growth. Analogues $\mathbf{3 1}$ and $\mathbf{4 3}$ were only modest inhibitors of cell proliferation. Thus, while the present results suggest that inhibition of phosphatase activity may have a role in inhibition of cell proliferation, further studies will be necessary before robust conclusions can be drawn.

As observed with 3-A-AHPC (6), tetrazole 39 was able to compete with radiolabeled AHPN for binding to recombinantly expressed small heterodimer partner protein ${ }^{14}$ but was unable to induce KG-1 AML cell apoptosis. Earlier, we found that $\mathbf{6}$ was able to attenuate apoptosis induced by 3-Cl-AHPC (5). ${ }^{6}$ These results suggest that both $\mathbf{6}$ and $\mathbf{3 9}$ can function as antagonists of the apoptotic activity of $\mathbf{5}$. Thus, with identified potent agonists $(\mathbf{1}$ and $\mathbf{5})$ and antagonists (6 and 39) of SHP-Sin3A-mediated apoptotic activity, we plan on pursuing our studies on how these compounds regulate transcriptional signaling through SHP. Because both 31 and 43 exhibited similar modest antiproliferative activities but had very low apoptosisinducing activity, they may have application as probes of the pathway by which $\mathbf{5}$ induces cellcycle arrest independent of apoptosis.

\section{Experimental Section}

\section{Chemistry}

Chemicals and solvents from commercial sources were used without further purification unless specified. Abbreviations for solvents and reagents are as follows: DIBAL, diisobutylaluminum hydride; DIC, diisopropylcarbodiimide; DMAP, 4-(N,N-dimethylamino)pyridine; DMF, dimethylformamide; DME, ethylene glycol dimethyl ether; TBAF, tetra(n-butyl)ammonium fluoride; THF, tetrahydrofuran; $\mathrm{Tf}_{2} \mathrm{O}$, trifluoromethanesulfonic anhydride. Reactions were carried out under argon and monitored by thin-layer chromatography on silica gel (mesh size $60, \mathrm{~F}_{254}$ ) with visualization under $\mathrm{UV}$ light. Organic extracts were dried over $\mathrm{Na}_{2}-\mathrm{SO}_{4}$ unless otherwise specified and concentrated at reduced pressure. Standard and flash column chromatography employed silica gel (Merck 60, 230-400 mesh). Experimental procedures were not optimized. Melting points for samples were determined in capillaries using a MelTemp II apparatus and are uncorrected. Infrared spectra were obtained using an FT-IR Mason satellite spectrophotometer on powdered samples. ${ }^{1} \mathrm{H}$ NMR spectra were recorded on a 300$\mathrm{MHz}$ Varian Unity Inova spectrometer, and shift values are expressed in ppm $(\delta)$ relative to $\mathrm{CHCl}_{3}$ as an internal standard. Unless mentioned otherwise, compounds were dissolved in ${ }^{2} \mathrm{HCCl}_{3}$. MALDI-FAB mass spectra were run on an Applied Biosystems Voyager De-Pro MALDI-TOF instrument at the Burnham Institute. High-resolution mass spectra were recorded on an Agilent ESI-TOF mass spectrometer at The Scripps Research Institute (La Jolla, CA). Electrospray mass spectrometry was performed on an ABI EPI-3000 instrument.

\section{3-(1-Adamantyl)-4-benzyloxyphenylboronic Acid (16). 35}

Our reported procedure ${ }^{8}$ was adapted. To a solution of 3-(1-adamantyl)-4-benzyloxyphenyl bromide 8 (2.00 g, $5.04 \mathrm{mmol})$ in THF $(7 \mathrm{~mL})$ at $-78{ }^{\circ} \mathrm{C}$ (dry ice/acetone bath) under argon was added in one portion $1.6 \mathrm{M} n$ - $\mathrm{BuLi}(7.56 \mathrm{mmol})$ in hexane $(4.7 \mathrm{~mL})$. The mixture was stirred at $-78{ }^{\circ} \mathrm{C}$ for $15 \mathrm{~min},(i-\mathrm{PrO}){ }_{3} \mathrm{~B}(3.5 \mathrm{~mL}, 15.1 \mathrm{mmol})$ was added, and the resulting solution was stirred at $-78{ }^{\circ} \mathrm{C}$ for $20 \mathrm{~min}$ and then at room temperature overnight. The mixture was quenched with $0.1 \mathrm{~N} \mathrm{HCl}(30 \mathrm{~mL})$ and extracted with EtOAc $(3 \times 190 \mathrm{~mL})$. The extracts were washed (brine) and dried. The residue after concentration was purified on silica gel (40\% EtOAc/hexane) to give $1.63 \mathrm{~g}$ (89\%) of $\mathbf{1 6}$ as a white solid, mp $151-153{ }^{\circ} \mathrm{C} .{ }^{1} \mathrm{H}$ NMR $\delta 1.78$ 
(bs, 6H, $\mathrm{AdCH}_{2}$ ), 2.09 (bs, 3H, $\mathrm{AdCH}$ ), 2.27 (bs, 6H, $\mathrm{AdCH}_{2}$ ), 5.23 (s, 2H, $\mathrm{ArCH}_{2}$ ), 7.07 (d, $J=8.1 \mathrm{~Hz}, 1 \mathrm{H}, 5-\mathrm{ArH}), 7.33-7.55$ (m, 5H, ArH), 8.04 (dd, $J=8.1,1.5 \mathrm{~Hz}, 1 \mathrm{H}, 6-\mathrm{ArH}), 8.2$ $\operatorname{ppm}(\mathrm{d}, J=1.2 \mathrm{~Hz}, 1 \mathrm{H}, 2-\mathrm{ArH})$.

\section{4-Benzyloxy-3-chlorobenzaldehyde (18). ${ }^{72}$}

To a suspension of $17(4.68 \mathrm{~g}, 30 \mathrm{mmol})$ and $\mathrm{K}_{2} \mathrm{CO}_{3}(6.90 \mathrm{~g}, 50 \mathrm{mmol})$ in THF $(50 \mathrm{~mL})$ and DMF $(10 \mathrm{~mL})$ under argon was added benzyl bromide $(6.84 \mathrm{~g}, 40 \mathrm{mmol})$. The mixture was heated at reflux for overnight, concentrated, diluted with $\mathrm{CH}_{2} \mathrm{Cl}_{2}(100 \mathrm{~mL})$, washed (water, 1 $\mathrm{N} \mathrm{HCl}$ and brine), and dried. Concentration and chromatography (15\% EtOAc/hexane) afforded $6.22 \mathrm{~g}(84 \%)$ of $\mathbf{1 8}$ as a white solid; mp 92-94 ${ }^{\circ} \mathrm{C}$. IR $\left(\mathrm{CHCl}_{3}\right) 2966,1682 \mathrm{~cm}^{-1} ;{ }^{1} \mathrm{H}$ NMR $\delta 5.23\left(\mathrm{~s}, 2 \mathrm{H}, \mathrm{ArCH}_{2}\right), 7.08(\mathrm{~d}, J=8.4 \mathrm{~Hz}, 1 \mathrm{H}, 5-\mathrm{ArH}), 7.35-7.46(\mathrm{~m}, 5 \mathrm{H}, \mathrm{ArH}), 7.74$ (d, $J=6.6 \mathrm{~Hz}, 1 \mathrm{H}, 6-\mathrm{ArH}), 7.94(\mathrm{~d}, J=1.5 \mathrm{~Hz}, 1 \mathrm{H}, 2-\mathrm{ArH}), 9.85 \mathrm{ppm}(\mathrm{s}, 1 \mathrm{H}, \mathrm{CHO})$.

\section{(E)-4-Benzyloxy-3-chlorocinnamonitrile (19)}

To diethyl (cyanomethyl)phosphonate $(885 \mathrm{mg}, 5.0 \mathrm{mmol})$ in THF $(5 \mathrm{~mL})$ stirred with cooling in a dry ice/acetone bath was added under argon $10 \mathrm{~mL}$ of $0.5 \mathrm{M} \mathrm{KN}\left(\mathrm{SiMe}_{3}\right)_{2}(5.0 \mathrm{mmol})$ in toluene. Stirring was continued for $0.5 \mathrm{~h}$ before $\mathbf{1 8}^{72}(738 \mathrm{mg}, 3.0 \mathrm{mmol})$ in THF (5.0 mL) was slowly added over a 0.5 -h period. After being stirred for $1 \mathrm{~h}$ more, the mixture was allowed to warm to room temperature, stirred overnight, poured into $1 \mathrm{M} \mathrm{NH}_{4} \mathrm{Cl}(10 \mathrm{~mL})$ and water $(20 \mathrm{~mL})$, and extracted with hexane $(100 \mathrm{~mL})$. The extract was washed (water and brine) and dried. Concentration and chromatography on silica gel (EtOAc/hexane) afforded $710 \mathrm{mg}(91 \%)$ of $\mathbf{1 9}$ as a white powder, $R_{\mathrm{f}} 0.47$ (EtOAc/hexane); mp 110-114 ${ }^{\circ} \mathrm{C}$. IR $\left(\mathrm{CHCl}_{3}\right) 2966,2215$ $\mathrm{cm}^{-1} ;{ }_{1}^{1} \mathrm{H}$ NMR $\delta 5.21\left(\mathrm{~s}, 2 \mathrm{H}, \mathrm{ArCH}_{2}\right), 5.73(\mathrm{~d}, J=15.9 \mathrm{~Hz}, 1 \mathrm{H}, \mathrm{HC}=\mathrm{CCN}), 6.97(\mathrm{~d}, J=8.4$ $\mathrm{Hz}, 1 \mathrm{H}, 5-\mathrm{ArH}), 7.26(\mathrm{~d}, J=16.5 \mathrm{~Hz}, 1 \mathrm{H}, \mathrm{C}=\mathrm{CHCN}), 7.36-7.45$ (m, 6H, ArH, 6-ArH), 7.51 ppm (d, $J=2.1 \mathrm{~Hz}, 1 \mathrm{H}, 2-\mathrm{ArH})$. The crude nitrile was converted directly to $\mathbf{2 0}$.

\section{General Procedure for Debenzylation of 19, 22, 26, 29, 32, 38, 42, 44, 47, 56, 59, and 61}

To a stirred mixture of the benzyl ether $(2.5 \mathrm{mmol})$ in $\mathrm{CH}_{2} \mathrm{Cl}_{2}(10 \mathrm{~mL})$ at $-78{ }^{\circ} \mathrm{C}$ under argon was added slowly over a 10 -min period $6.0 \mathrm{~mL}$ of $1.0 \mathrm{M} \mathrm{BBr}_{3}(6.0 \mathrm{mmol})$ in $\mathrm{CH}_{2} \mathrm{Cl}_{2}$. The mixture was stirred for $2 \mathrm{~h}$ at $-78^{\circ} \mathrm{C}$. Water $(10 \mathrm{~mL})$ was added, and the mixture was stirred for $10 \mathrm{~min}$ and then extracted (EtOAc). The extract was washed (water and brine), dried, and concentrated. Flash chromatography of the residue on silica gel (10\% EtOAc/hexane) yielded the phenol.

\section{(E)-3-Chloro-4-hydroxycinnamonitrile (20)}

$19(672 \mathrm{mg}, 2.5 \mathrm{mmol})$ yielded $420 \mathrm{mg}(94 \%)$ of $\mathbf{2 0}$ as a pale-yellow powder, $R_{\mathrm{f}} 0.12(10 \%$ EtOAc/hexane); mp 165-169 ${ }^{\circ} \mathrm{C}$. IR (powder) $3416,2966,2213 \mathrm{~cm}^{-1} ;{ }^{1} \mathrm{H}$ NMR $\delta 6.32(\mathrm{~d}, J$ $=16.2 \mathrm{~Hz}, 1 \mathrm{H}, \mathrm{HC}=\mathrm{CHCN}), 7.02(\mathrm{dd}, J=3.0,8.7 \mathrm{~Hz}, 1 \mathrm{H}, 5-\mathrm{ArH}), 7.48(\mathrm{~d}, J=10.2 \mathrm{~Hz}, 1 \mathrm{H}$, 6-ArH), $7.54(\mathrm{~d}, J=16.2 \mathrm{~Hz}, 1 \mathrm{H}, H \mathrm{C}=\mathrm{CHCN}), 7.75(\mathrm{~s}, 1 \mathrm{H}, 2-\mathrm{ArH}), 10.88 \mathrm{ppm}(\mathrm{s}, 1 \mathrm{H}, \mathrm{OH})$. The crude product was converted directly to the triflate 21 .

\section{(E)-4-[3'-(1-Adamantyl)-4'-hydroxyphenyl]-3-chlorocinnamonitrile (23)}

22 (420 mg, $87 \mathrm{mmol}$ ) yielded $310 \mathrm{mg}(87 \%)$ of 23 as a pale-yellow solid, $R_{\mathrm{f}} 0.15$ (5\% EtOAc/ hexane); mp 142-148 ${ }^{\circ} \mathrm{C}$, which was used to prepare 24 . IR $\left(\mathrm{CHCl}_{3}\right) 3394,2906,2226,1284$ $\mathrm{cm}^{-1} ;{ }^{1} \mathrm{H}$ NMR $\delta 1.80\left(\mathrm{~s}, 6 \mathrm{H}, \mathrm{AdCH}_{2}\right), 2.10$ (s, 3H, AdCH), $2.16\left(\mathrm{~s}, 6 \mathrm{H}, \mathrm{AdCH}_{2}\right), 5.00(\mathrm{~s}, 1 \mathrm{H}$, $\mathrm{OH}), 5.90(\mathrm{~d}, J=17.1 \mathrm{~Hz}, 1 \mathrm{H}, \mathrm{HC}=\mathrm{C} H \mathrm{CN}), 6.72\left(\mathrm{~d}, J=7.8 \mathrm{~Hz}, 1 \mathrm{H}, 5^{\prime}-\mathrm{ArH}\right), 7.17(\mathrm{dd}, J=$ $\left.2.1,8.1 \mathrm{~Hz}, 1 \mathrm{H}, 6^{\prime}-\mathrm{ArH}\right), 7.32(\mathrm{~d}, J=9.3 \mathrm{~Hz}, 1 \mathrm{H}, 6-\mathrm{ArH}), 7.33(\mathrm{~d}, J=18.0 \mathrm{~Hz}, 1 \mathrm{H}, \mathrm{CH}=\mathrm{CHCN})$, 7.38 (s, 1H, 2'-Ar), 7.39 (d, $J=7.8 \mathrm{~Hz}, 1 \mathrm{H}, 6-\mathrm{ArH}), 7.55 \mathrm{ppm}(\mathrm{d}, J=1.8 \mathrm{~Hz}, 1 \mathrm{H}, 3-\mathrm{ArH})$. 


\section{3-Chloro-4-hydroxybenzonitrile (27)}

26 (850 mg, $3.5 \mathrm{mmol}$ ) yielded after chromatography (20\% EtOAc/hexane) (470 mg, 88\%) of phenol 27 as a pale-yellow solid, which was converted directly to triflate $\mathbf{2 8}$.

\section{4-[3'-(1-Adamantyl)-4'-hydroxyphenyl]-3-chlorobenzonitrile (30)}

$\mathbf{2 9}$ (300 $\mathrm{mg}, 0.66 \mathrm{mmol})$ yielded $0.45 \mathrm{~g}(87 \%)$ of $\mathbf{3 0}$ as a pale-yellow solid, $R_{\mathrm{f}} 0.37(10 \% \mathrm{EtOAc} /$ hexane); mp 220-222 ${ }^{\circ} \mathrm{C}$. IR $\left(\mathrm{CHCl}_{3}\right) 3410,2966,2237,1278 \mathrm{~cm}^{-1} ;{ }^{1} \mathrm{H}$ NMR $\delta 1.80$ (s, 6H, $\left.\mathrm{AdCH}_{2}\right), 2.10(\mathrm{~s}, 3 \mathrm{H}, \mathrm{AdCH}), 2.15\left(\mathrm{~s}, 6 \mathrm{H}, \mathrm{AdCH}_{2}\right), 5.02(\mathrm{~s}, 1 \mathrm{H}, \mathrm{OH}), 6.74(\mathrm{~d}, J=8.4 \mathrm{~Hz}, 1 \mathrm{H}$, $\left.5^{\prime}-\mathrm{ArH}\right), 7.17$ (dd, $\left.J=8.1,2.1 \mathrm{~Hz}, 1 \mathrm{H}, 6^{\prime}-\mathrm{ArH}\right), 7.30\left(\mathrm{~d}, J=2.4 \mathrm{~Hz}, 1 \mathrm{H}, 2^{\prime}-\mathrm{ArH}\right), 7.44$ (d, $J=$ $7.8 \mathrm{~Hz}, 1 \mathrm{H}, 5-\mathrm{ArH}), 7.57$ (dd, $J=7.8,1.5,1 \mathrm{H}, 6-\mathrm{ArH}), 7.75 \mathrm{ppm}(\mathrm{d}, J=1.5 \mathrm{~Hz}, 1 \mathrm{H}, 2-\mathrm{ArH})$. FTMS (HRMS) calcd $\mathrm{C}_{23} \mathrm{H}_{23}-\mathrm{ClNO}[\mathrm{M}+\mathrm{H}]^{+}$expected 364.1463, found 364.1461.

\section{Ethyl (E)-3-Chloro-4-hydroxycinnamate (33). 8}

$\mathbf{3 2}^{72}$ yielded after chromatography (24\% EtOAc/hexane) $0.855 \mathrm{~g}$ (92\%) of $\mathbf{3 3}$ as a white solid, mp 106-108 ${ }^{\circ} \mathrm{C} .{ }^{1} \mathrm{H}$ NMR $\delta 1.34\left(\mathrm{t}, J=7.2 \mathrm{~Hz}, 3 \mathrm{H}, \mathrm{CH}_{2} \mathrm{CH}_{3}\right), 4.26(\mathrm{q}, J=7.2 \mathrm{~Hz}, 2 \mathrm{H}$, $\left.\mathrm{CH}_{2} \mathrm{CH}_{3}\right), 5.84(\mathrm{~s}, 1 \mathrm{H}, \mathrm{OH}), 6.32(\mathrm{~d}, J=16.2 \mathrm{~Hz}, 1 \mathrm{H}, \mathrm{CH}=\mathrm{CHCO}), 7.04(\mathrm{~d}, J=8.4 \mathrm{~Hz}, 1 \mathrm{H}$, 5-ArH), 7.37 (dd, $J=8.4,2.1 \mathrm{~Hz}, 1 \mathrm{H}, 6-\operatorname{ArH}), 7.52(\mathrm{~d}, J=1.8 \mathrm{~Hz}, 1 \mathrm{H}, 2-\operatorname{ArH}), 7.58 \mathrm{ppm}(\mathrm{d}$, $J=16.2 \mathrm{~Hz}, 1 \mathrm{H}, \mathrm{CH}=\mathrm{CHCO})$. The product was used directly in the next step.

\section{5-[3-(3'-(1-Adamantyl)-2-chloro-4'-hydroxy-4-biphenyl)-(2E)-2-propenylidene]-2,4- thiazolidinedione (39)}

38 (35 mg, $0.06 \mathrm{mmol}$ ) yielded $25 \mathrm{mg}(85 \%)$ of 39 as an orange powder, $R_{\mathrm{f}} 0.27(30 \% \mathrm{EtOAcl}$ hexane); mp 162-164 ${ }^{\circ} \mathrm{C}(\mathrm{dec})$. IR $\left(\mathrm{CHCl}_{3}\right) 3394,2912,1695,1601,1278 \mathrm{~cm}^{-1} ;{ }^{1} \mathrm{H}$ NMR $\left(\mathrm{C}^{2} \mathrm{H}_{3} \mathrm{O}^{2} \mathrm{H}\right) \delta 1.78\left(\mathrm{~s}, 6 \mathrm{H}, \mathrm{AdCH}_{2}\right) .2 .07$ (s, 3H, $\left.\mathrm{AdCH}\right), 2.17$ (s, 6H, $\left.\mathrm{AdCH}_{2}\right), 6.80(\mathrm{~d}, J=8.1$ $\left.\mathrm{Hz}, 1 \mathrm{H}, 5^{\prime}-\mathrm{ArH}\right), 6.91(\mathrm{dd}, J=15.9,11.4 \mathrm{~Hz}, 1 \mathrm{H}, \mathrm{ArCH}=C H \mathrm{CH}=\mathrm{C}), 7.12(\mathrm{dd}, J=7.8,2.1$ $\left.\mathrm{Hz}, 1 \mathrm{H}, 6^{\prime}-\mathrm{ArH}\right), 7.16(\mathrm{~d}, J=15 \mathrm{~Hz}, 1 \mathrm{H}, \mathrm{ArCH}=\mathrm{CHCH}=\mathrm{C}), 7.26\left(\mathrm{~d}, J=2.1 \mathrm{~Hz}, 1 \mathrm{H}, 2^{\prime}-\mathrm{ArH}\right)$, $7.38(\mathrm{~d}, J=8.1 \mathrm{~Hz}, 1 \mathrm{H}, 5-\mathrm{ArH}), 7.52(\mathrm{~d}, J=11.4 \mathrm{~Hz}, 1 \mathrm{H}, \mathrm{ArCH}=\mathrm{CHCH}=\mathrm{C}), 7.58(\mathrm{dd}, J=$ $8.1,1.8 \mathrm{~Hz}, 1 \mathrm{H}, 6-\mathrm{ArH}), 7.70 \mathrm{ppm}(\mathrm{d}, J=1.8 \mathrm{~Hz}, 1 \mathrm{H}, 2-\mathrm{ArH}) . \mathrm{HRMS}$ calcd $\mathrm{C}_{28} \mathrm{H}_{26} \mathrm{ClNO}_{3} \mathrm{~S}$ $[\mathrm{M}-\mathrm{H}]^{-}$490.1249, found 490.1245 .

\section{5-\{4-[3'-(1-Adamantyl)-4'-hydroxyphenyl]-3-chlorobenzylidene\}-2,4-thiazolidinedione (43)}

$42(12 \mathrm{mg}, 0.02 \mathrm{mmol})$ yielded after chromatography (20\% EtOAc/hexane) $8.3 \mathrm{mg}(91 \%)$ of 43 as a yellow powder, $R_{\mathrm{f}} 0.36$ (20\% EtOAc/hexane); mp 280-284 ${ }^{\circ} \mathrm{C}$. IR $\left(\mathrm{CHCl}_{3}\right) 3372,2902$, $1655,1577 \mathrm{~cm}^{-1} ;{ }^{1} \mathrm{H}$ NMR $\left(\mathrm{C}^{2} \mathrm{H}_{3} \mathrm{O}^{2} \mathrm{H}\right) \delta 1.85\left(\mathrm{~s}, 6 \mathrm{H}, \mathrm{AdCH}_{2}\right), 2.08(\mathrm{~s}, 3 \mathrm{H}, \mathrm{AdCH}), 2.22(\mathrm{~d}$, $\left.J=2.4 \mathrm{~Hz}, 6 \mathrm{H}, \mathrm{AdCH}_{2}\right), 6.82\left(\mathrm{~d}, J=8.1 \mathrm{~Hz}, 1 \mathrm{H}, 5^{\prime}-\mathrm{ArH}\right), 7.16\left(\mathrm{dd}, J=8.4,1.8 \mathrm{~Hz}, 1 \mathrm{H}, 6^{\prime}-\right.$ $\operatorname{ArH}), 7.28\left(\mathrm{~d}, J=2.4 \mathrm{~Hz}, 1 \mathrm{H}, 2^{\prime}-\mathrm{ArH}\right), 7.50(\mathrm{~d}, J=8.1 \mathrm{~Hz}, 1 \mathrm{H}, 5-\mathrm{ArH}), 7.55(\mathrm{~d}, J=8.1 \mathrm{~Hz}$, $1 \mathrm{H}, 6-\mathrm{ArH}), 7.68(\mathrm{~s}, 1 \mathrm{H}, 2-\mathrm{ArH}), 7.80 \mathrm{ppm}(\mathrm{s}, 1 \mathrm{H}, \mathrm{ArCH}=\mathrm{C})$. HRMS calcd $\mathrm{C}_{26} \mathrm{H}_{24} \mathrm{ClNO}_{3} \mathrm{~S}$ $[\mathrm{M}-\mathrm{H}]^{-}$464.1093, found 464.1107.

\section{2-\{[3'-(1-Adamantyl)-2-chloro-4'-hydroxy-4-biphenyl]methylene\}-propanedinitrile (45)}

44 (74 mg, $0.15 \mathrm{mmol}$ ) yielded after chromatography (20\% EtOAc/hexane) $42.5 \mathrm{mg}$ (70\%) of 45 as a yellow solid, mp $225-226{ }^{\circ} \mathrm{C}$. IR $3450,2901,2848,2230,1276 \mathrm{~cm}^{-1} ;{ }^{1} \mathrm{H}$ NMR $\delta 1.80$ (bs, 6H, $\mathrm{AdCH}_{2}$ ), 2.11 (bs, 3H, AdCH), 2.15 (bs, 6H, $\mathrm{AdCH}_{2}$ ), 5.08 (s, 1H, OH), 6.76 (d, J = $\left.8.4 \mathrm{~Hz}, 1 \mathrm{H}, 5^{\prime}-\mathrm{ArH}\right), 7.24$ (dd, $\left.J=7.8,2.4 \mathrm{~Hz}, 1 \mathrm{H}, 6^{\prime}-\mathrm{ArH}\right), 7.36$ (d, $\left.J=1.8 \mathrm{~Hz}, 1 \mathrm{H}, 5-\mathrm{ArH}\right)$, $7.53\left(\mathrm{~d}, J=7.8 \mathrm{~Hz}, 1 \mathrm{H}, 2^{\prime}-\mathrm{ArH}\right), 7.74\left(\mathrm{~s}, 1 \mathrm{H}, \mathrm{CH}=\mathrm{C}(\mathrm{CN})_{2}\right), 7.90-7.94 \mathrm{ppm}(\mathrm{m}, 2 \mathrm{H}, 3-\mathrm{ArH}$, 6-ArH). HRMS calcd $\mathrm{C}_{26} \mathrm{H}_{23} \mathrm{ClN}_{2} \mathrm{O}[\mathrm{M}-\mathrm{H}]^{-}$413.1426, found 413.1418 .

\section{N-(Hydroxy)(E)-4-[3'-(1-Adamantyl)-4'-hydroxyphenyl]-3-chlorocinnamamide (48)}

47 (70 mg, $0.117 \mathrm{mmol}$ ) yielded after chromatography (HOAc/EtOAc/hexane, 0.3:10:10) 22 $\mathrm{mg}(45 \%)$ of 48 as a pale-tan solid, mp $208{ }^{\circ} \mathrm{C}$ (dec). IR 3334, 2899, 1652, $1382 \mathrm{~cm}^{-1}$; ${ }^{1} \mathrm{H}$ 
NMR [ $\left.\left(\mathrm{C}^{2} \mathrm{H}_{3}\right)_{2} \mathrm{SO}\right] \delta 1.75$ (bs, 6H, $\mathrm{AdCH}_{2}$ ), 2.04 (bs, 3H, AdCH), 2.16 (bs, 6H, $\mathrm{AdCH}_{2}$ ), 6.65 $(\mathrm{d}, J=15.9 \mathrm{~Hz}, 1 \mathrm{H}, \mathrm{CH}=\mathrm{CHCO}), 6.88\left(\mathrm{~d}, J=8.1 \mathrm{~Hz}, 1 \mathrm{H}, 5^{\prime}-\mathrm{ArH}\right), 7.12(\mathrm{dd}, J=8.1,1.8 \mathrm{~Hz}$, $\left.1 \mathrm{H}, 6^{\prime}-\mathrm{ArH}\right), 7.16$ (d, $\left.J=1.8 \mathrm{~Hz}, 1 \mathrm{H}, 2^{\prime}-\mathrm{ArH}\right), 7.41(\mathrm{~s}, 1 \mathrm{H}, 3-\mathrm{ArH}), 7.50(\mathrm{~d}, J=15.9 \mathrm{~Hz}, 1 \mathrm{H}$, $\mathrm{CH}=\mathrm{CHCO}), 7.55(\mathrm{~d}, J=8.4 \mathrm{~Hz}, 1 \mathrm{H}, 5-\mathrm{ArH}), 7.71(\mathrm{~d}, J=8.4 \mathrm{~Hz}, 1 \mathrm{H}, 6-\mathrm{ArH}), 9.63(\mathrm{bs}, 1 \mathrm{H}$, $\mathrm{OH}), 9.69$ (bs, $1 \mathrm{H}, \mathrm{N} \mathrm{HOH}), 10.81 \mathrm{ppm}(\mathrm{bs}, 1 \mathrm{H}, \mathrm{NHO} \mathrm{H})$. HRMS calcd $\mathrm{C}_{25} \mathrm{H}_{26} \mathrm{ClNO}_{3}[\mathrm{M}+$ $\mathrm{H}]^{+}$424.1674, found 424.1669 .

(E)-2-[3'-(1-Adamantyl)-2-chloro-4'-hydroxy-4-biphenyl] - ethenylboronic Acid (57)

$\mathbf{5 6}(56 \mathrm{mg}, 0.097 \mathrm{mmol}$ ) yielded after chromatography (50\% EtOAc/hexane) $31 \mathrm{mg}(67 \%)$ of 57 as a paletan solid, mp $186-189^{\circ} \mathrm{C}$. IR 3350, 2901, 1621, $1217 \mathrm{~cm}^{-1},{ }^{1} \mathrm{H}$ NMR $\delta 1.81$ (bs, $6 \mathrm{H}, \mathrm{AdCH}_{2}$ ), 2.11 (bs, 3H, $\left.\mathrm{AdCH}\right), 2.18\left(\mathrm{~m}, 6 \mathrm{H}, \mathrm{AdCH}_{2}\right), 4.92(\mathrm{~s}, 1 \mathrm{H}, \mathrm{OH}), 6.38(\mathrm{~d}, J=18$ $\mathrm{Hz}, 1 \mathrm{H}, \mathrm{CH}=\mathrm{CHB}), 6.74$ (d, $\left.J=8.1 \mathrm{~Hz}, 1 \mathrm{H}, 5^{\prime}-\mathrm{ArH}\right), 7.22\left(\mathrm{dd}, J=8.4,2.1 \mathrm{~Hz}, 1 \mathrm{H}, 6^{\prime}-\mathrm{ArH}\right)$, $7.36\left(\mathrm{~d}, J=2.1 \mathrm{~Hz}, 1 \mathrm{H}, 2^{\prime}-\mathrm{ArH}\right), 7.39$ (d, $\left.J=8.1 \mathrm{~Hz}, 1 \mathrm{H}, 6-\mathrm{ArH}\right), 7.55$ (dd, $J=8.1,1.5 \mathrm{~Hz}$, $1 \mathrm{H}, 5-\mathrm{ArH}), 7.73$ (d, $J=1.5 \mathrm{~Hz}, 1 \mathrm{H}, 3-\mathrm{ArH}), 7.76 \mathrm{ppm}(\mathrm{d}, J=18 \mathrm{~Hz}, 1 \mathrm{H}, \mathrm{CH}=\mathrm{CHB})$. HRMS calcd $\mathrm{C}_{24} \mathrm{H}_{26} \mathrm{BClO}_{3}[\mathrm{M}+\mathrm{H}]^{+}$409.1736, found 409.1730 .

(3E)-4-[3'-(1-Adamantyl)-2-chloro-4'-hydroxy-4-biphenyl]-2-oxobut-3-enal (60)

59 (35 mg, $0.068 \mathrm{mmol}$ ) yielded after chromatography (25\% to $33 \%$ EtOAc/hexane) $22 \mathrm{mg}$ (77\%) of $\mathbf{6 0}$ as a yellow wax, mp 121-123 ${ }^{\circ} \mathrm{C}$. IR 3383, 2902, 1695, 1678, 1603, 1251 $\mathrm{cm}^{-1} ;{ }^{1} \mathrm{H}$ NMR $\delta 1.80$ (bs, 6H, AdCH ${ }_{2}$ ), 2.11 (bs, 3H, AdCH), 2.16 (bs, 6H, $\mathrm{AdCH}_{2}$ ), 5.10 (s, $1 \mathrm{H}, \mathrm{OH}), 6.74\left(\mathrm{~d}, J=8.1 \mathrm{~Hz}, 1 \mathrm{H}, 5^{\prime}-\mathrm{ArH}\right), 6.97(\mathrm{~d}, J=16.2 \mathrm{~Hz}, 1 \mathrm{H}, \mathrm{CH}=\mathrm{CHCO}), 7.20$ (dd, $\left.J=8.4,2.1 \mathrm{~Hz}, 1 \mathrm{H}, 6^{\prime}-\mathrm{ArH}\right), 7.34\left(\mathrm{~d}, J=2.1 \mathrm{~Hz}, 1 \mathrm{H}, 2^{\prime}-\mathrm{ArH}\right), 7.41(\mathrm{~d}, J=8.1 \mathrm{~Hz}, 1 \mathrm{H}, 6-\mathrm{ArH})$, $7.52(\mathrm{dd}, J=8.1,2.1 \mathrm{~Hz}, 1 \mathrm{H}, 5-\mathrm{ArH}), 7.71(\mathrm{~d}, J=1.5 \mathrm{~Hz}, 1 \mathrm{H}, 3-\mathrm{ArH}), 7.80(\mathrm{~d}, J=16.2 \mathrm{~Hz}$, $1 \mathrm{H}, \mathrm{CH}=\mathrm{CHCO}$ ), $9.47 \mathrm{ppm}(\mathrm{s}, 1 \mathrm{H}, \mathrm{CHO})$. HRMS calcd $\mathrm{C}_{26} \mathrm{H}_{25} \mathrm{ClO}_{3}[\mathrm{M}+\mathrm{H}]^{+} 421.1565$, found 421.1573 .

\section{Diethyl (E)-2-[3'-(1-Adamantyl)-2-chloro-4'-hydroxy-4-biphenyl]ethenylphosphonate (62)}

$61(0.14 \mathrm{mmol}, 82 \mathrm{mg}$ ) yielded after chromatography (50\% to 67\% EtOAc/hexane) $61 \mathrm{mg}$ (87\%) of 62 as an off-white solid, mp $110-112^{\circ} \mathrm{C}$. IR 3414, 2932, 1028, $989 \mathrm{~cm}^{-1} ;{ }^{1} \mathrm{H}$ NMR $\delta 1.38$ (t, $J=6.9 \mathrm{~Hz}, 6 \mathrm{H}, \mathrm{OCH}_{2} \mathrm{CH}_{3}$ ), 1.79 (bs, $6 \mathrm{H}, \mathrm{AdCH}_{2}$ ), 2.09 (bs, 3H, $\mathrm{AdCH}$ ), 2.17 (bs, $\left.6 \mathrm{H}, \mathrm{AdCH}_{2}\right), 4.18\left(\mathrm{~m}, 4 \mathrm{H}, \mathrm{OCH}_{2} \mathrm{CH}_{3}\right), 6.29(\mathrm{t}, J=17.4 \mathrm{~Hz}, 1 \mathrm{H}, \mathrm{CH}=\mathrm{CHP}), 6.82(\mathrm{~d}, J=8.4$ $\left.\mathrm{Hz}, 1 \mathrm{H}, 5^{\prime}-\mathrm{ArH}\right), 7.17$ (dd, $\left.J=8.4,2.1 \mathrm{~Hz}, 1 \mathrm{H}, 6^{\prime}-\mathrm{ArH}\right), 7.31$ (d, $\left.J=2.1 \mathrm{~Hz}, 1 \mathrm{H}, 2^{\prime}-\mathrm{ArH}\right), 7.33-$ 7.41 (m, 3H, 5-ArH, 6-ArH, OH), 7.48 (dd, $J=17.4,22.5 \mathrm{~Hz}, 1 \mathrm{H}, \mathrm{CH}=\mathrm{CHP}$ ), 7.59 ppm (s, $1 \mathrm{H}, 3-\mathrm{ArH})$. HRMS calcd $\mathrm{C}_{28} \mathrm{H}_{34} \mathrm{ClO}_{4} \mathrm{P}[\mathrm{M}+\mathrm{H}]^{+}$501.1956, found 501.1958.

\section{General Procedure for Converting Phenols 20, 27, 33, 17, and 49 to Their Triflates}

To a stirred solution of the phenol $(2.0 \mathrm{mmol})$ in pyridine $(5 \mathrm{~mL})$ at $0{ }^{\circ} \mathrm{C}$ (ice-bath) under argon was slowly added $\mathrm{Tf}_{2} \mathrm{O}(846 \mathrm{mg}, 3.0 \mathrm{mmol})$ over a 0.5 -h period. The reaction mixture was stirred at room temperature overnight and then extracted (EtOAc). The extract was washed $\left(10 \% \mathrm{HCl}, 5 \% \mathrm{NaHCO}_{3}\right.$, brine and water), dried, and concentrated to afford an oil, which was purified by chromatography (5\% EtOAc/hexane) to give the triflate.

(E)-3-(3-Chloro-4-trifluoromethanesulfonyloxy)cinnamonitrile (21)

20 (358 $\mathrm{mg}, 2.0 \mathrm{mmol})$ gave $565 \mathrm{mg}(91 \%)$ of 21 as a white powder, $R_{\mathrm{f}} 0.68(10 \% \mathrm{EtOAc} /$ hexane); mp 93- $99{ }^{\circ} \mathrm{C}$. IR $\left(\mathrm{CHCl}_{3}\right) 2966,2226 \mathrm{~cm}^{-1} ;{ }^{1} \mathrm{H} \mathrm{NMR} \delta 5.93(\mathrm{~d}, J=16.5 \mathrm{~Hz}, 1 \mathrm{H}$, $\mathrm{HC}=\mathrm{CHCN}), 7.34(\mathrm{~d}, J=16.8 \mathrm{~Hz}, 1 \mathrm{H}, H \mathrm{C}=\mathrm{CHCN}), 7.42(\mathrm{~s}, 2 \mathrm{H}, 5,6-\mathrm{ArH}), 7.62 \mathrm{ppm}(\mathrm{s}, 1 \mathrm{H}$, 2-ArH). The crude product was used to prepare 22. 


\section{3-Chloro-4-(trifluoromethanesulfonyloxy)benzonitrile (28)}

Crude 27 (306 mg, $2.0 \mathrm{mmol}$ ) gave $530 \mathrm{mg}(93 \%)$ of $\mathbf{2 8}$ as a white powder, $R_{\mathrm{f}} 0.80(20 \%$ EtOAc/hexane); $\mathrm{mp} 55-56{ }^{\circ} \mathrm{C}$, which was used directly for coupling to produce 29. IR $\left(\mathrm{CHCl}_{3}\right) 2961,2243 \mathrm{~cm}^{-1} ;{ }^{1} \mathrm{H}$ NMR $\delta 7.50(\mathrm{~d}, J=8.7 \mathrm{~Hz}, 1 \mathrm{H}, 5-\mathrm{ArH}), 7.69$ (dd, $J=8.1,1.8$ $\mathrm{Hz}, 1 \mathrm{H}, 6-\mathrm{ArH}), 7.86 \mathrm{ppm}(\mathrm{s}, 1 \mathrm{H}, 2-\mathrm{ArH})$.

\section{Ethyl (E)-3-Chloro-4-(trifluoromethanesulfonyloxy)cinnamate (34). ${ }^{8}$}

33 ( $800 \mathrm{mg}, 3.54 \mathrm{mmol})$ gave $1.13 \mathrm{~g}(93 \%)$ of $\mathbf{3 4}$ as a white solid, $R_{\mathrm{f}} 0.62$ (10\% EtOAc/hexane); $\mathrm{mp} 78-80^{\circ} \mathrm{C}$. IR $\left(\mathrm{CHCl}_{3}\right) 2961,1706,1651,1432 \mathrm{~cm}^{-1} ;{ }_{1}^{1} \mathrm{H}$ NMR $\delta 1.35(\mathrm{t}, J=6.9 \mathrm{~Hz}, 3 \mathrm{H}$, $\left.\mathrm{CH}_{3}\right), 4.29\left(\mathrm{q}, J=7.2 \mathrm{~Hz}, 2 \mathrm{H}, \mathrm{OCH}_{2}\right), 6.44(\mathrm{~d}, J=15.9 \mathrm{~Hz}, 1 \mathrm{H}, \mathrm{HC}=\mathrm{CHCO}), 7.39(\mathrm{~d}, J=8.4$ $\mathrm{Hz}, 1 \mathrm{H}, 5 \mathrm{ArH}), 7.48(\mathrm{dd}, J=8.4,1.8 \mathrm{~Hz}, 1 \mathrm{H}, 6-\mathrm{ArH}), 7.60(\mathrm{~d}, J=16.2 \mathrm{~Hz}, 1 \mathrm{H}, \mathrm{CH}=\mathrm{CHCO})$, $7.68 \mathrm{ppm}$ (s, $1 \mathrm{H}, 2-\mathrm{ArH})$. HRMS calcd $\mathrm{C}_{12} \mathrm{H}_{10} \mathrm{ClF}_{3} \mathrm{O}_{5} \mathrm{~S}[\mathrm{M}+\mathrm{H}]^{+} 358.9962$, found 358.9951 .

\section{3-Chloro-4-(trifluoromethanesulfonyloxy)benzaldehyde (40)}

$17(1.56 \mathrm{~g}, 10.0 \mathrm{mmol})$ gave $2.30 \mathrm{~g}(79 \%)$ of $\mathbf{4 0}$ as a pale-yellow oil, $R_{\mathrm{f}} 0.65(20 \% \mathrm{EtOAc} /$ hexane). IR $\left(\mathrm{CHCl}_{3}\right) 2961,1717,1223 \mathrm{~cm}^{-1} ;{ }^{1} \mathrm{H}$ NMR $\delta 7.61(\mathrm{~d}, J=8.4 \mathrm{~Hz}, 1 \mathrm{H}, 5-\mathrm{ArH}), 7.94$ (dd, $J=8.6,1.8 \mathrm{~Hz}, 1 \mathrm{H}, 6 \mathrm{ArH}), 8.11$ (d, $J=1.8 \mathrm{~Hz}, 1 \mathrm{H}, 2-\mathrm{ArH}), 10.07 \mathrm{ppm}(\mathrm{s}, 1 \mathrm{H}, \mathrm{CHO})$. FTMS (HRMS) calcd $\mathrm{C}_{8} \mathrm{H}_{5} \mathrm{ClF}_{3} \mathrm{O}_{4} \mathrm{~S}[\mathrm{M}+\mathrm{H}]^{+}$expected 288.9544, found 288.9542.

\section{2-Chloro-4-nitrophenyl Trifluoromethanesulfonate (50)}

49 (1.58 g, $9.12 \mathrm{mmol})$ gave after chromatography (12.5\% EtOAc/hexane) $2.73 \mathrm{~g}(97 \%)$ of $\mathbf{5 0}$ as a yellow oil, which was used to prepare $51 .{ }^{1} \mathrm{H}$ NMR $\delta 7.59(\mathrm{~d}, J=9 \mathrm{~Hz}, 1 \mathrm{H}, 6-\mathrm{ArH})$, 8.26 (dd, $J=9,2.7 \mathrm{~Hz}, 1 \mathrm{H}, 5-\mathrm{ArH}), 8.45 \mathrm{ppm}(\mathrm{d}, J=2.7 \mathrm{~Hz}, 1 \mathrm{H}, 3-\mathrm{ArH})$.

General Procedure for the Coupling between Aryl Boronic Acid 16 and Aryl Triflates 21, 28, 34,40 , and 50

To a stirred suspension of the aryl triflate $(1.6 \mathrm{mmol}), \mathbf{1 6}(651 \mathrm{mg}, 1.8 \mathrm{mmol}), \mathrm{Pd}\left(\mathrm{PPh}_{3}\right)_{4}(115$ $\mathrm{mg}, 0.1 \mathrm{mmol})$, and $\mathrm{LiCl}(242 \mathrm{mg}, 2.8 \mathrm{mmol})$ in DME ( $8 \mathrm{~mL})$ was added under argon $1.3 \mathrm{~mL}$ of $2.0 \mathrm{M} \mathrm{aq} \mathrm{Na} \mathrm{CO}_{3}(2.6 \mathrm{mmol})$. The mixture was heated at reflux for $24 \mathrm{~h}$, cooled, and extracted (EtOAc). The extract was washed (water and brine), dried, and concentrated. Flash chromatography on silica gel (5\% EtOAc/hexane) yielded the diaryl-coupling product.

\section{(E)-3-[3'-(1-Adamantyl)-4'-benzyloxyphenyl]-3-chlorocinnamonitrile (22)}

21 (498 $\mathrm{mg}, 1.6 \mathrm{mmol})$ yielded $510 \mathrm{mg}(64 \%)$ of 22 as a white solid, $R_{\mathrm{f}} 0.55(5 \% \mathrm{EtOAc/}$ hexane); mp 72-74 ${ }^{\circ} \mathrm{C}$. IR $\left(\mathrm{CHCl}_{3}\right) 2906,2221 \mathrm{~cm}^{-1} ;{ }^{1} \mathrm{H}$ NMR $\delta 1.75$ (s, 6H, $\left.\mathrm{AdCH}_{2}\right), 2.06$ (s, 3H, AdCH), $2.20\left(\mathrm{~s}, 6 \mathrm{H}, \mathrm{AdCH}_{2}\right), 5.18\left(\mathrm{~s}, 2 \mathrm{H}, \mathrm{ArCH}_{2}\right), 5.91(\mathrm{~d}, J=16.8 \mathrm{~Hz}, 1 \mathrm{H}$, $\mathrm{CH}=\mathrm{CHCN}), 7.02\left(\mathrm{~d}, J=8.7 \mathrm{~Hz}, 1 \mathrm{H}, 5^{\prime}-\mathrm{ArH}\right), 7.28\left(\mathrm{dd}, J=8.4,2.1 \mathrm{~Hz}, 1 \mathrm{H}, 6^{\prime}-\mathrm{ArH}\right), 7.45-$ 7.35 (m, 7H, ArH, 5-ArH, 2'-ArH), $7.48(\mathrm{~d}, J=16.8 \mathrm{~Hz}, 1 \mathrm{H}, \mathrm{CH}=\mathrm{CHCN}), 7.53(\mathrm{~d}, J=8.4 \mathrm{~Hz}$, $1 \mathrm{H}, 6-\mathrm{ArH}), 7.56 \mathrm{ppm}(\mathrm{d}, J=1.5 \mathrm{~Hz}, 1 \mathrm{H}, 3-\mathrm{ArH})$. The crude product was used to prepare 23.

\section{4-[3'-(1-Adamantyl)-4'-benzyloxyphenyl]-3-chlorobenzonitrile (29)}

28 (428 mg, $1.5 \mathrm{mmol})$ yielded $390 \mathrm{mg}(57 \%)$ of 29 as a white solid, $R_{\mathrm{f}} 0.55$ (5\% EtOAc/ hexane); mp 60-62 ${ }^{\circ} \mathrm{C}$, which was used to prepare 30. IR $\left(\mathrm{CHCl}_{3}\right) 2906,2232 \mathrm{~cm}^{-1} ;{ }^{1} \mathrm{H}$ NMR $\delta 1.74\left(\mathrm{~s}, 6 \mathrm{H}, \mathrm{AdCH}_{2}\right), 2(\mathrm{~s}, 3 \mathrm{H}, \mathrm{AdCH}), 2.18\left(\mathrm{~s}, 6 \mathrm{H}, \mathrm{AdCH}_{2}\right), 5.18\left(\mathrm{~s}, 2 \mathrm{H}, \mathrm{ArCH}_{2}\right), 7.02(\mathrm{~d}$, $\left.J=8.4 \mathrm{~Hz}, 1 \mathrm{H}, 5^{\prime}-\mathrm{ArH}\right), 7.27$ (dd, $\left.J=8.4,2.1 \mathrm{~Hz}, 1 \mathrm{H}, 6^{\prime}-\mathrm{ArH}\right), 7.35-7.47$ (m, 6H, 2'-ArH, ArH), $7.51(\mathrm{~d}, J=7.8 \mathrm{~Hz}, 1 \mathrm{H}, 5-\mathrm{ArH}), 7.58$ (dd, $J=8.1,1.5 \mathrm{~Hz}, 1 \mathrm{H}, 6-\mathrm{ArH}), 7.76 \mathrm{ppm}(\mathrm{d}, J$ $=1.5 \mathrm{~Hz}, 1 \mathrm{H}, 2-\mathrm{ArH})$. 
Ethyl (E)-4-[3'-(1-Adamantyl)-4'-benzyloxyphenyl]-3-chlorocinnamate (35). 8

34 (500 mg, $1.40 \mathrm{mmol})$ yielded $1.33 \mathrm{~g} \mathrm{(91 \% )} \mathrm{of} \mathbf{3 5}$ as a white solid, which was reduced to 36. $R_{\mathrm{f}} 0.51$ (10\% EtOAc/hexane); $\mathrm{mp} 72-74{ }^{\circ} \mathrm{C}$. IR $\left(\mathrm{CHCl}_{3}\right) 2906,1713,1640 \mathrm{~cm}^{-1} ;{ }^{1} \mathrm{H} \mathrm{NMR}$ $\delta 1.35\left(\mathrm{t}, J=7.2 \mathrm{~Hz}, 3 \mathrm{H}, \mathrm{CH}_{3}\right), 1.72\left(\mathrm{~s}, 6 \mathrm{H}, \mathrm{AdCH}_{2}\right), 2.04(\mathrm{~s}, 3 \mathrm{H}, \mathrm{AdCH}), 2.17(\mathrm{~s}, 6 \mathrm{H}$, $\left.\mathrm{AdCH}_{2}\right), 4.27\left(\mathrm{q}, J=6.9 \mathrm{~Hz}, 2 \mathrm{H}, \mathrm{OCH}_{2}\right), 5.17\left(\mathrm{~s}, 2 \mathrm{H}, \mathrm{ArCH}_{2}\right), 6.46(\mathrm{~d}, J=15.2 \mathrm{~Hz}, 1 \mathrm{H}$, $\mathrm{HC}=\mathrm{CHCO}), 7.00\left(\mathrm{~d}, J=8.1 \mathrm{~Hz}, 1 \mathrm{H}, 5^{\prime}-\mathrm{ArH}\right), 7.29\left(\mathrm{~d}, J=8.1 \mathrm{~Hz}, 1 \mathrm{H}, 6^{\prime}-\mathrm{ArH}\right), 7.35-7.42(\mathrm{~m}$, $5 \mathrm{H}, \mathrm{ArH}), 7.43(\mathrm{~d} J=6.9 \mathrm{~Hz}, 1 \mathrm{H}, 5-\mathrm{ArH}), 7.50\left(\mathrm{~s}, 1 \mathrm{H}, 2^{\prime}-\mathrm{ArH}\right), 7.52(\mathrm{~d}, J=7.2 \mathrm{~Hz}, 1 \mathrm{H}, 6-$ ArH), 7.62 (s, 1H, 2-ArH), $7.64 \mathrm{ppm}(\mathrm{d}, J=15.3 \mathrm{~Hz}, 1 \mathrm{H}, \mathrm{CH}=\mathrm{CHCO})$.

\section{4-[3'-(1-Adamantyl)-4'-benzyloxyphenyl]-3-chlorobenzaldehyde (41)}

40 (289 mg, $1.00 \mathrm{mmol}$ ) yielded after chromatography (10\% EtOAc/hexane) $215 \mathrm{mg}$ (78\%) of 41 as a white solid, mp $115-116{ }^{\circ} \mathrm{C}$. IR 2902, 1699, 1596, $1262 \mathrm{~cm}^{-1} ;{ }^{1} \mathrm{H}$ NMR $\delta 1.75$ (bs, $6 \mathrm{H}, \mathrm{AdCH}_{2}$ ), 2.06 (bs, 3H, $\mathrm{AdCH}$ ), 2.19 (bs, 6H, $\mathrm{AdCH}_{2}$ ), 5.19 (s, 2H, $\mathrm{ArCH}_{2}$ ), 7.04 (d, $J=$ $8.4 \mathrm{~Hz}, 1 \mathrm{H}, 5^{\prime}-\mathrm{ArH}$ ), 7.31-7.56 (m, 8H, 6-ArH, 2'-ArH, 6'-ArH, ArH), 7.81 (dd, $J=7.8,1.5$ $\mathrm{Hz}, 1 \mathrm{H}, 5-\mathrm{ArH}), 7.99$ (d, $J=1.5 \mathrm{~Hz}, 1 \mathrm{H}, 2-\mathrm{ArH}), 10.01 \mathrm{ppm}$ (s, 1H, CHO). HRMS calcd $\mathrm{C}_{30} \mathrm{H}_{29} \mathrm{ClO}_{2}[\mathrm{M}+\mathrm{Na}]^{+}$479.1748, found 479.1763 .

\section{3'-(1-Adamantyl)-4'-benzyloxy-2-chloro-4-nitrobiphenyl (51)}

$\mathbf{5 0}$ (721 mg, $2.36 \mathrm{mmol}$ ) yielded after chromatography (7\% EtOAc/hexane) $908 \mathrm{mg}(81 \%)$ of $\mathbf{5 1}$ as a yellow solid, mp $52-54{ }^{\circ} \mathrm{C}$, which was reduced to 52. ${ }^{1} \mathrm{H}$ NMR $\delta 1.77$ (bs, $6 \mathrm{H}$, $\mathrm{AdCH}_{2}$ ), 2.09 (bs, 3H, AdCH), 2.21 (m, 6H, $\left.\mathrm{AdCH}_{2}\right), 5.21$ (s, $\left.2 \mathrm{H}, \mathrm{ArCH}_{2}\right), 7.06$ (d, $J=8.7$ $\left.\mathrm{Hz}, 1 \mathrm{H}, 5^{\prime}-\mathrm{ArH}\right), 7.32$ (dd, $\left.J=8.7,2.1 \mathrm{~Hz}, 1 \mathrm{H}, 6^{\prime}-\mathrm{ArH}\right), 7.35-7.56$ (m, 7H, 2'-ArH, 6-ArH, ArH), 8.16 (dd, $J=8.7,2.4 \mathrm{~Hz}, 1 \mathrm{H}, 5-\mathrm{ArH}), 8.37 \mathrm{ppm}(\mathrm{d}, J=2.4 \mathrm{~Hz}, 1 \mathrm{H}, 3-\mathrm{ArH})$.

\section{(E)-5-\{2-[3'-(1-Adamantyl)-2-chloro-4'-hydroxy-4-biphenyl]ethenyl\}-1 H-tetrazole (24)}

A reported procedure ${ }^{73}$ was applied. To $23(78 \mathrm{mg}, 0.2 \mathrm{mmol})$ in toluene $(2 \mathrm{~mL})$ were added $(n-\mathrm{Bu})_{2} \mathrm{SnO}(5.0 \mathrm{mg}, 0.02 \mathrm{mmol})$ and azidotrimethylsilane $(58 \mathrm{mg}, 1.0 \mathrm{mmol})$. The mixture was stirred at $90-95^{\circ} \mathrm{C}$ for $48 \mathrm{~h}$. Additional azidotrimethylsilane ( $34 \mathrm{mg}, 0.3 \mathrm{mmol}$ ) was added, and stirring was continued for $20 \mathrm{~h}$. The mixture was concentrated, diluted with EtOAc (10 $\mathrm{mL}$ ) and $10 \% \mathrm{HCl}(3 \mathrm{~mL})$, and stirred for $0.5 \mathrm{~h}$. The organic layer was washed (water and brine) and dried. Concentration and crystallization (EtOAc/ $\mathrm{CH}_{2} \mathrm{Cl}_{2} /$ hexane) gave $55 \mathrm{mg}$ (64\%) of 24 as a white powder, $R_{\mathrm{f}} 0.28$ (50\% EtOAc/hexane); mp 260- $262{ }^{\circ} \mathrm{C}$. IR $\left(\mathrm{CHCl}_{3}\right) 3405$, 2966, $2237 \mathrm{~cm}^{-1} ;{ }^{1} \mathrm{H}$ NMR $\left(\mathrm{C}^{2} \mathrm{H}_{3} \mathrm{O}^{2} \mathrm{H}\right) \delta 1.72\left(\mathrm{~s}, 6 \mathrm{H}, \mathrm{AdCH}_{2}\right), 2.01$ (s, 3H, AdCH), 2.12 (s, $\left.6 \mathrm{H}, \mathrm{AdCH}_{2}\right), 7.09$ (d, $\left.J=16.5 \mathrm{~Hz}, 1 \mathrm{H}, \mathrm{CH}=\mathrm{CH}\right), 7.11\left(\mathrm{~d}, J=10.5 \mathrm{~Hz}, 1 \mathrm{H}, 5^{\prime}-\mathrm{ArH}\right), 7.22$ (s, $\left.1 \mathrm{H}, 2^{\prime}-\mathrm{ArH}\right), 7.28$ (d, $\left.J=8.1 \mathrm{~Hz}, 1 \mathrm{H}, 6^{\prime}-\mathrm{ArH}\right), 7.32$ (d, $\left.J=7.8 \mathrm{~Hz}, 1 \mathrm{H}, 5-\mathrm{ArH}\right), 7.40$ (d, $J=$ $8.7 \mathrm{~Hz}, 1 \mathrm{H}, 6-\mathrm{ArH}), 7.56(\mathrm{~s}, 1 \mathrm{H}, 3-\mathrm{ArH}), 7.61 \mathrm{ppm}(\mathrm{d}, J=16.5 \mathrm{~Hz}, 1 \mathrm{H}, \mathrm{CH}=\mathrm{CH})$. FTMS (HRMS) calcd $\mathrm{C}_{25} \mathrm{H}_{25} \mathrm{ClN}_{4} \mathrm{O}(\mathrm{M}+\mathrm{H})^{+}$expected 433.1790, found 433.1801 .

\section{4-Benzyloxy-3-chlorobenzonitrile (26)}

To a solution of $\mathbf{1 8}(1.23 \mathrm{~g}, 5 \mathrm{mmol})$ in $\mathrm{MeOH}(10 \mathrm{~mL})$ and pyridine $(2 \mathrm{~mL})$ was added $\mathrm{NH}_{2} \mathrm{OH} \cdot \mathrm{HCl}(695 \mathrm{mg}, 10 \mathrm{mmol})$. The mixture was stirred at $50{ }^{\circ} \mathrm{C}$ under argon for $5 \mathrm{~h}$ and then poured into ice water to give a solid, which was collected by filtration, washed with water, and dried. Chromatography (9\% EtOAc/hexane) gave $1.21 \mathrm{~g}$ (94\%) of oxime 25 as a white solid, which was used for the elimination step.

To $25(1.1 \mathrm{~g}, 4.2 \mathrm{mmol})$ in toluene $(15 \mathrm{~mL})$ and pyridine $(2 \mathrm{~mL})$ cooled in an ice bath was slowly added methanesulfonyl chloride $(798 \mathrm{mg}, 7 \mathrm{mmol}$ ) over a 10-min period. The mixture was stirred at reflux for $3 \mathrm{~h}$, cooled to room temperature, and diluted with toluene $(30 \mathrm{~mL})$. The organic phase was washed $\left(1 \mathrm{~N} \mathrm{HCl}, 5 \% \mathrm{NaHCO}_{3}\right.$, water, and brine) and dried. Concentration and chromatography (10\% EtOAc/hexane) gave $910 \mathrm{mg}(91 \%)$ of $\mathbf{2 6}$ as a white solid, $R_{\mathrm{f}} 0.60$ (20\% EtOAc/hexane); mp $120-122{ }^{\circ} \mathrm{C}$. IR $\left(\mathrm{CHCl}_{3}\right) 2966,2232 \mathrm{~cm}^{-1} ;{ }^{1} \mathrm{H}$ NMR 
$\delta 5.23\left(\mathrm{~s}, 2 \mathrm{H}, \mathrm{ArCH}_{2}\right), 7.0(\mathrm{~d}, J=8.7 \mathrm{~Hz}, 1 \mathrm{H}, 5-\mathrm{ArH}), 7.35-7.45(\mathrm{~m}, 5 \mathrm{H}, \mathrm{ArH}), 7.50(\mathrm{dd}, J=$ $8.7,2.1 \mathrm{~Hz}, 1 \mathrm{H}, 6-\mathrm{ArH}), 7.68 \mathrm{ppm}(\mathrm{d}, J=2.1 \mathrm{~Hz}, 1 \mathrm{H}, 2-\mathrm{ArH})$. The crude product was used directly in the next step.

\section{5-[3'-(1-Adamantyl)-2-chloro-4'-hydroxy-4-biphenyl]-1H-tetrazole (31)}

A reported procedure was applied. ${ }^{73}$ To $30(73 \mathrm{mg}, 0.2 \mathrm{mmol})$ in toluene $(2 \mathrm{~mL})$ was added $(n-\mathrm{Bu})_{2} \mathrm{SnO}(5.0 \mathrm{mg}, 0.02 \mathrm{mmol})$ and azidotrimethylsilane $(115 \mathrm{mg}, 1.0 \mathrm{mmol})$. This mixture was stirred at $90-95^{\circ} \mathrm{C}$ for $48 \mathrm{~h}$ and then concentrated. EtOAc $(10 \mathrm{~mL})$ and $10 \% \mathrm{HCl}(3 \mathrm{~mL})$ were added. The mixture was stirred for $0.5 \mathrm{~h}$, washed (water and brine), and dried.

Concentration and crystallization (EtOAc/ $\mathrm{CH}_{2} \mathrm{Cl}_{2} /$ hexane) produced $58 \mathrm{mg}(72 \%)$ of $\mathbf{3 1}$ as a white powder, $R_{\mathrm{f}} 0.27$ (50\% EtOAc/hexane); $\mathrm{mp} 235-240{ }^{\circ} \mathrm{C}$. IR (powder) 3377, 2906, 1486, $1256 \mathrm{~cm}^{-1} ;{ }^{1} \mathrm{H}$ NMR $\left(\mathrm{C}^{2} \mathrm{H}_{3} \mathrm{O}^{2} \mathrm{H}\right) \delta 1.85\left(\mathrm{~s}, 6 \mathrm{H}, \mathrm{AdCH}_{2}\right), 2.08(\mathrm{~s}, 3 \mathrm{H}, \mathrm{AdCH}), 2.22(\mathrm{~s}, 6 \mathrm{H}$, $\left.\mathrm{AdCH}_{2}\right), 6.83\left(\mathrm{~d}, J=8.1 \mathrm{~Hz}, 1 \mathrm{H}, 5^{\prime}-\mathrm{ArH}\right), 7.18\left(\mathrm{dd}, J=8.1,2.1 \mathrm{~Hz}, 1 \mathrm{H}, 6^{\prime}-\mathrm{ArH}\right), 7.29$ (d, $J=$ $\left.2.4 \mathrm{~Hz}, 1 \mathrm{H}, 2^{\prime}-\mathrm{ArH}\right), 7.57$ (d, $\left.J=7.8 \mathrm{~Hz}, 1 \mathrm{H}, 5-\mathrm{ArH}\right), 8.01$ (dd, $\left.J=7.8,1.5 \mathrm{~Hz}, 1 \mathrm{H}, 6-\mathrm{ArH}\right)$, $8.18 \mathrm{ppm}\left(\mathrm{d}, J=1.5 \mathrm{~Hz}, 1 \mathrm{H}, 2\right.$-ArH). FTMS (HRMS) calcd $\mathrm{C}_{23} \mathrm{H}_{23} \mathrm{ClN}_{4} \mathrm{O}[\mathrm{M}+\mathrm{H}]^{+}$expected 407.1633, found 407.1630.

\section{Ethyl (E)-4-Benzyloxy-3-chlorocinnamate (32).8,72}

To triethyl phosphonoacetate $(2.24 \mathrm{~g}, 10 \mathrm{mmol})$ in $\mathrm{Et}_{2} \mathrm{O}(20 \mathrm{~mL})$ stirred under argon in a dry ice-acetone bath was added $0.91 \mathrm{M} \mathrm{KN}\left(\mathrm{SiMe}_{3}\right)_{2}(10.0 \mathrm{mmol})$ in THF $(11.0 \mathrm{~mL})$. The mixture was stirred for $0.5 \mathrm{~h}$ before 4-benzyloxy-3-chlorobenzaldehyde (18) (2.00 g, $8.1 \mathrm{mmol})$ in THF $(40 \mathrm{~mL})$ was added dropwise over a 0.5 -h period, stirred for $1 \mathrm{~h}$ more, allowed to warm to room temperature, stirred overnight, poured into water $(50 \mathrm{~mL})$ containing HOAc $(2 \mathrm{~mL})$, and extracted $\left(\mathrm{Et}_{2} \mathrm{O}, 100 \mathrm{~mL}\right)$. The extract was washed (water and brine), dried, and concentrated. Chromatography (EtOAC/hexane) afforded $2.3 \mathrm{~g}(91 \%)$ of $\mathbf{3 2}$ as a white solid, $R_{\mathrm{f}} 0.41(10 \%$ EtOAc/hexane); mp 72-74 ${ }^{\circ} \mathrm{C}$. IR $\left(\mathrm{CHCl}_{3}\right) 2961,1706,1634,1508 \mathrm{~cm}^{-1} ;{ }_{1}^{1} \mathrm{H}$ NMR $\delta 1.33(\mathrm{t}$, $\left.J=7.2 \mathrm{~Hz}, 3 \mathrm{H}, \mathrm{CH}_{3}\right), 4.25\left(\mathrm{q}, J=7.2 \mathrm{~Hz}, 2 \mathrm{H}, \mathrm{OCH}_{2}\right), 5.20\left(\mathrm{~s}, 2 \mathrm{H}, \mathrm{ArCH}_{2}\right), 6.31$ (d, $J=15.9$ $\mathrm{Hz}, 1 \mathrm{H}, \mathrm{CH}=\mathrm{CHCO}), 6.95(\mathrm{~d}, J=8.7 \mathrm{~Hz}, 1 \mathrm{H}, 5-\mathrm{ArH}), 7.36-7.45(\mathrm{~m}, 6 \mathrm{H}, 6-\mathrm{ArH}, \mathrm{ArH}), 7.56$ $(\mathrm{d}, J=16.2 \mathrm{~Hz}, 1 \mathrm{H}, \mathrm{CH}=\mathrm{CHCO}), 7.59 \mathrm{ppm}(\mathrm{s}, 1 \mathrm{H}, 2-\mathrm{ArH})$. This product was debenzylated to 33.

\section{(E)-4-[3'-(1-Adamantyl)-4'-benzyloxyphenyl]-3-chlorocinnamyl Alcohol (36)}

To a stirred solution of $35(264 \mathrm{mg}, 0.5 \mathrm{mmol})$ in $\mathrm{CH}_{2} \mathrm{Cl}_{2}(5 \mathrm{~mL})$ at $-78{ }^{\circ} \mathrm{C}$ under argon was added $1.5 \mathrm{~mL}$ of $1.0 \mathrm{M}$ DIBAL $(1.5 \mathrm{mmol})$ in hexane. The mixture was stirred at $-78{ }^{\circ} \mathrm{C}$ for $3 \mathrm{~h}$, diluted with $1 \mathrm{~N} \mathrm{HCl}$, and then extracted (EtOAc). The extract was washed (water and brine), dried, and concentrated. Chromatography (10\% EtOAc/hexane) gave $220 \mathrm{mg}$ (91\%) of 36 as a white powder, $R_{\mathrm{f}} 0.28$ (20\% EtOAc/hexane); mp 72-74 ${ }^{\circ} \mathrm{C}$. IR $\left(\mathrm{CHCl}_{3}\right) 3399,2906$, $1601 \mathrm{~cm}^{-1} ;{ }^{1} \mathrm{H}$ NMR $\delta 1.73$ (s, 6H, $\mathrm{AdCH}_{2}$ ), 2.04 (s, 3H, AdCH), 2.17 (s, 6H, $\left.\mathrm{AdCH}_{2}\right), 4.35$ $\left(\mathrm{d}, J=4.2 \mathrm{~Hz}, 2 \mathrm{H}, \mathrm{OCH}_{2}\right), 5.16$ (s, $\left.2 \mathrm{H}, \mathrm{ArCH}_{2}\right), 7.64$ (td, $J=5.4,16.2 \mathrm{~Hz}, 1 \mathrm{H}$, $\left.\mathrm{CH}=\mathrm{CHCH}_{2} \mathrm{OH}\right), 6.61\left(\mathrm{~d}, J=15.2 \mathrm{~Hz}, 1 \mathrm{H}, \mathrm{CH}=\mathrm{CHCH}_{2}-\mathrm{OH}\right), 7.00\left(\mathrm{~d}, J=8.7 \mathrm{~Hz}, 1 \mathrm{H}, 5^{\prime}-\right.$ ArH), 7.30-7.42 (m, 5H, ArH), $7.40\left(\mathrm{~d}, J=7.5 \mathrm{~Hz}, 1 \mathrm{H}, 6^{\prime}-\mathrm{ArH}\right), 7.42\left(\mathrm{~s}, 1 \mathrm{H}, 2^{\prime}-\mathrm{ArH}\right), 7.50$ (d, $J=8.1 \mathrm{~Hz}, 2 \mathrm{H}, 5,6-\mathrm{ArH}), 7.53 \mathrm{ppm}(\mathrm{s}, 1 \mathrm{H}, 2-\mathrm{ArH})$. HRMS calcd $\mathrm{C}_{32} \mathrm{H}_{33} \mathrm{ClO}_{2}[\mathrm{M}+$ $\mathrm{Na}]^{+}$507.2061, found 507.2066.

\section{(E)-4-[3'-(1-Adamantyl)-4'-benzyloxyphenyl]-3-chlorocinnamaldehyde (37)}

To a stirred solution of oxalyl chloride $(127 \mathrm{mg}, 1 \mathrm{mmol})$ in $\mathrm{CH}_{2} \mathrm{Cl}_{2}(2 \mathrm{~mL})$ at $-78{ }^{\circ} \mathrm{C}$ under argon was slowly added $\mathrm{Me}_{2} \mathrm{SO}(156 \mathrm{mg}, 2 \mathrm{mmol})$ in $\mathrm{CH}_{2} \mathrm{Cl}_{2}(1 \mathrm{~mL})$ according to the method of Swern. ${ }^{48}$ The solution was stirred at $-78{ }^{\circ} \mathrm{C}$ for $10 \mathrm{~min}, \mathbf{3 6}(170 \mathrm{mg}, 0.35 \mathrm{mmol})$ in $\mathrm{CH}_{2} \mathrm{Cl}_{2}(2 \mathrm{~mL})$ was slowly added, and stirring was continued at $-78^{\circ} \mathrm{C}$ for $20 \mathrm{~min}$ before $\mathrm{Et}_{3} \mathrm{~N}$ (303 $\mathrm{mg}, 3.0 \mathrm{mmol}$ ) was added. The mixture was allowed to warm to room temperature and diluted with $\mathrm{CH}_{2} \mathrm{Cl}_{2}(20 \mathrm{~mL})$. The organic layer was washed (water and brine), dried, and 
concentrated. Chromatography (5\% EtOAc/hexane) gave $122 \mathrm{mg}$ (72\%) of $\mathbf{3 7}$ as a white powder, mp 56-58 ${ }^{\circ} \mathrm{C}$. IR $\left(\mathrm{CHCl}_{3}\right) 2906,1681,1602 \mathrm{~cm}^{-1} ;{ }^{1} \mathrm{H}$ NMR $\delta 1.73\left(\mathrm{~s}, 6 \mathrm{H}, \mathrm{AdCH}_{2}\right)$, $2.05(\mathrm{~s}, 3 \mathrm{H}, \mathrm{AdCH}), 2.17\left(\mathrm{~s}, 6 \mathrm{H}, \mathrm{AdCH}_{2}\right), 5.17\left(\mathrm{~s}, 2 \mathrm{H}, \mathrm{ArCH}_{2}\right), 6.73(\mathrm{dd}, J=15.2,7.5 \mathrm{~Hz}, 1 \mathrm{H}$, $\mathrm{CH}=\mathrm{CHCHO}), 7.02\left(\mathrm{~d}, J=8.7 \mathrm{~Hz}, 1 \mathrm{H}, 5^{\prime}-\mathrm{ArH}\right), 7.29$ (dd, $\left.J=8.1,2.1 \mathrm{~Hz}, 1 \mathrm{H}, 6^{\prime}-\mathrm{ArH}\right), 7.35-$ $7.44(\mathrm{~m}, 5 \mathrm{H}, \mathrm{ArH}), 7.41(\mathrm{~d}, J=6.9 \mathrm{~Hz}, 1 \mathrm{H}, 5-\mathrm{ArH}), 7.49(\mathrm{~d}, J=6.9 \mathrm{~Hz}, 1 \mathrm{H}, 6-\mathrm{ArH}), 7.50(\mathrm{~s}$, $\left.1 \mathrm{H}, 2^{\prime}-\mathrm{ArH}\right), 7.51(\mathrm{~d}, J=15.9 \mathrm{~Hz}, 1 \mathrm{H}, \mathrm{CH}=\mathrm{CHCHO}), 7.66(\mathrm{~s}, 1 \mathrm{H}, 2-\mathrm{ArH}), 9.73 \mathrm{ppm}(\mathrm{d}, J=$ $7.5 \mathrm{~Hz}, 1 \mathrm{H}, \mathrm{CHO}$ ). FTMS (HRMS) calcd $\mathrm{C}_{32} \mathrm{H}_{32} \mathrm{ClO}_{2}[\mathrm{M}+\mathrm{H}]^{+}$expected 501.2200, found 501.2276 .

\section{General Procedure for Converting Aldehydes 37 and 41 to 2,4-Thiazolidinediones}

To a stirred solution of aldehyde $(0.1 \mathrm{mmol})$ and 2,4-thiazolidinedione $(23 \mathrm{mg}, 0.2 \mathrm{mmol})$ in toluene $(1 \mathrm{~mL})$ were added $\mathrm{NHEt}_{2}(0.1 \mathrm{~mL})$ and $\mathrm{HOAc}(0.05 \mathrm{~mL})$. The mixture was stirred at reflux for $2 \mathrm{~h}$, cooled, and diluted with $\mathrm{CH}_{2} \mathrm{Cl}_{2}(10 \mathrm{~mL})$. The organic layer was washed (water and brine) and dried. Concentration and chromatography gave the thiazolidinedione.

\section{5-\{3-[3'-(1-Adamantyl)-4'-benzyloxy-2-chloro-4-biphenyl]-(2E)-2-propenylidene\}-2,4- thiazolidinedione (38)}

37 (46 mg, $0.1 \mathrm{mmol})$ gave $34 \mathrm{mg}(62 \%)$ of $\mathbf{3 8}$ as a yellow powder, $R_{\mathrm{f}} 0.31(30 \%$ EtOAc/ hexane); mp 212-215 ${ }^{\circ} \mathrm{C}$. IR $\left(\mathrm{CHCl}_{3}\right) 3186,1733,1692 \mathrm{~cm}^{-1} ;{ }^{1} \mathrm{H}$ NMR $\delta 1.73(\mathrm{~s}, 6 \mathrm{H}$, $\mathrm{AdCH}_{2}$ ), 2.04 (s, 3H, $\mathrm{AdCH}$ ), 2.17 (s, 6H, $\mathrm{AdCH}_{2}$ ), 5.17 (s, 2H, $\mathrm{ArCH}_{2}$ ), 6.70 (dd, $J=15.6$, $8.7 \mathrm{~Hz}, 1 \mathrm{H}, \mathrm{ArCH}=\mathrm{CHCH}=\mathrm{C}), 7.00\left(\mathrm{~d}, J=8.4 \mathrm{~Hz}, 1 \mathrm{H}, 5^{\prime}-\mathrm{ArH}\right), 7.02(\mathrm{~d}, J=14.2 \mathrm{~Hz}, 1 \mathrm{H}$, $\mathrm{ArCH}=\mathrm{CHCH}=\mathrm{C}), 7.27-7.46\left(\mathrm{~m}, 7 \mathrm{H}, 5-\mathrm{ArH}, 6^{\prime}-\mathrm{ArH}, \mathrm{Ar}\right), 7.51\left(\mathrm{~d}, J=1.2 \mathrm{~Hz}, 1 \mathrm{H}, 2^{\prime}-\mathrm{ArH}\right)$, $7.52(\mathrm{~d}, J=6.6 \mathrm{~Hz}, 1 \mathrm{H}, 6-\mathrm{ArH}), 7.54(\mathrm{~d}, J=15.1 \mathrm{~Hz}, 1 \mathrm{H}, \mathrm{ArCH}=\mathrm{CHCH}=\mathrm{C}), 7.60(\mathrm{~s}, 1 \mathrm{H}, 3-$ $\mathrm{ArH}), 8.39 \mathrm{ppm}(\mathrm{s}, 1 \mathrm{H}, \mathrm{NH})$. HRMS calcd $\mathrm{C}_{35} \mathrm{H}_{32} \mathrm{ClNO}_{3} \mathrm{~S}[\mathrm{M}-\mathrm{H}]^{-} 580.1719$, found 580.1714 .

\section{5-\{4-[3'-(1-Adamantyl)-4'-benzyloxyphenyl]-3-chlorobenzylidene\}-2,4-thiazolidinedione (42)}

41 (46 mg, $0.1 \mathrm{mmol}$ ) gave $34 \mathrm{mg}(62 \%)$ of $\mathbf{4 2}$ as a yellow powder, $R_{\mathrm{f}}(10 \% \mathrm{EtOAc} / \mathrm{hexane})$; mp 200-203 ${ }^{\circ} \mathrm{C}$. IR $\left(\mathrm{CHCl}_{3}\right) 3173,2904,1739,1689 \mathrm{~cm}^{-1} ;{ }^{1} \mathrm{H} \mathrm{NMR} \delta 1.74$ (s, 6H, $\left.\mathrm{AdCH}_{2}\right)$, $2.05(\mathrm{~s}, 3 \mathrm{H}, \mathrm{AdCH}), 2.18\left(\mathrm{~d}, J=2.4 \mathrm{~Hz}, 6 \mathrm{H}, \mathrm{AdCH}_{2}\right), 5.18\left(\mathrm{~s}, 2 \mathrm{H}, \mathrm{ArCH}_{2}\right), 7.02(\mathrm{~d}, J=8.4$ $\left.\mathrm{Hz}, 1 \mathrm{H}, 5^{\prime}-\mathrm{ArH}\right), 7.30$ (dd, $\left.J=8.4,2.1 \mathrm{~Hz}, 1 \mathrm{H}, 6^{\prime}-\mathrm{ArH}\right), 7.35-7.43$ (m, 6H, $\left.2^{\prime}-\mathrm{ArH}, \mathrm{ArH}\right), 7.48$ $(\mathrm{d}, J=7.8 \mathrm{~Hz}, 1 \mathrm{H}, 6-\mathrm{ArH}), 7.52(\mathrm{~d}, J=6.6 \mathrm{~Hz}, 1 \mathrm{H}, 5-\mathrm{ArH}), 7.60(\mathrm{~d}, J=\mathrm{Hz}, 1 \mathrm{H}, 2-\mathrm{ArH}), 7.81$ (s, $1 \mathrm{H}, \mathrm{ArCH}=\mathrm{C}$ ), 8.14 ppm (bs, $1 \mathrm{H}, \mathrm{NH}$ ). HRMS calcd $\mathrm{C}_{33} \mathrm{H}_{30} \mathrm{ClNO}_{3} \mathrm{~S}[\mathrm{M}-\mathrm{H}]^{-}$554.1562, found 554.1552 .

\section{2-\{[3'-(1-Adamantyl)-4'-benzyloxy-2-chloro-4-biphenyl]-methylene\}propanedinitrile (44)}

A reported procedure ${ }^{49}$ was adapted. A mixture of $\mathbf{4 1}(102 \mathrm{mg}, 0.22 \mathrm{mmol})$ and malononitrile $(18 \mathrm{mg}, 0.27 \mathrm{mmol})$ in anhydrous DMF $(0.6 \mathrm{~mL})$ was stirred in a $103^{\circ} \mathrm{C}$ oil-bath for $7 \mathrm{~h}$, cooled to room temperature, and diluted with $\mathrm{H}_{2} \mathrm{O}(8 \mathrm{~mL})$ and EtOAc $(80 \mathrm{~mL})$. The organic layer was washed (brine) and dried. The residue obtained on concentration was purified by chromatography (9\% EtOAc/hexane) to give $78 \mathrm{mg}(70 \%)$ of $\mathbf{4 4}$ as a yellow solid, $\mathrm{mp} 170$ $171{ }^{\circ} \mathrm{C}$, which was deprotected to give $45 .{ }^{1} \mathrm{H}$ NMR $\delta 1.76$ (bs, $6 \mathrm{H}, \mathrm{AdCH}_{2}$ ), 2.08 (bs, 3H, $\mathrm{AdCH}$ ), 2.20 (bs, 6H, $\mathrm{AdCH}_{2}$ ), 5.20 (s, 2H, $\mathrm{ArCH}_{2}$ ), 7.05 (d, $\left.J=8.4 \mathrm{~Hz}, 1 \mathrm{H}, 5^{\prime}-\mathrm{ArH}\right), 7.32$ 7.57 (m, 8H, 5-ArH, 2'-ArH, 6'-ArH, ArH), $7.74\left(\mathrm{~s}, 1 \mathrm{H}, \mathrm{CH}=\mathrm{C}(\mathrm{CN})_{2}\right), 7.92-7.96 \mathrm{ppm}(\mathrm{m}, 2 \mathrm{H}$, 3-ArH, 6-ArH).

(E)-4-[3'-(1-Adamantyl)-4'-benzyloxyphenyl]-3-chlorocinnamic Acid (46). 5

A mixture of $35^{5}(174 \mathrm{mg}, 0.34 \mathrm{mmol})$ and $\mathrm{LiOH} \cdot \mathrm{H}_{2} \mathrm{O}(47 \mathrm{mg}, 3.3 \mathrm{mmol})$ in $\mathrm{CH}_{3} \mathrm{OH} / \mathrm{THF} /$ $\mathrm{H}_{2} \mathrm{O}(0.6: 1.6: 0.55)$ was stirred for $6 \mathrm{~h}$. After removal of solvent, the residue suspended in $\mathrm{H}_{2} \mathrm{O}(7 \mathrm{~mL})$ and $2 \mathrm{~N} \mathrm{HCl}(5 \mathrm{~mL})$ was extracted with EtOAc $(100 \mathrm{~mL})$. The organic layer was washed (brine) and dried. Removal of solvent gave $157 \mathrm{mg}$ (93\%) of $\mathbf{4 6}$ as a pale-tan solid, 
which was used directly in the next step. ${ }^{1} \mathrm{H}$ NMR $\delta 1.74$ (bs, $\left.6 \mathrm{H}, \mathrm{AdCH}_{2}\right), 2.05(\mathrm{bs}, 3 \mathrm{H}$, $\mathrm{AdCH}$ ), 2.19 (bs, 6H, $\mathrm{AdCH}_{2}$ ), 5.18 (s, $2 \mathrm{H}, \mathrm{ArCH}_{2}$ ), 6.48 (d, $J=15 \mathrm{~Hz}, 1 \mathrm{H}, \mathrm{CH}=\mathrm{CHCO}$ ), 7.01 (m, 1H, 5'-ArH), 7.28-7.55 (m, 9H, 6'-ArH, 2-ArH, 5-ArH, 6-ArH, ArH), 7.66 (s, 1H, 2'-ArH), $7.75 \mathrm{ppm}(\mathrm{d}, J=15 \mathrm{~Hz}, 1 \mathrm{H}, \mathrm{CH}=\mathrm{CHCO})$.

\section{$\mathrm{N}$-(Tetrahydro-2H-pyran-2-yloxy) (E)-4-[3'-(1-Adamantyl)-4'-benzyloxyphenyl]-3- chlorocinnamamide (47)}

A reported procedure ${ }^{50}$ was followed. To a stirred solution of $\mathbf{4 6}(102 \mathrm{mg}, 0.205 \mathrm{mmol})$ in $\mathrm{CHCl}_{3}(4 \mathrm{~mL})$ at $0{ }^{\circ} \mathrm{C}$ (ice-bath) were added DMAP $(47 \mathrm{mg}, 0.39 \mathrm{mmol})$ and $O$ (tetrahydro- $2 \mathrm{H}$-pyran-2-yl)hydroxylamine $\left(36 \mathrm{mg}, 0.31 \mathrm{mmol}\right.$ ). Stirring was continued at $0^{\circ}$ $\mathrm{C}$ for $20 \mathrm{~min}$ more, before DIC ( $48 \mu \mathrm{L}, 0.31 \mathrm{mmol}$ ) was added. After $1 \mathrm{~h}$, the mixture was warmed to room temperature, stirred for $48 \mathrm{~h}$, quenched with saturated $\mathrm{NH}_{4} \mathrm{Cl}(8 \mathrm{~mL})$, and extracted with EtOAc $(90 \mathrm{~mL})$. The extract was washed (sat. $\mathrm{NH}_{4} \mathrm{Cl}$ and brine) and dried. Solvent was removed at reduced pressure and the residue chromatographed $(33 \% \mathrm{EtOAc} /$ hexane) to give $56 \mathrm{mg}(46 \%)$ of $\mathbf{4 7}$ as a pale-tan solid, $91-93{ }^{\circ} \mathrm{C} .{ }^{1} \mathrm{H}$ NMR $\delta 1.64$ (m, 4H, 4THPH, 5-THPH), 1.74 (bs, 6H AdCH ${ }_{2}$ ), 1.87 (m, 2H, 3-THPH), 2.06 (bs, 3H, AdCH), 2.18 (bs, 6H, $\mathrm{AdCH}_{2}$ ), 3.64 (m, 1H, 6-THPH), 3.98 (m, 1H, 6-THPH), 5.06 (bs, 1H, 2-THPH), 5.18 (s, $\left.2 \mathrm{H}, \mathrm{ArCH}_{2}\right), 7.01\left(\mathrm{~d}, J=8.1 \mathrm{~Hz}, 1 \mathrm{H}, 5^{\prime}-\mathrm{ArH}\right), 7.29$ (dd, $\left.J=8.4,1.5 \mathrm{~Hz}, 1 \mathrm{H}, 6^{\prime}-\mathrm{ArH}\right), 7.33-$ 7.46 (m, 7H, $\mathrm{CH}=\mathrm{CHCO}, 5-\mathrm{ArH}, \mathrm{ArH}), 7.51-7.63$ (m, 3H, 2-ArH, 6-ArH, 2'-ArH), $7.72 \mathrm{ppm}$ (d, $J=15.3 \mathrm{~Hz}, 1 \mathrm{H}, \mathrm{CH}=\mathrm{CHCO}$ ).

\section{3'-(1-Adamantyl)-4'-benzyloxyphenyl)-3-chloroaniline (52)}

A mixture of $\mathbf{5 1}(2.08 \mathrm{~g}, 4.4 \mathrm{mmol})$ and $\mathrm{SnCl}_{2} \cdot 2 \mathrm{H}_{2} \mathrm{O}(4.96 \mathrm{~g}, 44 \mathrm{mmol})$ in $\mathrm{EtOH}(20 \mathrm{~mL})$ was heated at $88{ }^{\circ} \mathrm{C}$ (oil-bath) for $2.5 \mathrm{~h}$, cooled to room temperature, diluted with $\mathrm{H}_{2} \mathrm{O}(10 \mathrm{~mL})$, and adjusted to $\mathrm{pH} 7-8$ by addition of $2 \mathrm{~N} \mathrm{NaOH}(21 \mathrm{~mL})$ and $5 \% \mathrm{NaHCO}_{3}(19 \mathrm{~mL})$. This mixture was stirred for $1 \mathrm{~h}$ and extracted $(3 \times 350 \mathrm{~mL}$ EtOAc). The organic layer was washed (sat. brine) and dried. The concentrated residue was chromatographed (28\% EtOAc/hexane) to give $1.766 \mathrm{~g} \mathrm{(90 \% )} \mathrm{of} \mathbf{5 2}$ as a white solid, $\mathrm{mp} 154-155^{\circ} \mathrm{C}$. IR 3391, 2905, $1189 \mathrm{~cm}^{-1} ;{ }^{1} \mathrm{H}$ NMR $\delta 1.73\left(\mathrm{~m}, 6 \mathrm{H}, \mathrm{AdCH}_{2}\right), 2.05(\mathrm{~m}, 3 \mathrm{H}, \mathrm{AdCH}), 2.18\left(\mathrm{~m}, 6 \mathrm{H}, \mathrm{AdCH}_{2}\right), 3.73(\mathrm{bs}, 2 \mathrm{H}$, $\left.\mathrm{NH}_{2}\right), 5.16\left(\mathrm{~s}, 2 \mathrm{H}, \mathrm{ArCH}_{2}\right), 6.62$ (dd, $\left.J=8.1,2.4 \mathrm{~Hz}, 1 \mathrm{H}, 5-\mathrm{ArH}\right), 6.8(\mathrm{~d}, J=2.4 \mathrm{~Hz}, 1 \mathrm{H}, 2-$ ArH), $6.97(\mathrm{~d}, J=8.1 \mathrm{~Hz}, 1 \mathrm{H}, 6-\mathrm{ArH}), 7.15\left(\mathrm{~d}, J=8.4 \mathrm{~Hz}, 1 \mathrm{H}, 5^{\prime}-\mathrm{ArH}\right), 7.35$ (dd, $J=8.4,2.4$ $\left.\mathrm{Hz}, 1 \mathrm{H}, 6^{\prime}-\mathrm{ArH}\right), 7.32\left(\mathrm{~d}, J=8.4 \mathrm{~Hz}, 1 \mathrm{H}, 2^{\prime}-\mathrm{ArH}\right), 7.33-7.55 \mathrm{ppm}(\mathrm{m}, 5 \mathrm{H}, \mathrm{ArH})$. HRMS calcd $\mathrm{C}_{29} \mathrm{H}_{30} \mathrm{ClNO}[\mathrm{M}+\mathrm{H}]^{+}$444.2089, found 444.2096.

\section{3'-(1-Adamantyl)-4'-benzyloxy-4-bromo-2-chlorobiphenyl (53)}

$\mathrm{To} \mathrm{CuBr}_{2}(1.19 \mathrm{~g}, 5.32 \mathrm{mmol})$ and tert-butyl nitrite $(899 \mu \mathrm{L}, 6.81 \mathrm{mmol})$ in anhydrous $\mathrm{MeCN}$ $(5 \mathrm{~mL})$ at $0{ }^{\circ} \mathrm{C}$ were slowly added under argon $52(1.89 \mathrm{~g}, 4.25 \mathrm{mmol})$ and $\mathrm{MeCN}(11 \mathrm{~mL})$, and stirring was continued for $30 \mathrm{~min}$. The mixture was warmed to room temperature, stirred for $2 \mathrm{~h}$, at which time no insoluble 52 remained, quenched with $2 \mathrm{~N} \mathrm{HCl}(100 \mathrm{~mL})$, and extracted $\left(3 \times 300 \mathrm{~mL} \mathrm{Et}_{2} \mathrm{O}\right)$. The organic layer was washed (sat. brine) and dried. After concentration, the residue was chromatographed (hexane) to give $973 \mathrm{mg} \mathrm{(45 \% )} \mathrm{of} \mathbf{5 3}$ as a pale-yellow solid, mp 58-60 ${ }^{\circ} \mathrm{C}$. IR 2902, $1220 \mathrm{~cm}^{-1}$; ${ }^{1} \mathrm{H}$ NMR $\delta 1.74$ (bs, 6H, $\mathrm{AdCH}_{2}$ ), 2.05 (bs, 3H, AdCH), $2.18\left(\mathrm{~m}, 6 \mathrm{H}, \mathrm{AdCH}_{2}\right), 5.17\left(\mathrm{~s}, 2 \mathrm{H}, \mathrm{ArCH}_{2}\right), 7.01\left(\mathrm{~d}, J=8.1 \mathrm{~Hz}, 1 \mathrm{H}, 5^{\prime}-\mathrm{ArH}\right), 7.23$ (d, $J=8.4$ $\mathrm{Hz}, 1 \mathrm{H}, 6-\mathrm{ArH}), 7.25$ (dd, $\left.J=8.4,2.1 \mathrm{~Hz}, 1 \mathrm{H}, 6^{\prime}-\mathrm{ArH}\right), 7.32$ (d, $\left.J=2.1 \mathrm{~Hz}, 1 \mathrm{H}, 2^{\prime}-\mathrm{ArH}\right), 7.33-$ 7.55 (m, 6H, 5-ArH, ArH), $7.64 \mathrm{ppm}(\mathrm{d}, J=2.1 \mathrm{~Hz}, 1 \mathrm{H}, 3-\mathrm{ArH})$. HRMS calcd $\mathrm{C}_{29} \mathrm{H}_{28} \mathrm{BrClO}$ $[\mathrm{M}+\mathrm{H}]^{+}$507.1085, found 507.1068.

\section{3'-(1-Adamantyl)-4'-benzyloxy-2-chloro-4-(2-trimethylsilylethynyl) biphenyl (54)}

A reported procedure ${ }^{52}$ was adapted. A mixture of $\mathbf{5 3}(340 \mathrm{mg}, 0.67 \mathrm{mmol})$, trimethylsilylacetylene $(186 \mu \mathrm{L}, 1.34 \mathrm{mmol}), \mathrm{Pd}\left(\mathrm{PPh}_{3}\right)_{4}(92 \mathrm{mg}, 0.08 \mathrm{mmol})$, and $\mathrm{CuI}(5 \mathrm{mg}$, $0.026 \mathrm{mmol}$ ) was heated at $102{ }^{\circ} \mathrm{C}$ (oil-bath) under argon for $3.5 \mathrm{~h}$, cooled to room temperature, 
diluted with EtOAc $(90 \mathrm{~mL})$, and filtered through silica gel. The filtrate was concentrated, and the residue was chromatographed (1\% EtOAc/hexane) to give $350 \mathrm{mg}(99 \%)$ of $\mathbf{5 4}$ as a paleyellow solid, mp 55-57 ${ }^{\circ} \mathrm{C}$. IR 2902, 2221, $1286 \mathrm{~cm}^{-1} ;{ }_{1}^{1} \mathrm{H}$ NMR $\delta 0.27\left(\mathrm{~s}, 9 \mathrm{H}, \mathrm{Si}\left(\mathrm{CH}_{3}\right)_{3}\right), 1.74$ (bs, 6H, $\mathrm{AdCH}_{2}$ ), 2.05 (bs, 3H, $\left.\mathrm{AdCH}\right), 2.18\left(\mathrm{~m}, 6 \mathrm{H}, \mathrm{AdCH}_{2}\right), 5.17$ (s, $\left.2 \mathrm{H}, \mathrm{ArCH}_{2}\right), 7.01$ (d, $\left.J=8.7 \mathrm{~Hz}, 1 \mathrm{H}, 5^{\prime}-\mathrm{ArH}\right), 7.27$ (dd, $\left.J=8.7,2.1 \mathrm{~Hz}, 1 \mathrm{H}, 6^{\prime}-\mathrm{ArH}\right), 7.29(\mathrm{~d}, J=8.4 \mathrm{~Hz}, 1 \mathrm{H}, 6-$ ArH), 7.30-7.46 (m, 6H, 2'-ArH, ArH), 7.53 (dd, $J=8.4,1.5 \mathrm{~Hz}, 1 \mathrm{H}, 5-\mathrm{ArH}), 7.58 \mathrm{ppm}(\mathrm{d}$, $J=1.5 \mathrm{~Hz}, 1 \mathrm{H}, 3-\mathrm{ArH})$. HRMS calcd $\mathrm{C}_{34} \mathrm{H}_{37} \mathrm{ClOSi}[\mathrm{M}+\mathrm{H}]^{+}$525.2375, found 525.2379.

\section{3'-(1-Adamantyl)-4'-benzyloxy-2-chloro-4-ethynylbiphenyl (55)}

To a solution of $54(350 \mathrm{mg}, 0.67 \mathrm{mmol})$ in THF $(15 \mathrm{~mL})$ was added $0.9 \mathrm{~mL}$ of $1.0 \mathrm{M}(n-$ $\mathrm{Bu})_{4} \mathrm{NF}(0.88 \mathrm{mmol})$ in THF. The mixture was stirred for $1 \mathrm{~h}$, diluted with $\mathrm{H}_{2} \mathrm{O}(20 \mathrm{~mL})$, and extracted with EtOAc $(3 \times 200 \mathrm{~mL})$. The extract was washed (sat. brine) and dried. After concentration, the residue was chromatographed (1\% EtOAc/hexane) to give $295 \mathrm{mg}(96 \%)$ of 55 as a white solid, mp 94-96 ${ }^{\circ} \mathrm{C} .{ }^{1} \mathrm{H}$ NMR $\delta 1.74$ (bs, $6 \mathrm{H}, \mathrm{AdCH}_{2}$ ), 2.06 (bs, 3H, AdCH), $2.18\left(\mathrm{~m}, 6 \mathrm{H}, \mathrm{AdCH}_{2}\right), 3.14(\mathrm{~s}, 1 \mathrm{H}, \mathrm{C} \equiv \mathrm{CH}), 5.17\left(\mathrm{~s}, 2 \mathrm{H}, \mathrm{ArCH}_{2}\right), 7.01\left(\mathrm{~d}, J=8.4 \mathrm{~Hz}, 1 \mathrm{H}, 5^{\prime}-\right.$ ArH), $7.28\left(\mathrm{dd}, J=8.1,2.4 \mathrm{~Hz}, 1 \mathrm{H}, 6^{\prime}-\mathrm{ArH}\right), 7.31(\mathrm{~d}, J=8.1 \mathrm{~Hz}, 1 \mathrm{H}, 6-\mathrm{ArH}), 7.35(\mathrm{~d}, J=2.4$ $\left.\mathrm{Hz}, 1 \mathrm{H}, 2^{\prime}-\mathrm{ArH}\right), 7.32-7.55$ (m, 6H, 5ArH, ArH), $7.6 \mathrm{ppm}$ (d, $\left.J=1.5 \mathrm{~Hz}, 1 \mathrm{H}, 3-\mathrm{ArH}\right)$. HRMS calcd $\mathrm{C}_{31} \mathrm{H}_{29} \mathrm{ClO}[\mathrm{M}+\mathrm{H}]^{+}$453.1980, found 453.1978.

\section{(E)-2-[3'-(1-Adamantyl)-4'-benzyloxy-2-chloro-4-biphenyl]ethenyl-1,3,2-benzodioxaborole} (56)

The procedure of Brown et al. ${ }^{53}$ was adapted. A mixture of $55(295 \mathrm{mg}, 0.65 \mathrm{mmol})$ and 0.67 $\mathrm{mL}$ of $1.0 \mathrm{M}$ catecholborane $(0.67 \mathrm{mmol})$ in THF was stirred under argon at $91^{\circ} \mathrm{C}$ (oil-bath) for $5 \mathrm{~h}$, cooled to room temperature, and diluted with THF ( $3 \mathrm{~mL})$ for transfer. After concentration, the residue was chromatographed ( $1 \%$ to $40 \% \mathrm{EtOAc} /$ hexane) to give $59 \mathrm{mg}$ (26\%) of 56 as a pale-yellow solid, mp $158-161{ }^{\circ} \mathrm{C} .{ }^{1} \mathrm{H}$ NMR $\delta 1.75$ (bs, $6 \mathrm{H}, \mathrm{AdCH}_{2}$ ), 2.07 (bs, $3 \mathrm{H}, \mathrm{AdCH}), 2.21\left(\mathrm{~m}, 6 \mathrm{H}, \mathrm{AdCH}_{2}\right), 5.19\left(\mathrm{~s}, 2 \mathrm{H}, \mathrm{ArCH}_{2}\right), 6.42(\mathrm{~d}, J=18 \mathrm{~Hz}, 1 \mathrm{H}$, $\mathrm{CH}=\mathrm{CHB}$ ), 7.01-7.07 (m, 3H, ArH), 7.27-7.49 (m, 8H, ArH), 7.52-7.60 (m, 3H, ArH), 7.75 (s, 1H, ArH), $7.79 \mathrm{ppm}(\mathrm{d}, J=18 \mathrm{~Hz}, 1 \mathrm{H}, \mathrm{CH}=\mathrm{CHB})$.

\section{(3E)-4-[3'-(1-Adamantyl)-4'-benzyloxy-2-chloro-4-biphenyl]but-3-en-2-one (58)}

A reported procedure ${ }^{54}$ was modified. A mixture of 4-[3'-(1-adamantyl)-4'benzyloxyphenyl]-3-chlorobenzaldehyde (41) (303 mg, $0.66 \mathrm{mmol}$ ), (2-oxopropyl) triphenylphosphonium bromide (397 $\mathrm{mg}, 0.99 \mathrm{mmol}$ ) and 1,5,7-triazabicyclo[4.4.0]dec-5-ene $(157 \mathrm{mg}, 1.13 \mathrm{mmol})$ in THF $(3 \mathrm{~mL})$ was stirred for $23 \mathrm{~h}$ at room temperature and then at 70 ${ }^{\circ} \mathrm{C}$ for $2 \mathrm{~h}$. The mixture was cooled to room temperature and diluted with $\mathrm{H}_{2} \mathrm{O}(10 \mathrm{~mL})$ and EtOAc $(150 \mathrm{~mL})$. The organic layer was washed (sat. brine) and dried. The residue obtained on concentration was chromatographed (12\% EtOAc/hexane) to give $124 \mathrm{mg}(38 \%)$ of $\mathbf{5 8}$ as a yellow wax, mp $73-75^{\circ} \mathrm{C}$. IR 2902, 2849, $1683 \mathrm{~cm}^{-1} ;{ }^{1} \mathrm{H}$ NMR $\delta 1.74$ (bs, $6 \mathrm{H}, \mathrm{AdCH}_{2}$ ), 2.06 (bs, 3H, AdCH), 2.19 (bs, 6H, $\mathrm{AdCH}_{2}$ ), 2.42 (s, 3H, $\mathrm{CH}_{3} \mathrm{CO}$ ), 5.18 (s, $2 \mathrm{H}, \mathrm{ArCH}_{2}$ ), 6.75 (d, $J=16.2 \mathrm{~Hz}, 1 \mathrm{H}, \mathrm{CH}=\mathrm{CHCO}), 7.02\left(\mathrm{~d}, J=8.4 \mathrm{~Hz}, 1 \mathrm{H}, 5^{\prime}-\mathrm{ArH}\right), 7.30(\mathrm{dd}, J=8.4,2.1 \mathrm{~Hz}$, $\left.1 \mathrm{H}, 6^{\prime}-\mathrm{ArH}\right), 7.34-7.56$ (m, 9H, 2'-ArH, 5-ArH, 6-ArH, CH=CHCO, ArH), $7.66 \mathrm{ppm}$ (d, $J=$ $1.2 \mathrm{~Hz}, 1 \mathrm{H}, 3-\mathrm{ArH})$. HRMS calcd $\mathrm{C}_{33} \mathrm{H}_{33} \mathrm{ClO}_{2}[\mathrm{M}+\mathrm{H}]^{+}$497.2242, found 497.2240.

\section{(3E)-4-[3'-(1-Adamantyl)-4'-benzyloxy-2-chloro-4-biphenyl]-2-oxobut-3-enal (59)}

A reported procedure 55 was applied. A mixture of $\mathbf{5 8}(124 \mathrm{mg}, 0.25 \mathrm{mmol})$ and $\mathrm{H}_{2} \mathrm{SeO}_{3}(35$ $\mathrm{mg}, 0.27 \mathrm{mmol}$ ) in $1.0 \mathrm{~mL}$ of dioxane and $0.1 \mathrm{~mL}$ of $\mathrm{H}_{2} \mathrm{O}$ was heated at reflux for $1.5 \mathrm{~h}$ under argon, cooled to room temperature, and diluted with EtOAc $(120 \mathrm{~mL})$. The organic layer was washed (sat. brine) and dried. The residue obtained on concentration was chromatographed (33\% EtOAc/hexane) to give $35 \mathrm{mg}(27 \%)$ of $\mathbf{5 9}$ as a yellow wax, mp $84-86{ }^{\circ} \mathrm{C}$. IR 2904 , 2853, 1713, $1690 \mathrm{~cm}^{-1}$; ${ }^{1} \mathrm{H}$ NMR $\delta 1.74$ (bs, 6H, $\mathrm{AdCH}_{2}$ ), 2.06 (bs, 3H, AdCH), 2.19 (bs, 6H, 
$\left.\mathrm{AdCH}_{2}\right), 5.18\left(\mathrm{~s}, 2 \mathrm{H}, \mathrm{ArCH}_{2}\right), 6.93(\mathrm{~d}, J=16.2 \mathrm{~Hz}, 1 \mathrm{H}, \mathrm{CH}=\mathrm{CHCO}), 7.02(\mathrm{dd}, J=8.1,2.1$ $\left.\mathrm{Hz}, 1 \mathrm{H}, 6^{\prime}-\mathrm{ArH}\right), 7.28-7.56$ (m, 9H, 5-ArH, 6-ArH, 2'-ArH, 5'-ArH, ArH), 7.76 (d, $J=1.5 \mathrm{~Hz}$, $1 \mathrm{H}, 3-\mathrm{ArH}), 7.97$ (d, $J=16.2 \mathrm{~Hz}, 1 \mathrm{H}, \mathrm{CH}=\mathrm{CHCO}), 9.47 \mathrm{ppm}$ (s, 1H, CHO). HRMS calcd $\mathrm{C}_{33} \mathrm{H}_{31} \mathrm{ClO}_{3}[\mathrm{M}+\mathrm{H}]^{+}$511.2034, found 511.2038.

\section{Diethyl (E)-2-[3'-(1-Adamantyl)-4'-benzyloxy-2-chloro-4-biphenyl]ethenylphosphonate (61)}

A reported method ${ }^{56}$ was modified. To a solution of $41(0.14 \mathrm{mmol}, 65 \mathrm{mg})$ and tetraethyl methylenebisphosphonate $(0.14 \mathrm{mmol}, 36 \mu \mathrm{L})$ in $\mathrm{CH}_{2} \mathrm{Cl}_{2}(0.8 \mathrm{~mL})$ was added $50 \%$ aq $\mathrm{NaOH}$ $(0.8 \mathrm{~mL})$. The mixture was stirred for $10 \mathrm{~min}$, diluted with $\mathrm{H}_{2} \mathrm{O}(8 \mathrm{~mL})$, and extracted $(60 \mathrm{~mL}$ EtOAc). The extract was washed ( $2 \mathrm{~N} \mathrm{HCl}$ and brine) and dried. The residue obtained on concentration was purified by chromatography (50\% to 60\% EtOAc/hexane) to give $82 \mathrm{mg}$ $(98 \%)$ of 61 as a colorless gel. ${ }^{1} \mathrm{H}$ NMR $\delta 1.40\left(\mathrm{t}, J=6.9 \mathrm{~Hz}, 6 \mathrm{H}, \mathrm{OCH}_{2} \mathrm{CH}_{3}\right), 1.76(\mathrm{bs}, 6 \mathrm{H}$, $\mathrm{AdCH}_{2}$ ), 2.07 (bs, 3H, $\mathrm{AdCH}$ ), 2.20 (bs, 6H, $\left.\mathrm{AdCH}_{2}\right), 4.18\left(\mathrm{~m}, 4 \mathrm{H}, \mathrm{OCH}_{2} \mathrm{CH}_{3}\right), 5.20$ (s, $2 \mathrm{H}$, $\left.\mathrm{ArCH}_{2}\right), 6.32$ (t, $\left.J=17.4 \mathrm{~Hz}, 1 \mathrm{H}, \mathrm{CH}=\mathrm{CHP}\right), 7.03\left(\mathrm{~d}, J=8.1 \mathrm{~Hz}, 1 \mathrm{H}, 5^{\prime}-\mathrm{ArH}\right), 7.31$ (dd, $J=$ 8.1, 2.1 Hz, 1H, 6'-ArH), 7.28-7.57 (m, 9 H, 2'-ArH, 5-ArH, 6-ArH, ArH, CH=CHP), 7.64 (s, $1 \mathrm{H}, 3-\mathrm{ArH})$. HRMS calcd $\mathrm{C}_{35} \mathrm{H}_{40} \mathrm{ClO}_{4} \mathrm{P}[\mathrm{M}+\mathrm{H}]^{+}$591.2425, found 591.2429.

\section{(E)-2-[3'-(1-Adamantyl)-2-chloro-4'-hydroxy-4-biphenyl]ethenylphosphonic Acid Monoethyl Ester (63)}

A literature method ${ }^{57}$ was adapted. A suspension of $62(0.12 \mathrm{mmol}, 61 \mathrm{mg})$ in aq $20 \% \mathrm{HCl}$ $(5 \mathrm{~mL})$ was heated at reflux under argon for $6 \mathrm{~h}$. After removal of some water at reduced pressure from the resultant solution, the residue was extracted $(3 \times 40 \mathrm{~mL}$ EtOAc). The organic extract was washed (brine) and dried. The residue obtained on concentration was chromatographed (EtOAc/hexane/MeOH, 2:2:1, to EtOAc/MeOH/HOAc, 5:3:0.01) to give 45 $\mathrm{mg}(80 \%)$ of $\mathbf{6 3}$ as an off-white solid, $\mathrm{mp} 260{ }^{\circ} \mathrm{C}(\mathrm{dec})$. IR 3328, 2902, 1617, 1603, 1035 $\mathrm{cm}^{-1} ;{ }^{1} \mathrm{H}$ NMR $\delta 1.27$ (t, $J=6.9 \mathrm{~Hz}, 3 \mathrm{H}, \mathrm{OCH}_{2} \mathrm{CH}_{3}$ ), 1.81 (bs, 6H, $\mathrm{AdCH}_{2}$ ), 2.05 (bs, 3H, $\mathrm{AdCH}), 2.17$ (bs, $\left.6 \mathrm{H}, \mathrm{AdCH}_{2}\right), 3.93\left(\mathrm{~m}, J=6.9 \mathrm{~Hz}, 2 \mathrm{H}, \mathrm{OCH}_{2} \mathrm{CH}_{3}\right), 6.46$ (dd, $J=17.4,15.0$ $\mathrm{Hz}, 1 \mathrm{H}, \mathrm{CH}=\mathrm{CHP}), 6.76\left(\mathrm{~d}, J=7.8 \mathrm{~Hz}, 1 \mathrm{H}, 5^{\prime}-\mathrm{ArH}\right), 7.06\left(\mathrm{dd}, J=7.8,2.1 \mathrm{~Hz}, 1 \mathrm{H}, 6^{\prime}-\mathrm{ArH}\right)$, $7.18\left(\mathrm{~d}, J=2.1 \mathrm{~Hz}, 1 \mathrm{H}, 2^{\prime}-\mathrm{ArH}\right), 7.23(\mathrm{dd}, J=17.4,15.0 \mathrm{~Hz}, 1 \mathrm{H}, \mathrm{CH}=\mathrm{CHP}), 7.29$ (d, $J=7.8$ $\mathrm{Hz}, 1 \mathrm{H}, 6-\mathrm{ArH}), 7.43$ (d, $J=7.8 \mathrm{~Hz}, 1 \mathrm{H}, 5-\mathrm{ArH}), 7.57 \mathrm{ppm}$ (s, 1H, 3-ArH). HRMS calcd $\mathrm{C}_{26} \mathrm{H}_{30} \mathrm{ClO}_{4} \mathrm{P}[\mathrm{M}-\mathrm{H}]^{-}$471.1492, found 471.1487 .

\section{Computational Studies}

Conformational libraries were prepared for a training set of 55 AHPN (1) analogues including 24 active analogues using $30^{\circ}$ increment grid rotations for all rotatable bonds employing the CHARMm forcefield in Accelerys Quanta, a continuum dielectric constant of 80 and no potential truncation for correlation with their apoptotic activity at $1.0 \mu \mathrm{M}$ against MDAMB-231 breast cancer cells after treatment for $96 \mathrm{~h}$. Most of the analogues had a carboxylate moiety and a hydroxyl group adjacent to a bulky hydrophobic group as in AHPN ( $\mathbf{1}$ in Figure 1) and variable hydrophobic groups and ring systems. While not all of the analogues with these features were apoptosis inducers, these moieties appeared to be core-recognition elements inasmuch as their removal eliminated apoptotic acitivity. An initial pharmacophore/overlap rule was developed using the in-house program MOL-MOD, ${ }^{74,75}$ which took as input trial pharmacophore hypotheses in the form of (i) either ligand or 'receptor-based' sites of hydrogen-bond acceptors/donors, hydrophobic moieties, centroids, or user-defined criteria; (ii) an energy window for the low-energy conformations to employ in pharmacophore testing; and (iii) a distance criterion (cutoff) for pharmacophoric distances in order to determine whether a conformation of each ligand had a 3D-distance matrix between the pharmacophore points in common with at least one conformation of each of the other ligands in the training set. Any pharmacophore found within the energy and distance criteria was reported along with all conformers of each analogue complying with the pharmacophore. The program also output a 
superposition of the analogues at their pharmacophore points for use in 3D-QSAR. Following development of the initial apoptosis pharmacophore for these compounds, the properties of all analogues in their conformations complying with the pharmacophore definition were evaluated using a combination of semiempirical quantum mechanics, a MOPAC-7 AM1 Hamiltonian, 76 density functional theory as incorporated in Gaussian ${ }^{77}$ and Jaguar (Schrödinger, Portland, OR), and the comparative molecular similarity index analysis (CoMSIA) field descriptors employed in Tripos QSAR (St. Louis, MO). The validity of the MOLMOD pharmacophore developed from the training set was assessed by using the overlap rule in 3DQSAR (CoMSIA). Models predictive of the percentage of apoptosis of MDA-MB-231 breast cancer cells were developed and used to predict the percentage of apoptosis of MDA-MB-231 breast cancer cells of analogues not included in building the CoMSIA models. A fragment QSAR model was constructed using the isosteric polar/H-bond acceptor replacements shown in Table 3 for the 3-Cl-AHPC carboxyl group. In an effort to understand the SAR of these substitutions we computed: (i) frontier orbital energetics, (ii) Sterimol parameters, (iii) group hydrophobicities, (iv) volumes, (v) areas, (vi) solvent-accessible surface areas, (vii) polar and nonpolar volumes, (viii) globularities, (ix) electrostatic potentials on the van der Waals surface using MOPACAM1-derived properties developed by the in-house program GRAPHA and (x) solvation energies and raw $\mathrm{p} K_{\mathrm{a}}$ values using density functional theory evaluation. The raw $\mathrm{p} K_{\mathrm{a}}$ values were computed from unscaled/uncorrected gas-phase protonation energies. ${ }^{58}$ Combinations of 19 properties were used in several SAR models to interrogate the data for $50 \%$ proliferation inhibition ( $\mathrm{IC}_{50}$ value) of KG-1, H292, MDA-MB-231, and Du-145 cancer cells in terms of fundamental changes in the polar region. We were able to obtain predictive models for all of the data sets.

\section{Biology}

Cell Growth-Cancer cell lines were obtained from ATCC (Manassas, VA) and grown in DMEM (MDA-MB-231 breast cancer) or RPMI-1640 medium (H292 lung cancer and Du-145 prostate cancer) containing $10 \%$ fetal bovine serum (FBS; Tissue Culture Biologicals, Tulare, $\mathrm{CA}$ ) at $37{ }^{\circ} \mathrm{C}$ under $6 \% \mathrm{CO}_{2}$. MDA-MB-231 cells were also grown and cultured in DMEM/ F-12 medium supplemented with 5\% heat-inactivated FBS, as we have previously described. ${ }^{6}$ KG-1 cells were obtained from Dr. H. Phillip Koeffler (UCLA, Cedars-Sinai Medical Center, Los Angeles, CA) and were grown in RPMI-1640 medium supplemented with 5\% heatinactivated FBS and gentamycin $(10 \mu \mathrm{g} / \mathrm{mL})$. Retinoid-resistant HL-60R leukemia cells were obtained from Dr. Steve Collins (University of Washington, Seattle) and grown under the same conditions.

Cryopreserved, pooled primary human microvascular endothelial (HMVE) cells (Clonetics, San Diego, CA) were grown in endothelial cell growth medium EGM-MV (Clonetics) or in MEV growth medium containing 5\% fetal calf serum plus the growth factors and antimicrobials in the accompanying kit (Clonetics). Human dermal microvascular endothelial (HMVE) cells (Cambrex Bioscience, Walkersville, MD) were grown and maintained in EGM-MV medium (Cambrex).

\section{Growth Inhibition}

Cells ( $4 \times 10^{3} /$ well in 96-well plates for MDA-MB-231 or $2 \times 10^{3} /$ well for H292 and Du-145) were allowed to attach for $24 \mathrm{~h}$ and then treated for $72 \mathrm{~h}$ with each analogue dissolved in $\mathrm{Me}_{2} \mathrm{SO}$ or $\mathrm{Me}_{2} \mathrm{SO}$ alone $\left(0.1 \% \mathrm{Me}_{2} \mathrm{SO}\right.$ final concentration). Media and compounds were replaced after $48 \mathrm{~h}$. The number of viable cells was determined using the 3-(4,5dimethylthiazol-2-yl)-5-(3-carboxymethoxyphenyl)-2-(4-sulfophenyl)-2H-tetrazolium inner salt (MTS) reduction assay (Cell Titer 96 AQueous Non-radioactive Cell Proliferation Assay, Promega, Madison, WI). Three replicates were done at each concentration. 
KG-1, HL-60R, and MDA-MB-231 cells were seeded in six-well plates containing $3 \mathrm{~mL}$ of media plus 5\% FBS per well and incubated overnight. Compounds were then added in $\mathrm{Me}_{2} \mathrm{SO}$ ( $0.1 \%$ final $\mathrm{Me}_{2} \mathrm{SO}$ concentration), and cells were incubated at various concentrations for the cited times and harvested. Cell numbers were determined using a hemocytometer for counting as we described. ${ }^{6}$ HMVE cells $\left(3 \times 10^{3}\right.$ in $200-\mu \mathrm{L}$ medium/well in 96 -well plates) were allowed to attach for $24 \mathrm{~h}$. Compounds dissolved in $\mathrm{Me}_{2} \mathrm{SO}$ were added to give 100, 125, 250, and 500$\mathrm{nM}$ final concentrations (final $\mathrm{Me}_{2} \mathrm{SO}$ concentration $\leq 0.1 \%$ ). Medium and test compound were replaced every $48 \mathrm{~h}$. After 7 days of treatment, cell growth was determined by Alamar blue staining (BioSource, Camarillo, CA) and measuring emission at $590 \mathrm{~nm}$ after excitation at 530 $\mathrm{nm}$ by using a fluorimeter (Cytoflor, ABI, Foster City, CA). Results shown in Table 2 are averages of five replicates. HMVE cells $\left(1 \times 10^{4}\right.$ in $1.0 \mathrm{~mL}$ of EGM-MV medium/well $)$ were plated into 24-well plates and incubated for $1 \mathrm{~h}$ at $37^{\circ} \mathrm{C}$. Compounds in $\mathrm{Me}_{2} \mathrm{SO}$ or $\mathrm{Me}_{2} \mathrm{SO}$ alone $\left(0.5 \%\right.$ final concentration) were added. After 72 -h incubation at $37^{\circ} \mathrm{C}$, cells were detached using trypsin/EDTA and counted using a hemocytometer. Three replicates were performed for the experiments shown in Figure 6.

\section{Cell Apoptosis}

KG-1 and HL-60R leukemia and MDA-MB-231 breast cancer cells were seeded and incubated as described in the growth inhibition experiments. Apoptotic cells were identified using acridine orange staining as we have described. ${ }^{6}$

HMVE cells $\left(6 \times 10^{4} /\right.$ well $)$ were seeded in EGM-MV medium into 24-well plates. After a 6$\mathrm{h}$ incubation at $37^{\circ} \mathrm{C}$, cells were further incubated with medium containing various concentrations of 3-Cl-AHPC or $1.0 \mu \mathrm{M}$ doxorubicin (Sigma, St. Louis, MO) in $\mathrm{Me}_{2} \mathrm{SO}$, or $\mathrm{Me}_{2} \mathrm{SO}$ alone (control) ( $0.5 \%$ final $\mathrm{Me}_{2} \mathrm{SO}$ concentration) for $20 \mathrm{~h}$ more. Cells were lysed, lysates were centrifuged, and the supernate was analyzed for cytoplasmic histone-associated DNA fragments indicative of apoptosis-induced DNA laddering using the Cell Death Detection ELISA $^{\text {PLUS }}$ kit (Roche Diagnostics, Indianapolis, IN) according to the manufacturer's protocol and a microtiter plate reader (Fisher Scientific, Pittsburgh, PA). Experiments were done in triplicate. This protocol was used to obtain data shown in Figure 7.

\section{HMVE Cell Migration}

Migration was assayed using 6.5 -mm Transwell Chambers having $8 \mu \mathrm{m}$-diameter pores (Corning Costar, Cambridge, MA). Their membrane undersides were coated overnight at $4^{\circ}$ C with Matrigel (Becton Dickinson Labware, Bedford, MA) $(30 \mu \mathrm{g} / \mathrm{mL})$ in EBM medium. Chambers were blocked for $2 \mathrm{~h}$ with a solution of $1 \%$ bovine serum albumin in phosphatebuffered saline, $\mathrm{pH}$ 7.2, and then transferred to wells in 24-well plates filled with EGM-MV medium $(500 \mu \mathrm{L} /$ well). HMVE cells ( $80 \%$ confluent) were released with enzyme-free cell dissociation buffer (Gibco, Long Island, NY), washed, and resuspended in medium containing 3-Cl-AHPC (5) $\left(0.05,0.5,5.0,50\right.$, and $500 \mathrm{nM}$ final concentration) in $\mathrm{Me}_{2} \mathrm{SO}$ or $\mathrm{Me}_{2} \mathrm{SO}$ alone ( $0.01 \%$ final $\mathrm{Me}_{2} \mathrm{SO}$ concentration). Cells $\left(40 \times 10^{4} /\right.$ well $)$ in $200 \mu \mathrm{L}$ of medium were placed in the Transwells, and migration to the underside of the precoated filter was examined after 5$\mathrm{h}$ incubation at $37^{\circ} \mathrm{C}$. Membranes were fixed and stained with Diff-Quick (Dade Diagnostics, Aguada, PR). Three high-power microscope fields were counted in each replicate well, and results were expressed as mean number of cells per field \pm SD of three replicates.

\section{HMVE Tubule Formation}

Tube formation was assayed as described by Nangia-Makker et al. ${ }^{78}$ with some modification. Matrigel $(100 \mu \mathrm{L})$ liquified on ice was added to 96 -well plates and then heated at $37^{\circ} \mathrm{C}$ for 1 $\mathrm{h}$ to induce gelation. Trypsinized HMVE cells $\left(5 \times 10^{4}\right.$ in $150 \mu \mathrm{L}$ EGM-MV medium/well $)$ were plated in each well. After a 1-h incubation at $37^{\circ} \mathrm{C}$, cells were incubated at $37^{\circ} \mathrm{C}$ with $0.25 \mu \mathrm{M}$ or $1.0 \mu \mathrm{M} 3-\mathrm{Cl}$-AHPC (5) in $\mathrm{Me}_{2} \mathrm{SO}$ or $\mathrm{Me}_{2}-\mathrm{SO}$ alone (0.05\% final concentration) 
for $18 \mathrm{~h}$. Tubule formation was assessed using an Optiphot microscope (Nikon, Melville, KN) attached to a camera (Coolsnap Pro) having $1392 \times 1040$ resolution (Media Cybernetics, Silver Spring, MD). Phase-contrast images were captured using Image-Pro Express software (Media Cybernetics) and a PlanApo 10x objective (Nikon) with a 0.5 numerical aperture. Total tube length was determined using NIH Image software (NIMH, Rockville, MD). Four random fields were measured for each well of three replicates.

\section{Inhibition of PTP Activity}

The phosphatase-catalyzed hydrolysis of 6,8-difluoro-4-methylumbelliferyl phosphate (Invitrogen, Carlsbad, CA) in the presence of each compound in $\mathrm{Me}_{2} \mathrm{SO}$ or $\mathrm{Me}_{2} \mathrm{SO}$ alone (5\% final concentration) was assayed at $30^{\circ} \mathrm{C}$ in $60 \mu \mathrm{L}$ of $0.15 \mathrm{M}$ Bis-Tris buffer, $\mathrm{pH} 6.0$, having 150-mM ionic strength (adjusted with $\mathrm{NaCl}$ ) and containing $1.0 \mathrm{mM}$ dithiothreitol per well in 96-well plates. SHP-2 (gift of Dr. Gen-Sheng Feng, Burnham Institute) was at $5 \mathrm{nM}$ and CD45 (BioMol, Plymouth Meeting, PA) at $1 \mathrm{nM}$. Compounds were assayed at 0, 0.032, 0.16, 0.8, $4.0,20.0,100$, and $500 \mu \mathrm{M}$. The initial reaction rate at a fixed substrate concentration, which was equal to the corresponding $K_{\mathrm{m}}$ value of $100 \mu \mathrm{M}$ for SHP-2 and CD 45 , was determined by measuring the 460-nm emission after excitation of the fluorescent cleavage product, 6,8difluoro-7-hydroxy-4-methylcoumarin, at $360 \mathrm{~nm}$ using a FLx 800 microplate reader (Bio-Tek Instruments, Winooski, VT). Nonenzymatic hydrolysis of the substrate was corrected by measuring the $\mathrm{Me}_{2} \mathrm{SO}$ control without enzyme. $\mathrm{IC}_{50}$ values were determined by plotting the relative activity versus inhibitor concentration using Prism software (GraphPad Software, San Diego, CA) and fitting to the equation $V_{\mathrm{i}} / V_{0}=\mathrm{IC}_{50} /\left(\mathrm{IC}_{50}+[\mathrm{I}]\right)$, where $V_{\mathrm{i}}$ was reaction velocity at inhibitor concentration [I], $V_{0}$ was the reaction velocity without inhibitor and $\mathrm{IC}_{50}=K_{\mathrm{i}}+$ $K_{\mathrm{i}}[\mathrm{S}] / K_{\mathrm{m}}$, where $K_{\mathrm{i}}$ was the dissociation constant for binding of inhibitor to enzyme, [S] was the substrate concentration, and $K_{\mathrm{m}}$ was the Michaelis-Menten constant.

\section{Assay for NR4A1 Expression by Western Blotting}

MDA-MB-231, H292, and DU145 cells were grown for $24 \mathrm{~h}$ in medium containing $10 \% \mathrm{FBS}$ and then treated with $1.0 \mu \mathrm{M} 3-\mathrm{Cl}-\mathrm{AHPC}(\mathbf{5})$ for 3 or $6 \mathrm{~h}$. Cell lysates were prepared and boiled in sodium dodecyl sulfate (SDS) sample buffer and resolved by SDS-8\% polyacrylamide gel electrophoresis. PAGE-separated proteins were transferred to nitrocellulose membranes, which were then blocked in 5\% milk in TBST buffer $(10 \mathrm{mM}$ Tris. $\mathrm{HCl}, \mathrm{pH} 8.0$, containing $150 \mathrm{mM} \mathrm{NaCl}$ and $0.05 \%$ Tween 20) for $30 \mathrm{~min}$, incubated with monoclonal anti-NGFI-B (rat NR4A1) antibody (1:1000 dilution) (R\&D, Minneapolis, MN) in 5\% milk in TBST for $2 \mathrm{~h}$ at room temperature, washed $(3 \times$ TBST), incubated in TBST containing horseradish peroxidaselinked anti-mouse immunoglobulin $\mathrm{G}$ for $1 \mathrm{~h}$ at room temperature, and washed $(3 \times \mathrm{TBST})$. Immunoreactive products were detected by chemiluminescence using an enhanced chemiluminescence system (Amersham, Piscataway, NJ).

\section{Receptor Binding Assay}

Expression of recombinant glutathione $S$-transferase (GST)-human SHP chimeric protein (GST-SHP), cell lysis, isolation of GST-SHP using glutathione-Sepharose beads, incubation of beads with $\left[5,5^{\prime}-{ }^{3} \mathrm{H}_{2}\right] \mathrm{AHPN}^{42}$ in the presence or absence of 3-Cl-AHPC (5), an analogue, or vehicle alone, and separation of bound from nonbound label were performed as we described. 14 Briefly, to GST-SHP (150-500 ng)-bound beads was added nonlabeled 5 or an analogue at a final concentration of $50 \mu \mathrm{M}$ in binding buffer $(0.4 \mathrm{~mL})$. This mixture was incubated on ice for $45 \mathrm{~min}$ before $\left[5,5^{\prime}-{ }^{3} \mathrm{H}_{2}\right]$ AHPN (5-nM final concentration) was added. Incubation was continued for $2 \mathrm{~h}$ at $4{ }^{\circ} \mathrm{C}$. Beads were then washed (binding buffer) and either added directly to the scintillation liquid or first eluted with $50 \mathrm{mM}$ sodium bicarbonate and $1 \%$ sodium dodecyl sulfate and the eluate added to scintillation fluid. Both methods gave similar results. 


\section{Acknowledgment}

We are grateful for support of this research by the following grants P01 CA51993 (M.I.D., J.A.F., X.-K. Z.), R01 CA109370 (M.I.D., J.A.F.), California Breast Cancer Research Program Grant 6XB-0018 (M.I.D., D.L.H., G.H.L.) and California Tobacco-Related Diseases Research Grant 11RT-0081 (M.I.D., X.-K. Z.).

\section{References}

1. Bernard BA, Bernardon JM, Delescluse C, Martin B, Lenoir MC, Maignan J, Charpentier B, Pilgrim WR, Reichert U, Shroot B. Identification of synthetic retinoids with selectivity for human nuclear retinoic acid receptor gamma. Biochem. Biophys. Res. Commun 1992;186:977-983. [PubMed: 1323296]

2. Charpentier B, Bernardon JM, Eustache J, Millois C, Martin B, Michel S, Shroot B. Synthesis, structure-affinity relationships, and biological activities of ligands binding to retinoic acid receptor subtypes. J. Med. Chem 1995;38:4993-5006. [PubMed: 8544175]

3. Shao ZM, Dawson MI, Li XS, Rishi AK, Sheikh MS, Han QX, Ordonez JV, Shroot B, Fontana JA. p53 independent $\mathrm{G}_{0} / \mathrm{G}_{1}$ arrest and apoptosis induced by a novel retinoid in human breast cancer cells. Oncogene 1995;11:493-504. [PubMed: 7630633]

4. Li XS, Rishi AK, Shao ZM, Dawson MI, Jong L, Shroot B, Reichert U, Ordonez J, Fontana JA. Posttranscriptional regulation of p21 WAF1/CIP1 expression in human breast carcinoma cells. Cancer Res 1996;56:5055-5062. [PubMed: 8895764]

5. Zhang Y, Dawson MI, Mohammad R, Rishi AK, Farhana L, Feng KC, Leid M, Peterson V, Zhang XK, Edelstein M, Eilander D, Biggar S, Wall N, Reichert U, Fontana JA. Induction of apoptosis of human B-CLL and ALL cells by a novel retinoid and its nonretinoidal analog. Blood 2002;100:29172925. [PubMed: 12351403]

6. Dawson MI, Harris DL, Liu G, Hobbs PD, Lange CW, Jong L, Bruey-Sedano N, James SY, Zhang XK, Peterson VJ, Leid M, Farhana L, Rishi AK, Fontana JA. Antagonist analogue of 6-[3'-(1adamantyl)-4'-hydroxyphenyl]-2-naphthalene-carboxylic acid (AHPN) family of apoptosis inducers that effectively blocks AHPN-induced apoptosis but not cell-cycle arrest. J. Med. Chem 2004;47:3518-3536. [PubMed: 15214780]

7. Farhana L, Dawson MI, Fontana JA. Apoptosis induction by a novel retinoid-related molecule requires nuclear factor- $\kappa \mathrm{B}$ activation. Cancer Res 2005;65:4909-4917. [PubMed: 15930313]

8. Zhang Y, Dawson MI, Ning Y, Polin L, Parchment RE, Corbett T, Mohamed AN, Feng KC, Farhana L, Rishi AK, Hogge D, Leid M, Peterson VJ, Zhang XK, Mohammad R, Lu JS, Willman C, VanBuren E, Biggar S, Edelstein M, Eilender D, Fontana JA. Induction of apoptosis in retinoid-refractory acute myelogenous leukemia by a novel AHPN analog. Blood 2003;102:3743-3752. [PubMed: 12893763]

9. Han YH, Cao X, Lin B, Lin F, Kolluri SK, Stebbins J, Reed JC, Dawson MI, Zhang X-K. Regulation of Nur77 nuclear export by c-Jun N-terminal kinase and Akt. Oncogene 2006;25:2974-2986. [PubMed: 16434970]

10. Widschwendter M, Berger J, Muller HM, Zeimet AG, Marth C. Epigenetic downregulation of the retinoic acid receptor-beta2 gene in breast cancer. J. Mammary Gland Biol. Neoplasia 2001;6:193201. [PubMed: 11501579]

11. Lotan R. Retinoids and their receptors in modulation of differentiation, development, and prevention of head and neck cancers. Anticancer Res 1996;16:2415-2419. [PubMed: 8816844]

12. Lynch CJ, Milner J. Loss of one p53 allele results in four-fold reduction of p53 mRNA and protein: A basis for p53 haplo-insufficiency. Oncogene 2006;25:3463-3470. [PubMed: 16449974]

13. Hollstein M, Sidransky D, Vogelstein B, Harris CC. p53 mutations in human cancers. Science 1991;253:49-53. [PubMed: 1905840]

14. Farhana L, Dawson MI, Leid M, Wang L, Moore DD, Liu G, Xia Z, Fontana JA. Adamantylsubstituted retinoid-related molecules bind small heterodimer partner and modulate the Sin3A repressor. Cancer Res 2007;67:318-325. [PubMed: 17210713]

15. Borgius LJ, Steffensen KR, Gustafsson JA, Treuter E. Glucocorticoid signaling is perturbed by the atypical orphan receptor and corepressor SHP. J. Biol. Chem 2002;277:49761-49766. [PubMed: 12324453] 
16. Brendel C, Schoonjans K, Botrugno OA, Treuter E, Auwerx J. The small heterodimer partner interacts with the liver $\mathrm{X}$ receptor alpha and represses its transcriptional activity. Mol. Endocrinol 2002;16:2065-2076. [PubMed: 12198243]

17. Gobinet J, Carascossa S, Cavailles V, Vignon F, Nicolas JC, Jalaguier S. SHP represses transcriptional activity via recruitment of histone deacetylases. Biochemistry 2005;44:6312-6320. [PubMed: 15835920]

18. Kassam A, Capone JP, Rachubinski RA. The short heterodimer partner receptor differentially modulates peroxisome proliferator-activated receptor alpha-mediated transcription from the peroxisome proliferator-response elements of the genes encoding the peroxisomal beta-oxidation enzymes acyl-CoA oxidase and hydratase-dehydrogenase. Mol. Cell. Endocrinol 2001;176:49-56. [PubMed: 11369442]

19. Klinge CM, Jernigan SC, Risinger KE, Lee JE, Tyulmenkov VV, Falkner KC, Prough RA. Short heterodimer partner (SHP) orphan nuclear receptor inhibits the transcriptional activity of aryl hydrocarbon receptor (AHR)/AHR nuclear translocator (ARNT). Arch. Biochem. Biophys 2001;390:64-70. [PubMed: 11368516]

20. Seol W, Chung M, Moore DD. Novel receptor interaction and repression domains in the orphan receptor SHP. Mol. Cell. Biol 1997;17:7126-7131. [PubMed: 9372944]

21. Yeo MG, Yoo YG, Choi HS, Pak YK, Lee MO. Negative cross-talk between Nur77 and small heterodimer partner and its role in apoptotic cell death of hepatoma cells. Mol. Endocrinol 2005;19:950-963. [PubMed: 15625237]

22. Dhanabal M, Jeffers M, Larochelle WJ. Anti-angiogenic therapy as a cancer treatment paradigm. Curr. Med. Chem. Anticancer Agents 2005;5:115-130. [PubMed: 15777219]

23. Blagosklonny MV. Prospective strategies to enforce selectively cell death in cancer cells. Oncogene 2004;23:2967-2975. [PubMed: 15077157]

24. Fenaux P, De Botton S. Retinoic acid syndrome. Recognition, prevention and management. Drug Saf 1998;18:273-279. [PubMed: 9565738]

25. Cheer SM, Foster RH. Alitretinoin. Am. J. Clin. Dermatol 2000;1:307-314. [PubMed: 11702321] discussion 315-316

26. Dawson MI, Chan RL, Derdzinski K, Hobbs PD, Chao WR, Schiff LJ. Synthesis and pharmacological activity of 6-[(E)-2-(2,6,6-trimethyl-1-cyclohexen-1-yl)ethen1-yl]- and 6-(1,2,3,4tetrahydro-1,1,4,4-tetramethyl-6-naphthyl)-2-naphthalenecarboxylic acids. J. Med. Chem 1983;26:1653-1656. [PubMed: 6195339]

27. Newton DL, Henderson WR, Sporn MB. Structure-activity relationships of retinoids in hamster tracheal organ culture. Cancer Res 1980;40:3413-3425. [PubMed: 6159964]

28. Strickland S, Breitman TR, Frickel F, Nurrenbach A, Hadicke E, Sporn MB. Structure-activity relationships of a new series of retinoidal benzoic acid derivatives as measured by induction of differentiation of murine F9 teratocarcinoma cells and human HL60 promyelocytic leukemia cells. Cancer Res 1983;43:5268-5272. [PubMed: 6577946]

29. Verma AK, Shapas BG, Rice HM, Boutwell RK. Correlation of the inhibition by retinoids of tumor promoter-induced mouse epidermal ornithine decarboxylase activity and of skin tumor promotion. Cancer Res 1979;39:419-425. [PubMed: 761215]

30. Sporn, MB.; Roberts, AB. Biological methods for analysis and assay of retinoids: Relationships between structure and activity. Chapter 5. In: Sporn, MB.; Roberts, AB.; Goodman, DS., editors. The Retinoids. Vol. 1. Orlando, FL: Academic Press, Inc.; 1984. p. 236-279.

31. Schiff, LJ.; Okamura, WH.; Dawson, MI.; Hobbs, PD. Structure-biological activity relationships of new synthetic retinoids on epithelial differentiation of cultured hamster trachea. In: Dawson, MI.; Okamura, WH., editors. Chemistry and Biology of Synthetic Retinoids. Boca Raton, FL: CRC Press; 1990. p. 307-363.

32. Dawson, MI.; Chao, W-R.; Hobbs, PD.; Delair, T. The inhibitory effects of retinoids on the induction of ornithine decarboxylase and the promotion of tumors in mouse epidermis. In: Dawson, MI; Okamura, WH., editors. Chemistry and Biology of Synthetic Retinoids. Boca Raton, FL: CRC Press; 1990. p. 385-466.

33. Cincinelli R, Dallavalle S, Nannei R, Carella S, De Zani D, Merlini L, Penco S, Garattini E, Giannini G, Pisano C, Vesci L, Carminati P, Zuco V, Zanchi C, Zunino F. Synthesis and structure-activity 
relationships of a new series of retinoid-related biphenyl-4-ylacrylic acids endowed with antiproliferative and proapoptotic activity. J. Med. Chem 2005;48:4931-4946. [PubMed: 16033272]

34. Parrella E, Gianni M, Fratelli M, Barzago MM, Raska IJ, Diomede L, Kurosaki M, Pisano C, Carminati P, Merlini L, Dallavalle S, Tavecchio M, Rochette-Egly C, Terao M, Garattini E. Antitumor activity of the retinoid related molecules, ST1926 and CD437, in F9 teratocarcinoma: Role of retinoic acid receptor $\gamma$ and retinoid-independent pathways. Mol. Pharmacol 2006;70:909924. [PubMed: 16788091]

35. Dawson MI, Hobbs PD, Peterson VJ, Leid M, Lange CW, Feng KC, Chen G, Gu J, Li H, Kolluri SK, Zhang X, Zhang Y, Fontana JA. Apoptosis induction in cancer cells by a novel analogue of 6-[3-(1adamantyl)-4-hydroxyphenyl]-2-naphthalene carboxylic acid lacking retinoid receptor transcriptional activation activity. Cancer Res 2001;61:4723-4730. [PubMed: 11406543]

36. Robertson KA, Emami B, Collins SJ. Retinoic acid-resistant HL-60R cells harbor a point mutation in the retinoic acid receptor ligand-binding domain that confers dominant negative activity. Blood 1992;80:1885-1889. [PubMed: 1327285]

37. Tashima T, Kagechika H, Tsuji M, Fukasawa H, Kawachi E, Hashimoto Y, Shudo K. Polyenylidene thiazolidinedione derivatives with retinoidal activities. Chem. Pharm. Bull. (Tokyo) 1997;45:18051813. [PubMed: 9396157]

38. Ebisawa M, Kawachi E, Fukasawa H, Hashimoto Y, Itai A, Shudo K, Kagechika H. Novel thiazolidinedione derivatives with retinoid synergistic activity. Biol. Pharm. Bull 1998;21:547-549. [PubMed: 9635519]

39. Yang DY. 4-Hydroxyphenylpyruvate dioxygenase as a drug discovery target. Drug News Perspect 2003;16:493-496. [PubMed: 14668946]

40. Renaud JP, Rochel N, Ruff M, Vivat V, Chambon P, Gronemeyer H, Moras D. Crystal structure of the RAR- $\alpha$ ligand-binding domain bound to all-trans retinoic acid. Nature 1995;378:681-689. [PubMed: 7501014]

41. Klaholz BP, Mitschler A, Belema M, Zusi C, Moras D. Enantiomer discrimination illustrated by highresolution crystal structures of the human nuclear receptor hRAR $\alpha$. Proc. Natl. Acad. Sci. U.S.A 2000;97:6322-6327. [PubMed: 10841540]

42. Fontana JA, Dawson MI, Leid M, Rishi AK, Zhang Y, Hsu CA, Lu JS, Peterson VJ, Jong L, Hobbs $\mathrm{P}$, Chao WR, Shroot B, Reichert U. Identification of a unique binding protein specific for a novel retinoid inducing cellular apoptosis. Int. J. Cancer 2000;86:474-479. [PubMed: 10797258]

43. Shipanova IN, Glomb MA, Nagaraj RH. Protein modification by methylglyoxal: Chemical nature and synthetic mechanism of a major fluorescent adduct. Arch. Biochem. Biophys 1997;344:29-36. [PubMed: 9244378]

44. Richardson RM, Pares X, Cuchillo CM. Chemical modification by pyridoxal 5'-phosphate and cyclohexane-1,2-dione indicates that Lys-7 and Arg-10 are involved in the p2 phosphate-binding subsite of bovine pancreatic ribonuclease A. Biochem. J 1990;267:593-599. [PubMed: 2111131]

45. Jiang ZY, Thorpe C. Modification of an arginine residue in pig kidney general acyl-coenzyme A dehydrogenase by cyclohexane-1,2-dione. Biochem. J 1982;207:415-419. [PubMed: 7165702]

46. Miyaura N, Suzuki A. Palladium-catalyzed cross-coupling reactions of organoboron compounds. Chem. Rev 1995;95:2457-2483.

47. Ek F, Manner S, Wistrand LG, Frejd T. Synthesis of fused tetrazole derivatives via a tandem cycloaddition and $\mathrm{N}$-allylation reaction and parallel synthesis of fused tetrazole amines. J. Org. Chem 2004;69:1346-1352. [PubMed: 14961689]

48. Mancuso AJ, Huang S-L, Swern D. Oxidation of long-chain and related alcohols to carbonyls by dimethyl sulfoxide "activated" by oxalyl chloride. J. Org. Chem 1978;43:2480-2482.

49. Cho BR, Chajara K, Oh HJ, Son KH, Jeon SJ. Synthesis and nonlinear optical properties of 1,3,5methoxy-2,4,6-tris(styryl)-benzene derivatives. Org. Lett 2002;4:1703-1706. [PubMed: 12000278]

50. Bouchain G, Leit S, Frechette S, Khalil EA, Lavoie R, Moradei O, Woo SH, Fournel M, Yan PT, Kalita A, Trachy-Bourget MC, Beaulieu C, Li Z, Robert MF, MacLeod AR, Besterman JM, Delorme D. Development of potential antitumor agents. Synthesis and biological evaluation of a new set of sulfonamide derivatives as histone deacetylase inhibitors. J. Med. Chem 2003;46:820-830. [PubMed: 12593661] 
51. Doyle MP, Siegfried B, Dellaria JF Jr. Alkyl nitrile-metal halide deamination reactions. 2. Substitutive deamination of arylamines by alkyl nitrites and copper(II) halides. A direct and remarkably efficient conversion of arylamines to aryl halides. J. Org. Chem 1977;42:2426-2430.

52. Musso DL, Clarke MJ, Kelley JL, Boswell GE, Chen G. Novel 3-phenylprop-2-ynylamines as inhibitors of mammalian squalene epoxidase. Org. Biomol. Chem 2003;1:498-506. [PubMed: 12926252]

53. Brown HC, Subrahmanyam C, Hamaoka T, Ravindran N. Vinylic organoboranes. 13. A convenient stereospecific synthesis of $(Z)$-1-halo-1-alkenes from 1-alkynes via $(E)$-1-alkenylborane derivatives with halogens. J. Org. Chem 1989;54:6068-6075.

54. Simoni D, Rossi M, Rondanin R, Mazzali A, Baruchello R, Malagutti C, Roberti M, Invidiata FP. Strong bicyclic guanidine base-promoted Wittig and Horner-Wadsworth-Emmons reactions. Org. Lett 2000;2:3765-3768. [PubMed: 11101414]

55. Miyano M, Dorn CR, Mueller RA. Prostaglandins. IV. A synthesis of F-type prostaglandins. A total synthesis of prostaglandin $F_{1}$. J. Org. Chem 1972;37:1810-1818. [PubMed: 5037449]

56. Zabell AP, Corden S, Helquist P, Stauffacher CV, Wiest O. Inhibition studies with rationally designed inhibitors of the human low molecular weight protein tyrosine phosphatase. Bioorg. Med. Chem 2004;12:1867-1880. [PubMed: 15051056]

57. Palacios F, Aparicio D, Vicario J. Synthesis of quinolinylphosphane oxides and -phosphonates from $\mathrm{N}$-arylimines derived from the phosphane oxides and phosphonates. Eur. J. Org. Chem 2002:41314136.

58. Klicic J, Friesner F, Liu S-Y, Guida W. Accurate prediction of acidity constants in aqueous solution via density functional theory and self-consistent reaction field methods. J. Phys. Chem. A 2002;106:1327-1335.

59. Li H, Kolluri SK, Gu J, Dawson MI, Cao X, Hobbs PD, Lin B, Chen G, Lu J, Lin F, Xie Z, Fontana JA, Reed JC, Zhang X. Cytochrome c release and apoptosis induced by mitochondrial targeting of nuclear orphan receptor TR3. Science 2000;289:1159-1164. [PubMed: 10947977]

60. Zhang Y, Huang Y, Rishi AK, Sheikh MS, Shroot B, Reichert U, Dawson M, Poirer G, Fontana JA. Activation of the p38 and JNK/SAPK mitogen-activated protein kinase pathways during apoptosis is mediated by a novel retinoid. Exp. Cell. Res 1999;247:233-240. [PubMed: 10047465]

61. Pfahl M, Piedrafita FJ. Retinoid targets for apoptosis induction. Oncogene 2003;22:9058-9062. [PubMed: 14663484]

62. Schubbert S, Lieuw K, Rowe SL, Lee CM, Li X, Loh ML, Clapp DW, Shannon KM. Functional analysis of leukemia-associated PTPN11 mutations in primary hematopoietic cells. Blood 2005;106:311-317. [PubMed: 15761018]

63. Yu WM, Daino H, Chen J, Bunting KD, Qu CK. Effects of a leukemia-associated gain-of-function mutation of SHP-2 phosphatase on interleukin-3 signaling. J. Biol. Chem 2006;281:5426-5434. [PubMed: 16371368]

64. Zhu XZ, Yu YZ, Fang YM, Liang Y, Lu QH, Xu RZ. Overexpression of Shp-2 is associated with the unlimited growth and apoptosis resistance of p210 bcr-abl-mediated chronic myeloid leukemia. Zhonghua Yi Xue Za Zhi 2005;85:1903-1906. [PubMed: 16255985]

65. Tauchi T, Miyazawa K, Feng GS, Broxmeyer HE, Toyama K. A coiled-coil tetramerization domain of BCR-ABL is essential for the interactions of SH2-containing signal transduction molecules. J. Biol. Chem 1997;272:1389-1394. [PubMed: 8995449]

66. Farhana L, Dawson MI, Huang Y, Zhang Y, Rishi AK, Reddy KB, Freeman RS, Fontana JA. Apoptosis signaling by the novel compound 3-Cl-AHPC involves increased EGFR proteolysis and accompanying decreased phosphatidylinositol 3-kinase and AKT kinase activities. Oncogene 2004;23:1874-1884. [PubMed: 14981538]

67. Tchilian EZ, Beverley PC. Altered CD45 expression and disease. Trends Immunol 2006;27:146-153. [PubMed: 16423560]

68. Miyachi H, Tanaka Y, Gondo K, Kawada T, Kato S, Sasao T, Hotta T, Oshima S, Ando Y. Altered expression of CD45 isoforms in differentiation of acute myeloid leukemia. Am. J. Hematol 1999;62:159-164. [PubMed: 10539882] 
69. Arsenou ES, Papadimitriou EP, Kliafa E, Hountala M, Nikolaropoulos SS. Effects of retinoic acid steroidal analogs on human leukemic HL60 cell proliferation in vitro and on angiogenesis in vivo. Anticancer Drugs 2005;16:151-158. [PubMed: 15655412]

70. Dawson MI, Zhang X-K. Discovery and design of retinoic acid receptor and retinoid X receptor classand subtype-selective synthetic analogs of all-trans-retinoic acid and 9-cis-retinoic acid. Curr. Med. Chem 2002;9:623-637. [PubMed: 11945128]

71. Peterson VJ, Barofsky E, Deinzer ML, Dawson MI, Feng KC, Zhang X-K, Madduru MR, Leid M. Mass-spectrometric analysis of agonist-induced retinoic acid receptor $\gamma$ conformational change. Biochem. J 2002;362:173-181. [PubMed: 11829754]

72. Rao AVR, Chakraborty TK, Reddy KL, Rao AS. An expeditious approach for the synthesis of $\beta$ hydroxylaryl $\alpha$-amino acids present in vancomycin. Tetrahedron Lett 1994;35:5043-5046.

73. Wittenberger SJ, Donner BG. Dialkyltin oxide mediated addition of trimethylsilyl azide to nitriles. A novel preparation of 5-substituted tetrazoles. J. Org. Chem 1993;58:4139-4141.

74. Harris DL, DeLorey TM. Determinants of recognition of ligands binding to benzodiazepine receptor/ $\mathrm{GABA}_{\mathrm{A}}$ receptors initiating sedation. Eur. J. Pharmacol 2000;401:271-287. [PubMed: 10936485]

75. Harris DL, Loew GH. Development and assessment of a 3D pharmacophore for ligand recognition of BDZR/GABA $\mathrm{A}_{\mathrm{A}}$ receptors initiating the anxiolytic response. Bioorg. Med. Chem 2000;8:25272538. [PubMed: 11092538]

76. Stewart JJP. A semiempirical molecular orbital program. MOPAC. J. Comput.-Aided Mol. Des 1990;4:1-105. [PubMed: 2197373]

77. Frisch, MJ.; Trucks, GW.; Schlegel, HB.; Scuseria, GE.; Robb, MA.; Cheeseman, JR.; Montgomery, JA., Jr; Vreven, T.; Kudin, KN.; Burant, JC.; Millam, JM.; Iyengar, SS.; Tomasi, J.; Barone, V.; Mennucci, B.; Cossi, M.; Scalmani, G.; Rega, N.; Petersson, GA.; Nakatsuji, H.; Hada, M.; Ehara, M.; Toyota, K.; Fukuda, R.; Hasegawa, J.; Ishida, M.; Nakajima, T.; Honda, Y.; Kitao, O.; Nakai, H.; Klene, M.; Li, X.; Knox, JE.; Hratchian, HP.; Cross, JB.; Bakken, V.; Adamo, C.; Jaramillo, J.; Gomperts, R.; Stratmann, RE.; Yazyev, O.; Austin, AJ.; Cammi, R.; Pomelli, C.; Ochterski, JW.; Ayala, PY.; Morokuma, K.; Voth, GA.; Salvador, P.; Dannenberg, JJ.; Zakrzewski, VG.; Dapprich, S.; Daniels, AD.; Strain, MC.; Farkas, O.; Malick, DK.; Rabuck, AD.; Raghavachari, K.; Foresman, JB.; Ortiz, JV.; Cui, Q.; Baboul, AG.; Clifford, S.; Cioslowski, J.; Stefanov, BB.; Liu, G.; Liashenko, A.; Piskorz, P.; Komaromi, I.; Martin, RL.; Fox, DJ.; Keith, T.; Al-Laham, MA.; Peng, CY.; Nanayakkara, A.; Challacombe, M.; Gill, PMW.; Johnson, B.; Chen, W.; Wong, MW.; Gonzalez, C.; Pople, JA. Gaussian 03, Revision C.02. Wallingford, CT: Gaussian, Inc.; 2004.

78. Nangia-Makker P, Honjo Y, Sarvis R, Akahani S, Hogan V, Pienta KJ, Raz A. Galectin-3 induces endothelial cell morphogenesis and angiogenesis. Am. J. Pathol 2000;156:899-909. [PubMed: 10702407] 
<smiles>[X]c1c(-c2ccc(O)c(C34CC5CC(CC(C5)C3)C4)c2)ccc2cc(C(=O)O)ccc12</smiles>

AHPN (1) 5-Cl-AHPN (2) $\quad X=\mathrm{Cl}$

5-Me-AHPN (3) $\quad X=M e$<smiles>[X]c1cc(/C=C/C(=O)O)ccc1-c1ccc(O)c(C23CC4CC(CC(C4)C2)C3)c1</smiles>

AHPC (4) $\quad \mathrm{X}=\mathrm{H}$

3-Cl-AHPC (5) $\mathrm{X}=\mathrm{Cl}$

3-A-AHPC (6) $\mathrm{X}=\mathrm{O}\left(\mathrm{CH}_{2}\right)_{3} \mathrm{NHAC}$<smiles>CC1=C(/C=C/C(C)=C/C=C/C(C)=C/C=C/C(=O)O)C(C)(C)CCC1</smiles>

trans-retinoic acid (7)<smiles>[R][R]([H])=C1CCC(C)(C)c2cc(-c3ccc4cc(C(=O)O)ccc4c3[R])ccc21</smiles><smiles>CC1(C)CCC(C)(C)c2cc(-c3ccc(/C=C/C(=O)O)cc3)ccc21</smiles>

TTNC (10)

Figure 1.

Structures of AHPN (1), 5-Cl-AHPN (2), 5-Me-AHPN (3), AHPC (4), 3-Cl-AHPC (5), 3-AAHPC (6), trans-RA (7), TTNN (8), 5-Me-TTNN (9), and TTNC (10). 

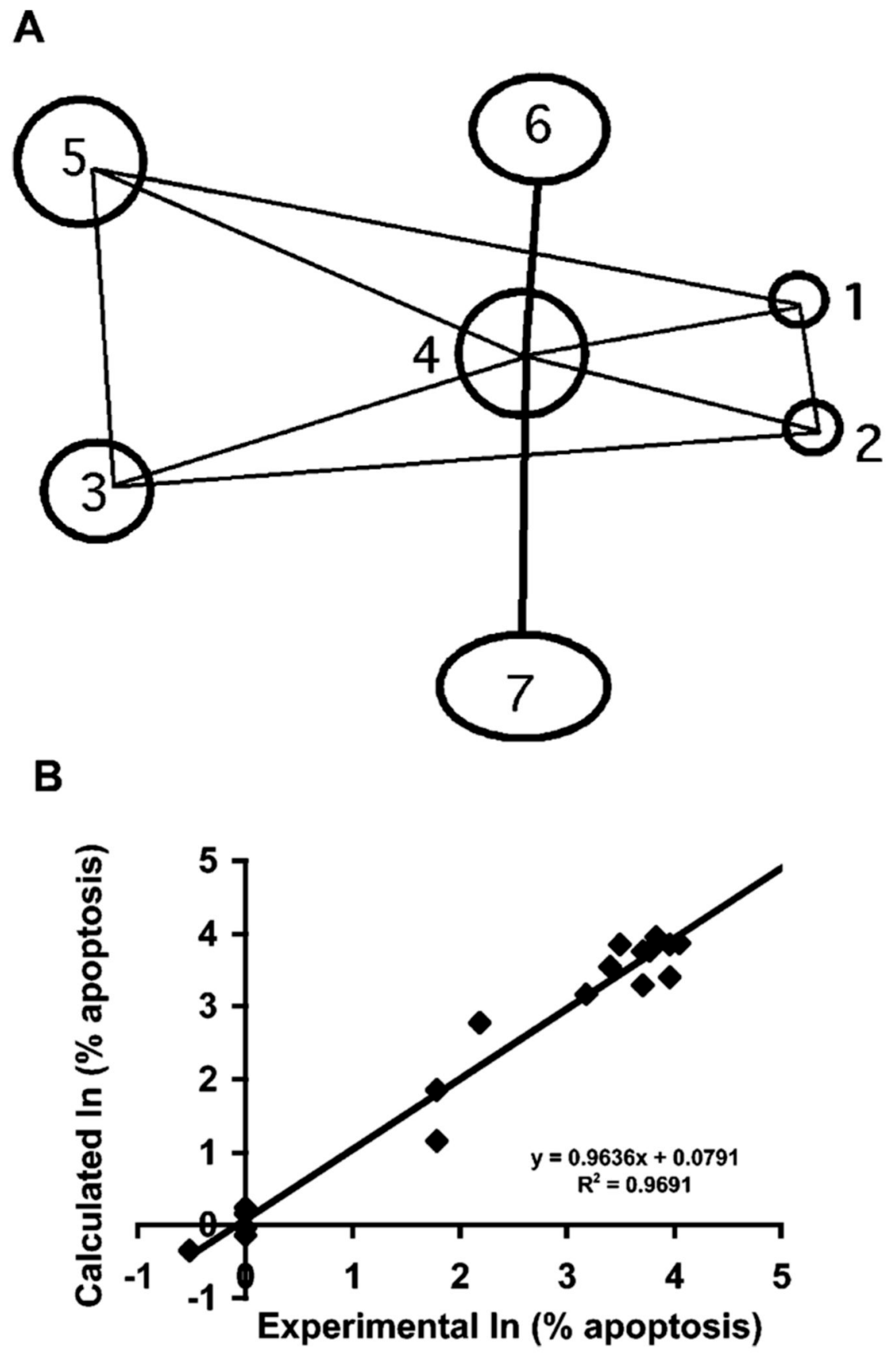

Figure 2.

Pharmacophoric model showing essential components of apoptosis-inducing activity used for the design of 3-Cl-AHPC and its analogues. (A) Three-dimensional seven-point pharmacophore descriptive of common elements in compounds in an AHPN analogue training set of which $44 \%$ were active at inducing MDA-MB-231 breast cancer cell apoptosis at 1.0 $\mu \mathrm{M}$ after a 96-h treatment. Components 1 and 2, hydrogen-bond acceptor; 3, hydrogen-bond donor/acceptor; 4, hydrophobic ring; 5, hydrophobic group; 6, sterically accessible hydrophobic region; and 7, sterically accessible polar-permissible region. Interpoint distances (A) \pm SD: $\Delta_{(1-2)}, 2.1 \pm 0.01 ; \Delta_{(1-3)}, 12.5 \pm 0.1 ; \Delta_{(1-4)}, 5.9 \pm 0.1 ; \Delta_{(1-5)}, 12.4 \pm 1.2 ; \Delta_{(2-3)}, 12.5$ $\pm 0.2 ; \Delta_{(2-4)}, 5.7 \pm 0.2 ; \Delta_{(3-5)}, 4.0 \pm 0.1 ; \Delta(4-5), 7.5 \pm 0.1 ; \Delta_{(4-6)} \geq 2.3$. (B) Comparative 
molecular similarity index analysis on 19 analogues using the overlap rule/ pharmacophore defined in (A) for prediction of induction of apoptosis of MDA-MB-231 breast cancer cells after treatment for $96 \mathrm{~h}$ at $1.0 \mu \mathrm{M}$ by comparing natural $\operatorname{logs}$ of experimental and calculated values. Predictive $R^{2}=0.78$; uncross-validated $R^{2} \pm \mathrm{SE}=0.95 \pm 0.45$. 

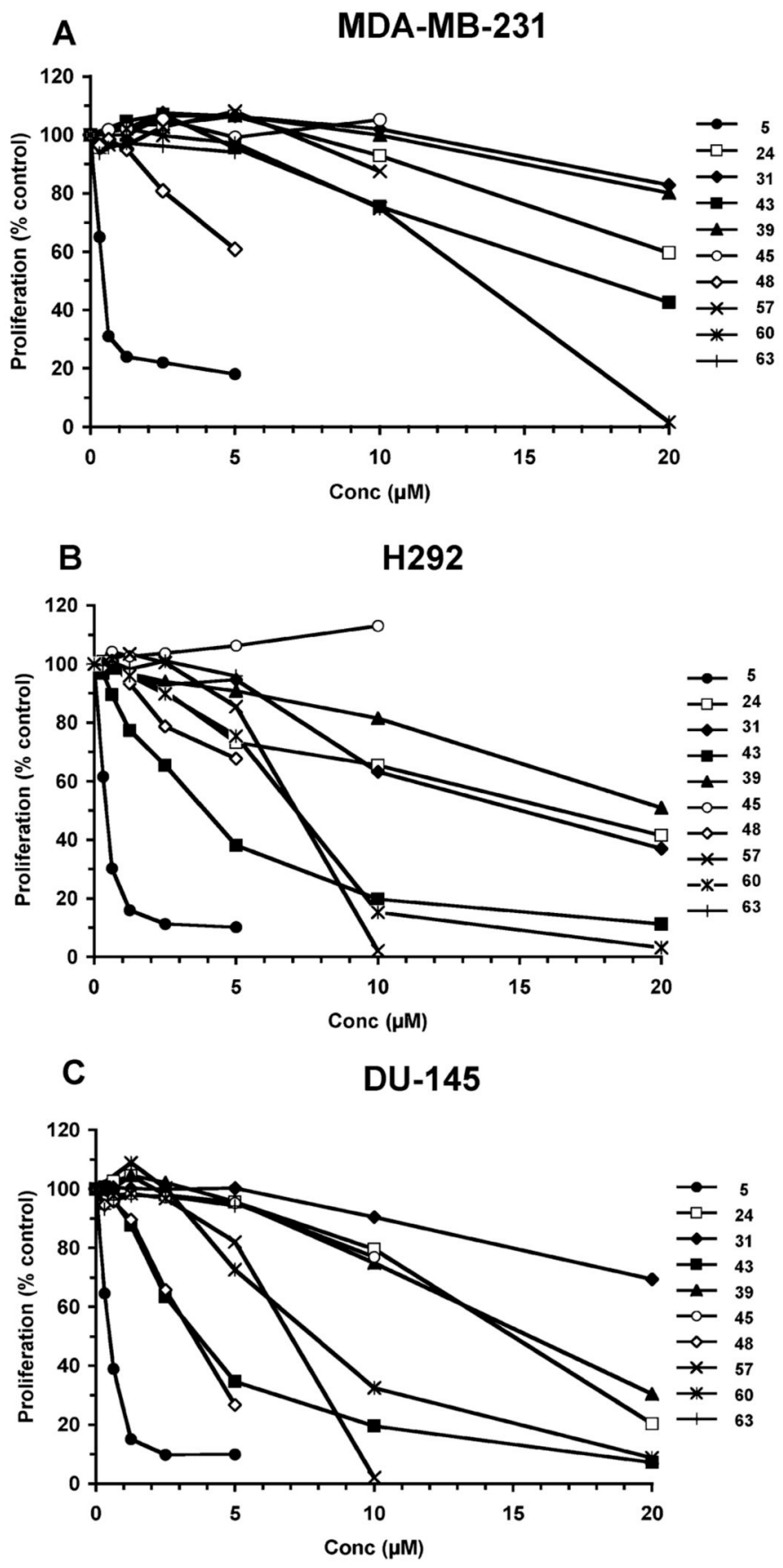

Figure 3.

Effects of 3-Cl-AHPC (5) and analogues $24,31,39,43,45,48,57,60$, and 63 on proliferation of trans-retinoic acid-refractory cancer cell lines after treatment for $72 \mathrm{~h}$ as described in the Experimental Section. (A) MDA-MB-231 breast cancer; (B) H292 lung cancer; and (C) DU-145 prostate cancer. Results shown are the averages of three replicates. Standard errors were below $10 \%$ 


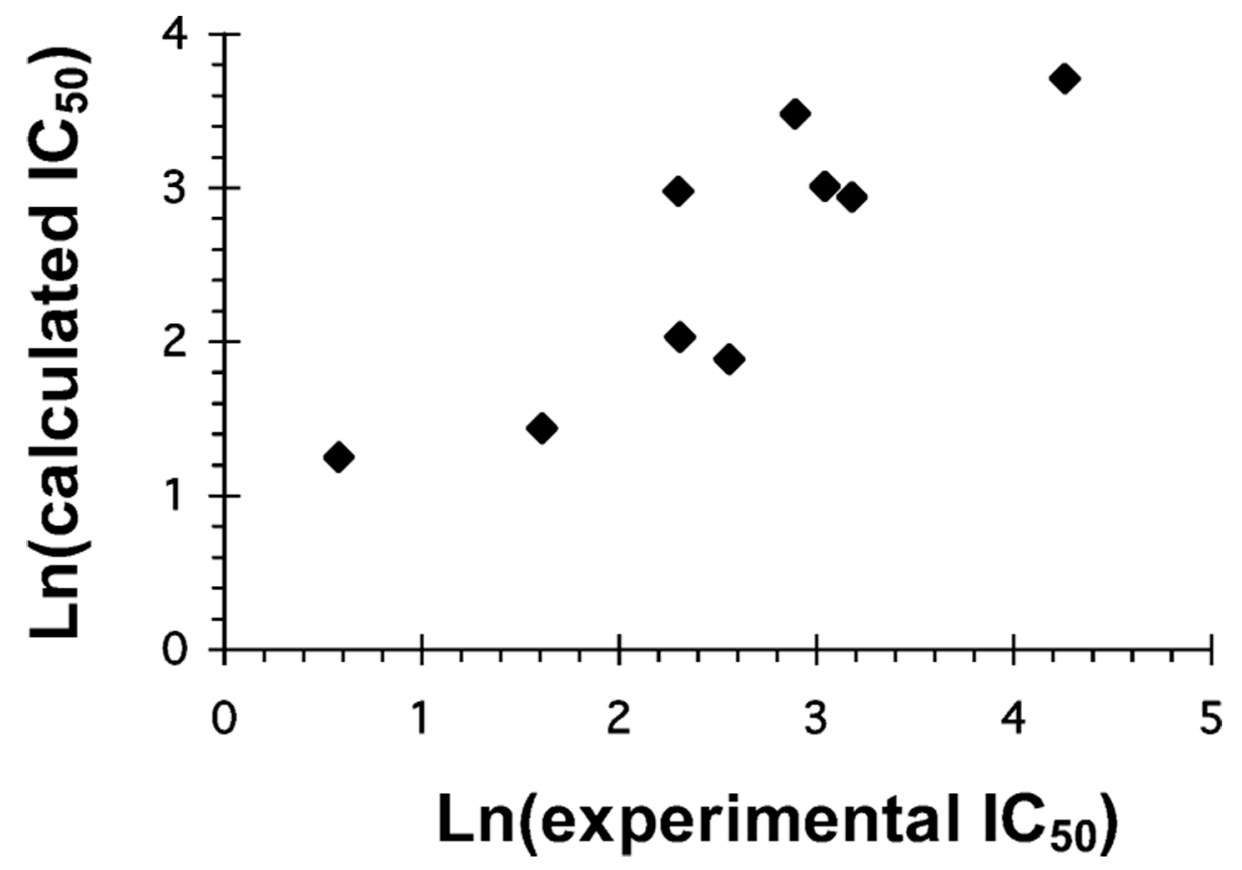

Figure 4.

Predictive fragment QSAR for isosteric replacements of hydrogen-bond acceptor region (components 1 and 2) in Figure 2 performed on 3-Cl-AHPC carboxylate and other polar termini shown in Table 3 and based on $\mathrm{IC}_{50}$ values for inhibition of MDA-MB-231 breast cancer proliferation after $96 \mathrm{~h}$ of treatment. The natural $\log$ of the antiproliferative activity in terms of $\mathrm{IC}_{50}$ values would be expressed as $4.14-0.30 L+14.9 \mathrm{MINIM}$-PS + 0.10POLAR_V, where $L$ is the longest length of the polar fragment; MINIM_PS is the minimum in the electrostatic potential on the van der Waals surface; and POLAR_V is volume of polar group, $\mathrm{R}^{2} \pm \mathrm{SE}=$ $0.75 \pm 0.6$. 


\section{A SHP-2}

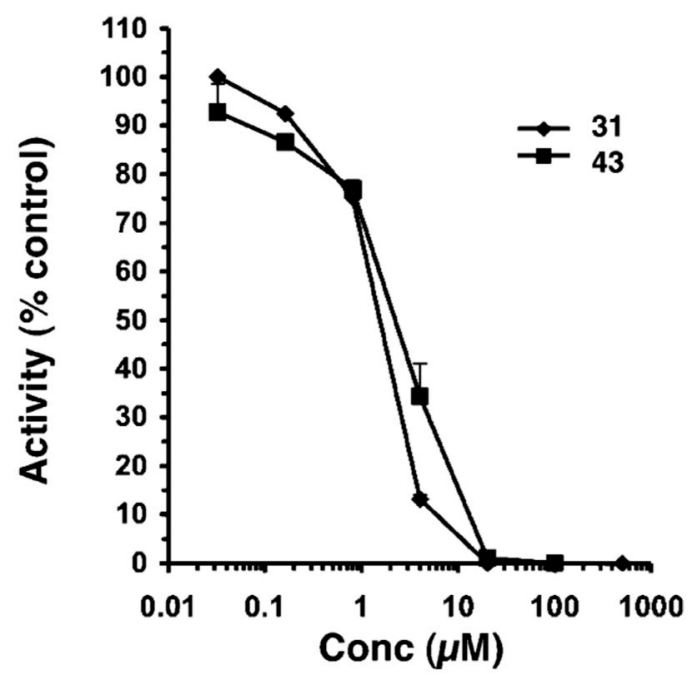

B $\quad$ CD45

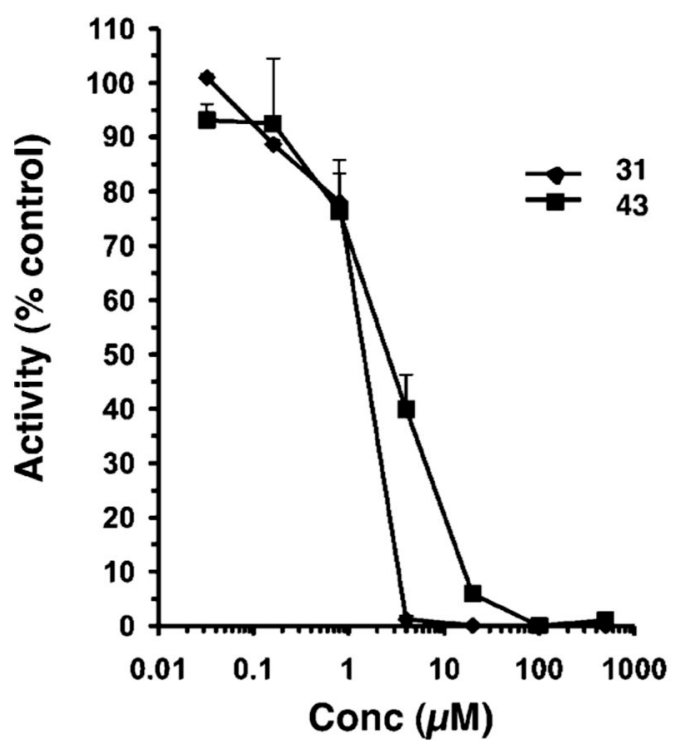

Figure 5.

3-Cl-AHPC analogues 31 and $\mathbf{4 3}$ inhibit the activity of SHP-2 and CD45 protein tyrosine phosphatases in cleaving 6,8-difluoro-4-methylumbelliferyl phosphate (100 $\mu \mathrm{M})$ as measured by fluorescence spectrometry of the cleavage product as described in the Experimental Section. SHP-2 and CD45 concentrations were $5 \mathrm{nM}$ and $1 \mathrm{nM}$, respectively. Tetrazole 31, solid diamond; thiazolidinedione 43 , solid square. Results shown are the average of duplicates \pm SE. 


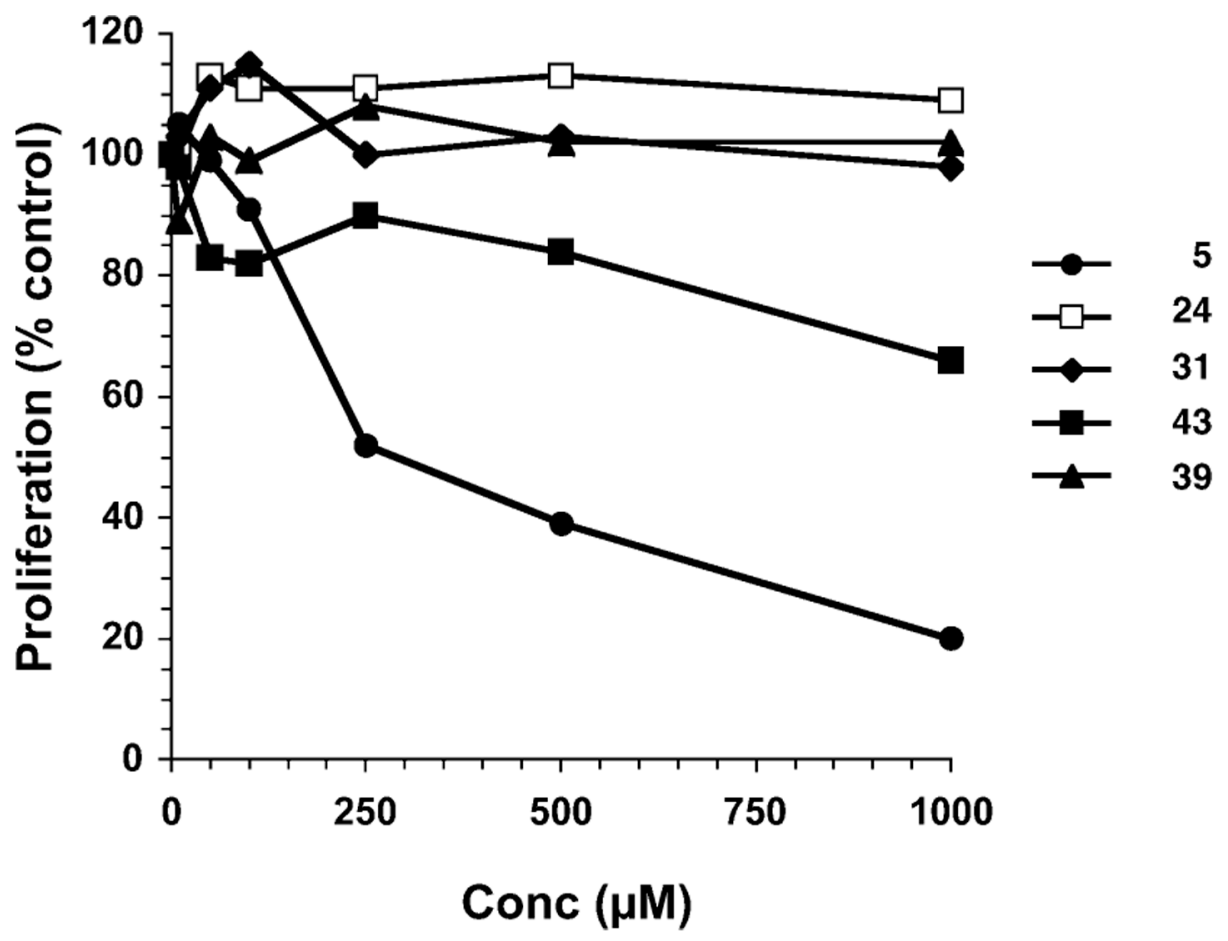

Figure 6.

3-Cl-AHPC (5) inhibits HMVE cell proliferation, whereas 43 is a poor inhibitor and 24, 31, and 39 do not inhibit. Cells were treated for $72 \mathrm{~h}$ at the indicated compound concentrations or with vehicle alone $\left(\mathrm{Me}_{2} \mathrm{SO}\right)$, detached by trypsinization and counted as described in the Experimental Section. A representative experiment is shown with proliferation expressed as the percent of vehicle alone-treated control. 


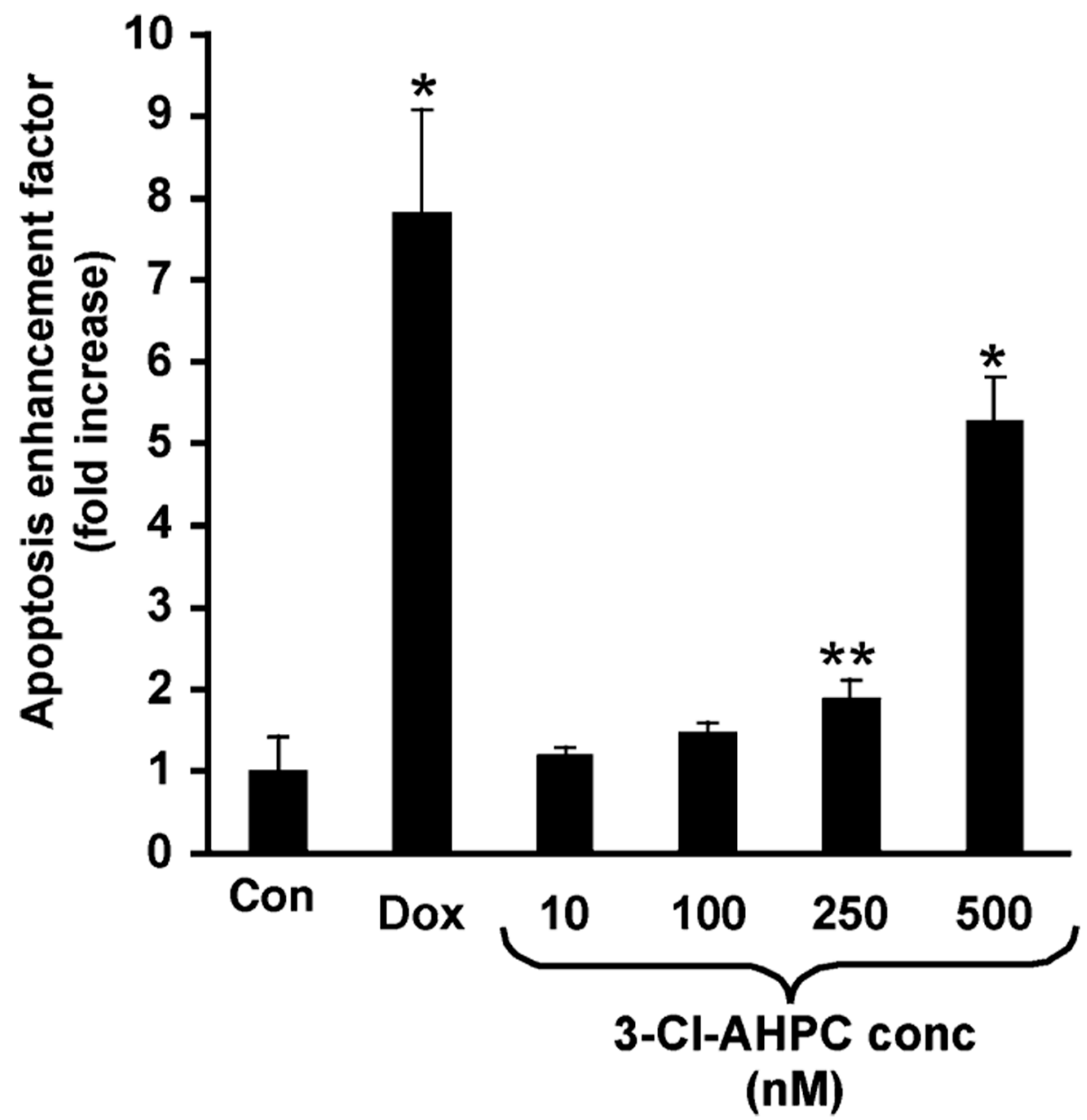

Figure 7.

3-Cl-AHPC (5) induces apoptosis of HMVE cells. Cells were incubated for $20 \mathrm{~h}$ in the presence of $\mathrm{Me}_{2} \mathrm{SO}$ (negative control), positive control doxorubicin $(1.0 \mu \mathrm{M})$, or $5(10 \mathrm{nM}$ to $500 \mathrm{nM})$ and assayed for apoptosis using a cell death detection ELISA as described in the the Experimental Section. Values represent the enrichment of mono- and oligonucleosome levels in treated sample relative to $\mathrm{Me}_{2} \mathrm{SO}$ control, and each bar represents the mean $\pm \mathrm{SD}$. Statistically significant differences (Student's t-test) compared with $\mathrm{Me}_{2} \mathrm{SO}$ control are indicated $(*, p<0.05 ; * *, p<0.001)$. 


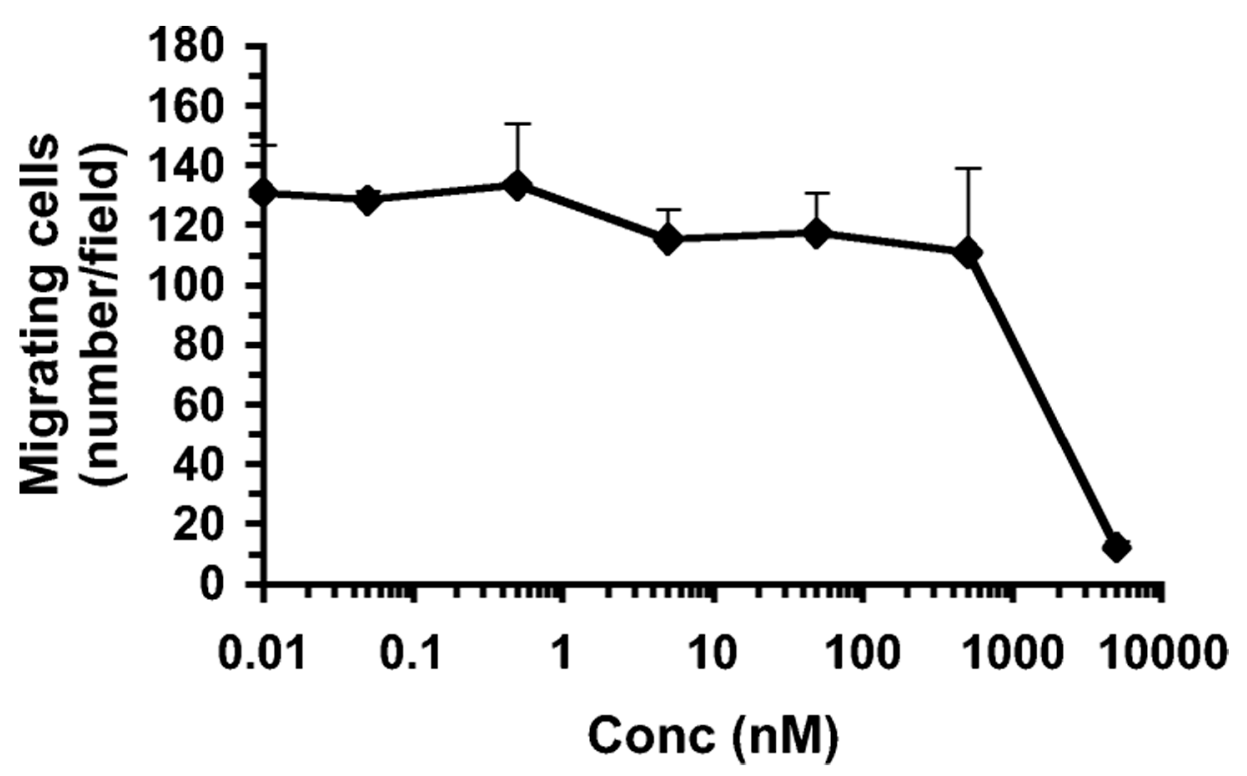

Figure 8.

3-Cl-AHPC (5) does not inhibit HMVE cell migration. Migration through Matrigel was measured after 5-h incubation with the indicated concentrations of $\mathbf{5}$ or with vehicle alone as described in the Experimental Section. Results shown represent the mean number of cells \pm $\mathrm{SD}$ of three fields in three replicates examined microscopically. 
A

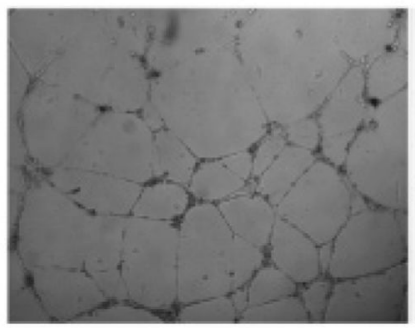

0.0

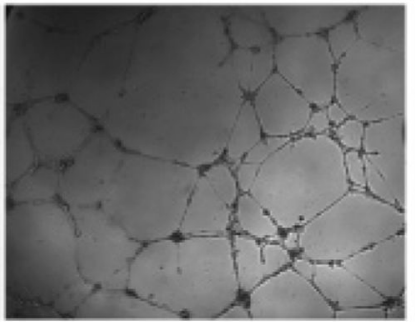

0.25

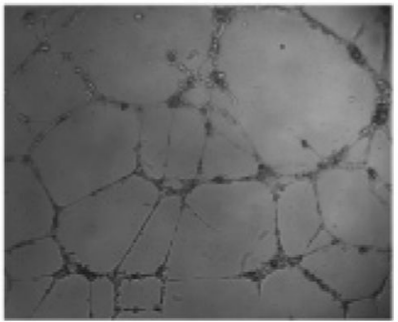

1.0

Conc $(\mu \mathrm{M})$

B

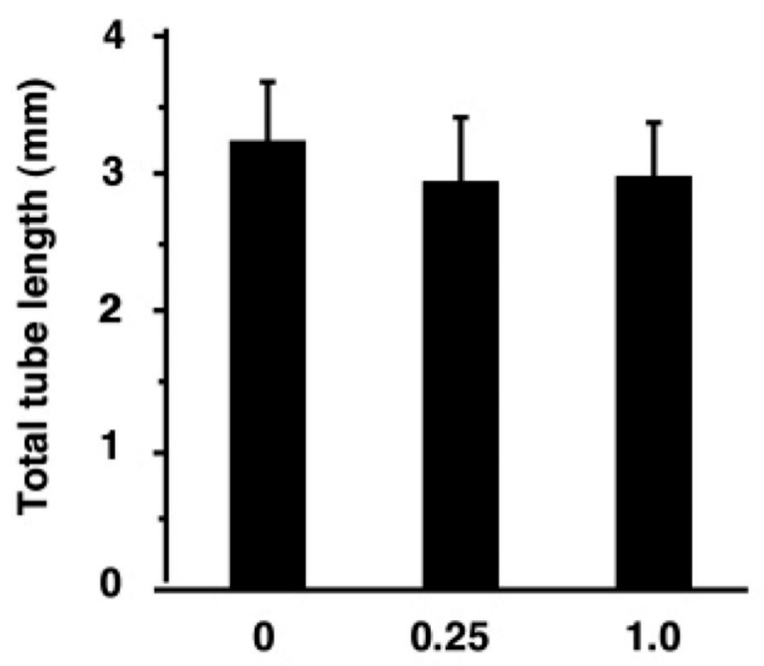

Conc ( $u$ M)

Figure 9.

3-Cl-AHPC (5) does not inhibit HMVE cell tubule formation or affect tube length. Cells in medium were layered onto Matrigel containing $0.25 \mu \mathrm{M}$ or $1.0 \mu \mathrm{M}$ 5, which was added as a $\mathrm{Me}_{2} \mathrm{SO}$ solution, or $\mathrm{Me}_{2} \mathrm{SO}$ alone. Tube formation was examined microscopically as described in the Experimental Section. (A) Results shown are representative of one field of four in triplicate experiments. (B) Total tube length was determined in four random fields for each triplicate experiment. Bars represent the means \pm SD. 


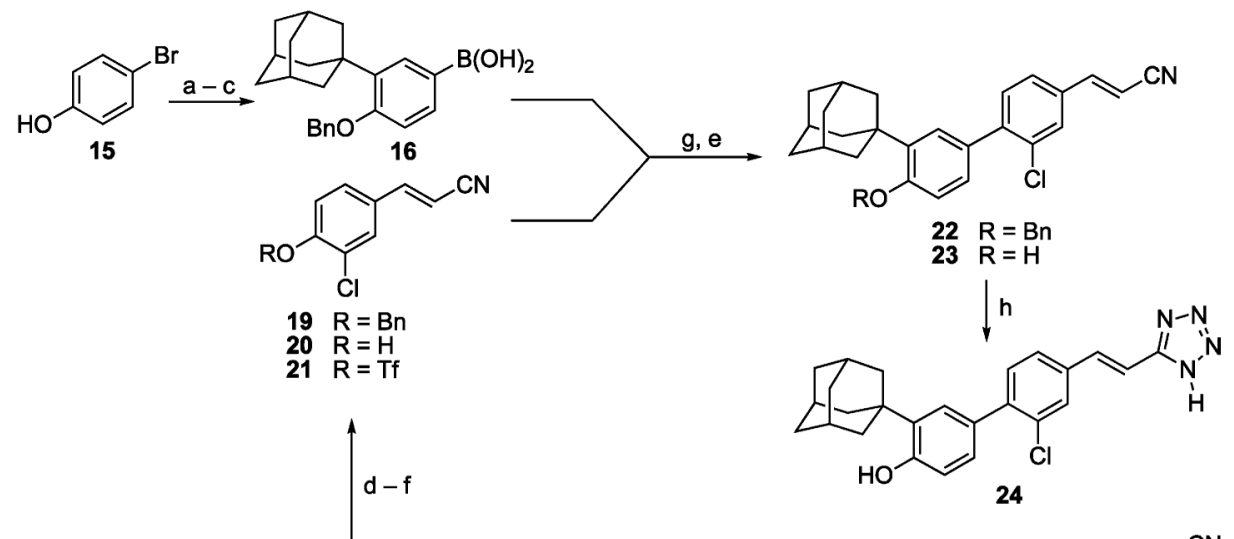<smiles>[R2]Oc1ccc([R])cc1Cl</smiles>

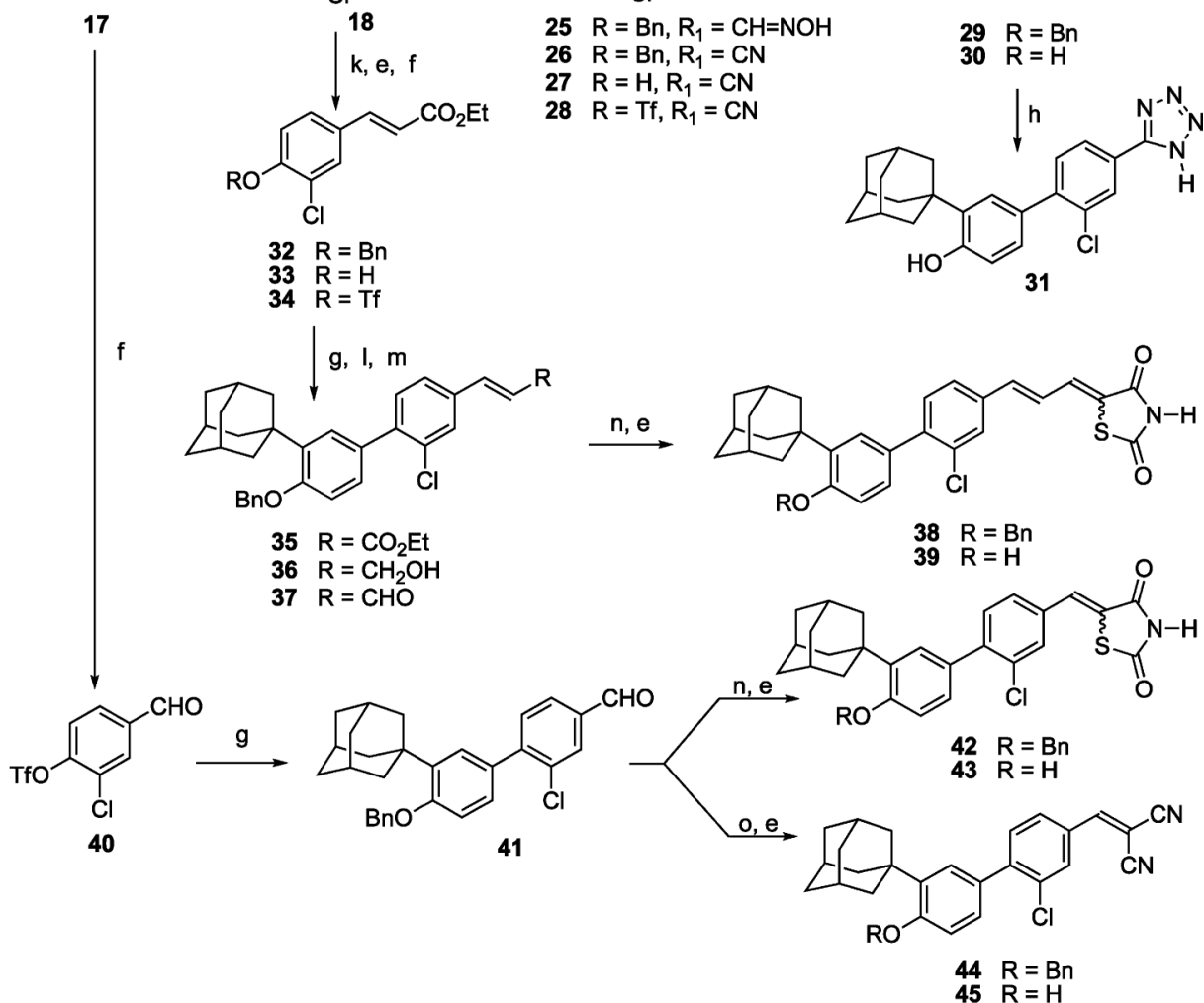

Scheme 1a.

${ }^{a}$ Reagents and conditions: (a) 1-AdOH, concd $\mathrm{H}_{2} \mathrm{SO}_{4}, \mathrm{CH}_{2} \mathrm{Cl}_{2}$. (b) $\mathrm{PhCH}_{2} \mathrm{Br}, \mathrm{K}_{2} \mathrm{CO}_{3}$, acetone, reflux. (c) $n$-BuLi, $-78{ }^{\circ} \mathrm{C} ; \mathrm{B}(\mathrm{O} i \text {-Pr })_{3},-78{ }^{\circ} \mathrm{C}$ to room temperature; dil. $\mathrm{HCl}$. (d) $\left[(\mathrm{EtO})_{2} \mathrm{P}(\mathrm{O})\right.$ $\left.\mathrm{CH}_{2} \mathrm{CN}, \mathrm{KN}(\mathrm{TMS})_{2}, \mathrm{THF},-78{ }^{\circ} \mathrm{C}\right],-78{ }^{\circ} \mathrm{C}$ to room temperature. (e) $\mathrm{BBr}_{3}, \mathrm{CH}_{2} \mathrm{Cl}_{2},-78{ }^{\circ} \mathrm{C}$; $\mathrm{H}_{3} \mathrm{O}^{+}$. (f) $\mathrm{Tf}_{2} \mathrm{O}$, pyridine, $\mathrm{CH}_{2} \mathrm{Cl}_{2}, 0^{\circ} \mathrm{C}$ to room temperature. (g) 16, $\mathrm{Pd}\left(\mathrm{PPh}_{3}\right)_{4}, 2 \mathrm{M}$ $\mathrm{Na}_{2} \mathrm{CO}_{3}$, $\mathrm{LiCl}, \mathrm{DME}$, reflux. (h) $\mathrm{Me}_{3} \mathrm{SiN}_{3},(n-\mathrm{Bu})_{2} \mathrm{SnO}, \mathrm{PhMe}, 90^{\circ}$ to $95^{\circ} \mathrm{C}$. (i) $\mathrm{NH}_{2} \mathrm{OH} \cdot \mathrm{HCl}$, $\mathrm{MeOH}$, pyridine, $50{ }^{\circ} \mathrm{C}$. (j) $\mathrm{MeSO}_{2} \mathrm{Cl}$, PhMe, pyridine. (k) $\left[(\mathrm{EtO})_{2} \mathrm{P}(\mathrm{O}) \mathrm{CH}_{2} \mathrm{CO}_{2} \mathrm{Et}, \mathrm{KN}\right.$ (TMS $\left.)_{2}, \mathrm{THF},-78{ }^{\circ} \mathrm{C}\right],-78{ }^{\circ} \mathrm{C}$ to room temperature. (l) DIBAL, $\mathrm{CH}_{2} \mathrm{Cl}_{2},-78{ }^{\circ} \mathrm{C}$; dil. $\mathrm{HCl}$. (m) $(\mathrm{COCl})_{2}, \mathrm{Me}_{2} \mathrm{SO}, \mathrm{NEt}_{3}$. (n) 2,4-Thiazolidinedione, $\mathrm{HOAc}, \mathrm{NHEt}_{2}, \mathrm{PhMe}, 50^{\circ}$ to $60^{\circ} \mathrm{C}$. (o) $\mathrm{CH}_{2}(\mathrm{CN})_{2}, \mathrm{DMF}$, reflux. 


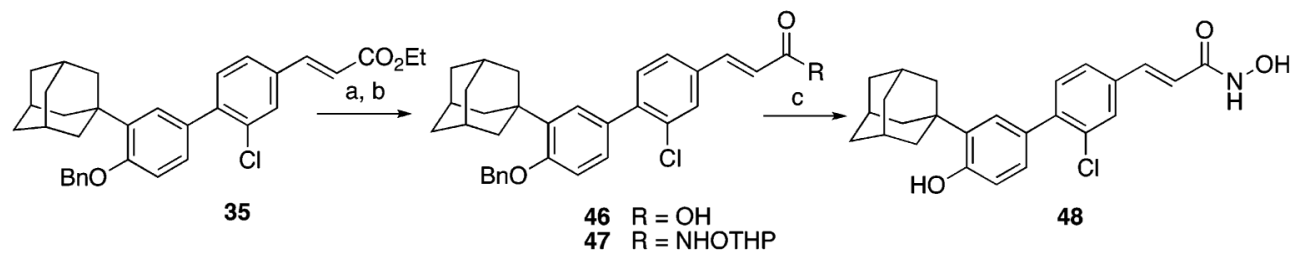<smiles>[R]c1ccc(-c2ccc(OC([B])=O)c(C34CC5CC(C3)C(C(C)(C)C)C5C4)c2)c([N+](=O)[O-])c1</smiles>

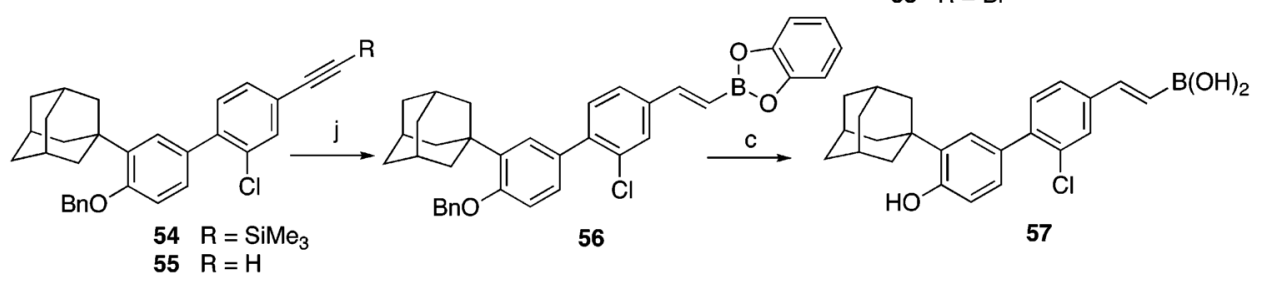

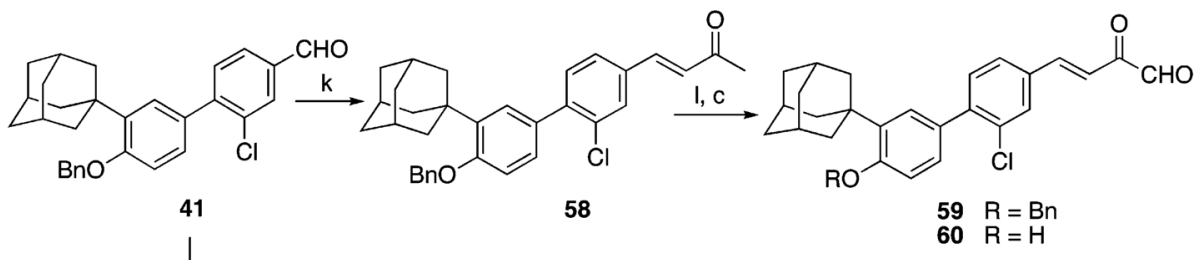<smiles>COP(=O)(/C=C/c1ccc(-c2ccc(O)c(C34CC5CC(CC(C5)C3)C4)c2)c(Cl)c1)OC</smiles><smiles>CCOP(=O)(O)/C=C/c1ccc(-c2ccc(O)c(C34CC5CC(CC(C5)C3)C4)c2)c(Cl)c1</smiles>

Scheme 2a.

${ }^{a}$ Reagents and conditions: (a) $\mathrm{LiOH} \cdot \mathrm{H}_{2} \mathrm{O}$, THF, $\mathrm{H}_{2} \mathrm{O}$; dil. $\mathrm{HCl}$. (b) $\mathrm{H}_{2} \mathrm{NOTHP}$, DIC, DMAP, $\mathrm{CHCl}_{3}, 0^{\circ} \mathrm{C}$ to room temperature. (c) $\mathrm{BBr}_{3}, \mathrm{CH}_{2} \mathrm{Cl}_{2},-78{ }^{\circ} \mathrm{C} ; \mathrm{H}_{3} \mathrm{O}^{+}$. (d) $\mathrm{Tf}_{2} \mathrm{O}$, pyridine,

$\mathrm{CH}_{2} \mathrm{Cl}_{2}, 0{ }^{\circ} \mathrm{C}$ to room temperature. (e) 16, $\mathrm{Pd}\left(\mathrm{PPh}_{3}\right)_{4}$, aq $\mathrm{K}_{3} \mathrm{PO}_{4}$, DME, reflux. (f) $\mathrm{SnCl}_{2} .2$ $\mathrm{H}_{2} \mathrm{O}$, EtOH, reflux. (g) $\mathrm{CuBr}_{2}, t-\mathrm{BuNO}_{2}, \mathrm{MeCN}, 0{ }^{\circ} \mathrm{C}$ to room temperature. (h) $\mathrm{Pd}(\mathrm{PPh})_{3}, \mathrm{CuI}$, $\mathrm{Et}_{3} \mathrm{~N}, \mathrm{Me}_{3} \mathrm{Si}$-acetylene, reflux. (i) $(n-\mathrm{Bu})_{4} \mathrm{NF}$, THF. (j) Catecholborane, THF, reflux. (k) $\mathrm{MeCOCH}_{2} \mathrm{P}(\mathrm{Ph})_{3} \mathrm{Br}, 1,5,7$-triazabicyclo[4.4.0]dec-5-ene, THF, room temperature to $70{ }^{\circ} \mathrm{C}$. (1) $\mathrm{H}_{2} \mathrm{SeO}_{3}$, dioxane/ $\mathrm{H}_{2} \mathrm{O}(10: 1)$. (m) Tetraethyl methylenediphosphonate, $50 \%$ aq $\mathrm{NaOH}$, $\mathrm{CH}_{2} \mathrm{Cl}_{2}$. (n) $20 \%$ aq $\mathrm{HCl}$, reflux. 
Table 1

Classical Retinoid Assays Used To Compare Activities of Comformationally Restricted Retinoids with Those of trans-Retinoic Acid $^{a}$

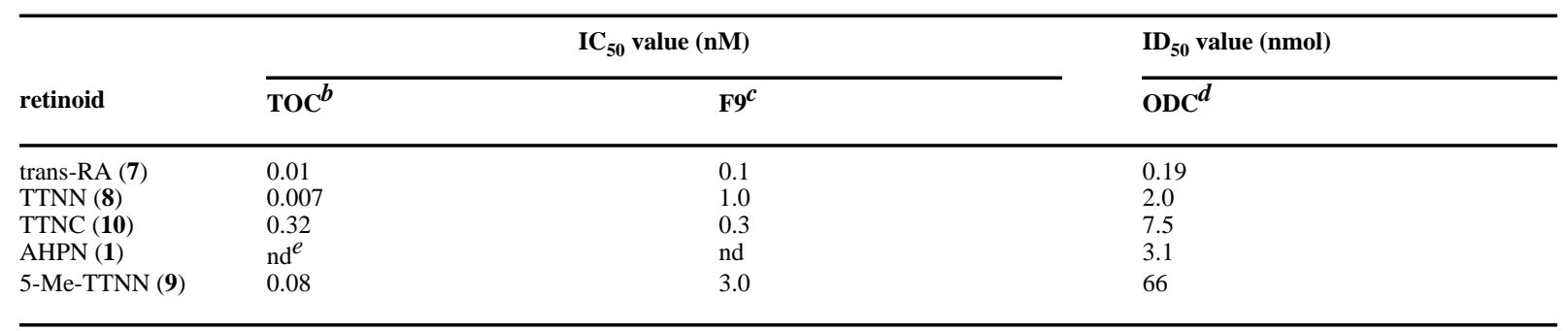

${ }^{a}$ For overview of these assays see Sporn and Roberts (1984).

$b_{\mathrm{TOC}}$

TOC assay, concentration required to reverse keratinization in $50 \%$ of vitamin A-deficient hamster tracheas in organ culture after 10 days as determined by analysis of stained cross-sections for the absence of keratin and keratohyaline granules.

${ }^{c}$ F9 assay, concentration required to induce terminal differentiation in $50 \%$ of F9 murine embryonic teratocarcinoma cells in culture after 3 days as measured by secreted plasminogen activator activity.

$d$ ODC assay, topical dose of retinoid preapplied to mouse dorsal epidermis at $1 \mathrm{~h}$ before TPA leading to $50 \%$ inhibition in level of ornithine decarboxylase induced by TPA $(7.5 \mathrm{nmol})$ at $4.5 \mathrm{~h}$ after TPA application as measured by the release of labeled $\mathrm{CO}_{2}$ from [ $\left.{ }^{14} \mathrm{C}\right]$ ornithine by epidermal homogenates. TPA, 12- $O$-tetradecanoylphorbol-13-acetate.

$e_{\text {nd, not determined. }}$ 


\section{Table 2}

Comparison of Effects of 3-Cl-AHPC (5) and Its Analogues on HMVE Cell Proliferation after $96 \mathrm{~h}$ of Treatment Compared to trans-Retinoic Acid (7) and Synthetic RAR $\gamma$-selective Analogues 13and 14

\begin{tabular}{|c|c|c|}
\hline compound & $\mathrm{IC}_{50}(\mu \mathrm{M})^{a}$ & inhibition (\%) at $0.5 \mu \mathrm{M}^{b}$ \\
\hline $\begin{array}{l}\text { AHPN (1) } \\
\text { 5-Cl-AHPN (2) } \\
\text { AHPC (4) } \\
\text { 3-Cl-AHPC (5) } \\
\text { trans-RA (7) }\end{array}$ & $\begin{array}{c}0.3 \\
0.5 \\
0.1 \\
0.3 \\
>0.5^{c}\end{array}$ & $\begin{array}{l}70 \\
45 \\
90 \\
60 \\
10\end{array}$ \\
\hline $\begin{array}{l}\text { AHPN-3- } \mathrm{CO}_{2} \mathrm{H}(\mathbf{1 1}) \mathrm{X}=\mathrm{H}, \mathrm{Y}=\mathrm{CO}_{2} \mathrm{H} \\
\text { AHPN-2-OH (12) X }=\mathrm{OH}, \mathrm{Y}=\mathrm{H}\end{array}$ & $\begin{array}{l}>0.5^{c} \\
>0.5^{c}\end{array}$ & $\begin{array}{l}15 \\
15\end{array}$ \\
\hline $\begin{array}{l}13 \mathrm{X}=\mathrm{NHOH} \\
14 \mathrm{X}=\left(\mathrm{SCH}_{2}\right)_{2}\end{array}$ & $\begin{array}{l}>0.5^{c} \\
>0.5^{c}\end{array}$ & $\begin{array}{l}30 \\
15\end{array}$ \\
\hline
\end{tabular}

${ }^{a}$ Concentration inhibiting proliferation by $50 \%$.

${ }^{b}$ Relative to vehicle alone control.

$c^{c}$ Highest concentration evaluated. 


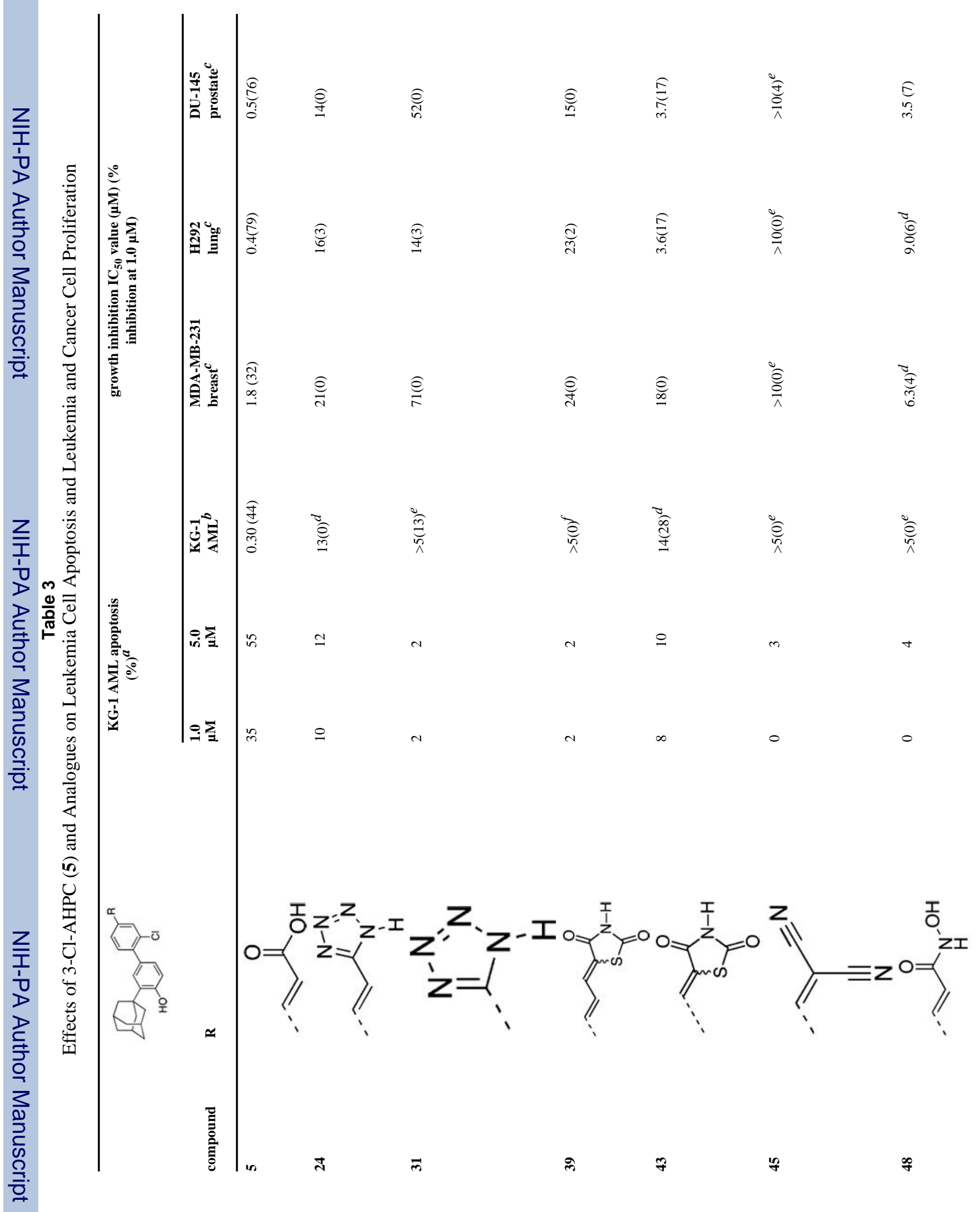


Dawson et al.

Page 44

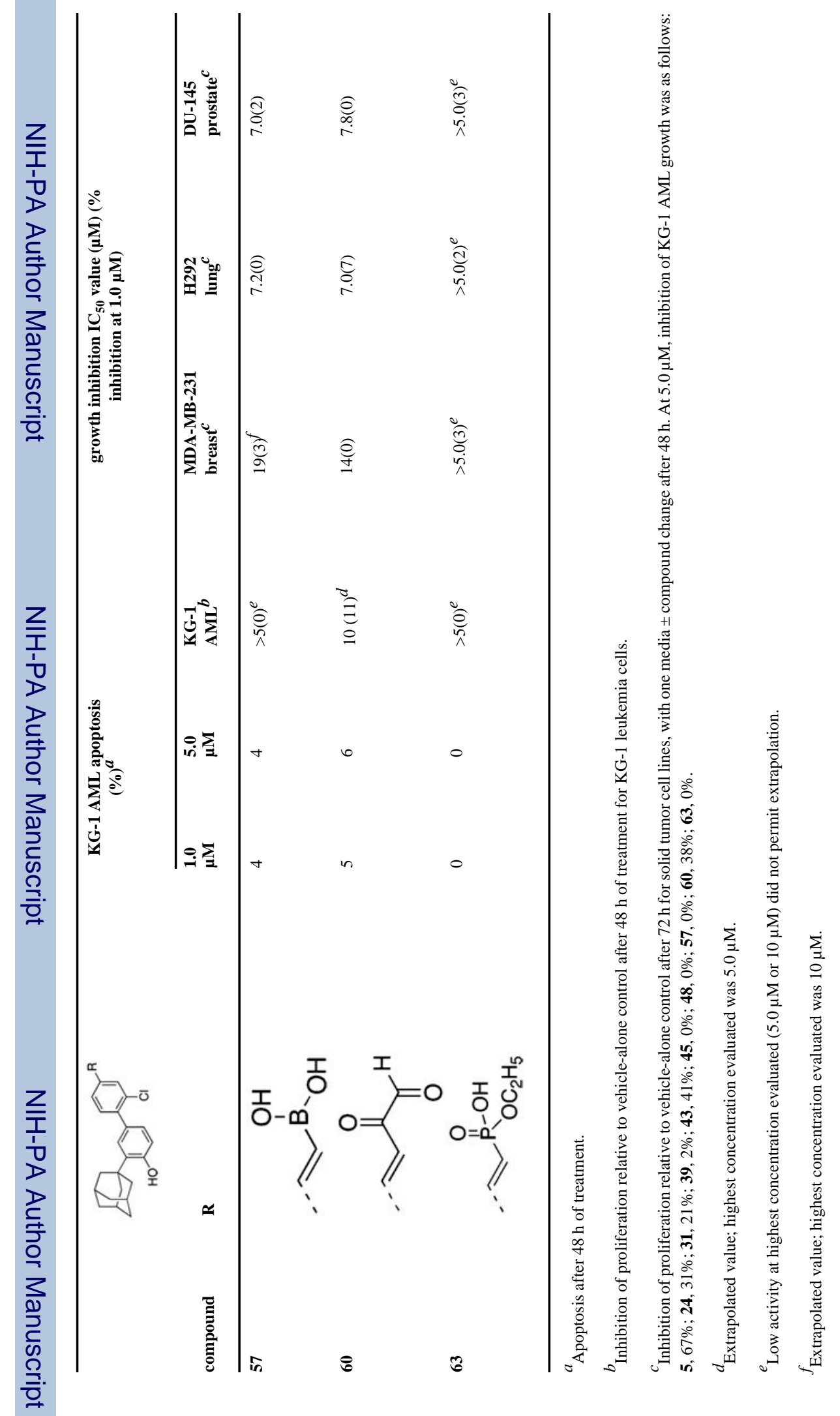

J Med Chem. Author manuscript; available in PMC 2008 September 3. 